\title{
Chapter 11 \\ Systems Level Regulation of Cardiac Energy \\ Fluxes Via Metabolic Cycles: Role of \\ Creatine, Phosphotransfer Pathways, \\ and AMPK Signaling
}

\author{
Valdur Saks, Uwe Schlattner, Malgorzata Tokarska-Schlattner, \\ Theo Wallimann, Rafaela Bagur, Sarah Zorman, Martin Pelosse, \\ Pierre Dos Santos, François Boucher, Tuuli Kaambre, and Rita Guzun
}

\author{
V. Saks $(\bowtie)$ \\ Laboratory of Fundamental and Applied Bioenergetics, Univ. Grenoble Alpes, Grenoble, \\ France \\ INSERM, U1055 Grenoble, France \\ Laboratory of Bioenergetics, National Institute of Chemical Physics and Biophysics, Tallinn, \\ Estonia \\ e-mail: valdur.saks@ujf-grenoble.fr \\ U. Schlattner $(\bowtie) \cdot$ M. Tokarska-Schlattner $・$ S. Zorman $・$ M. Pelosse \\ Laboratory of Fundamental and Applied Bioenergetics, Univ. Grenoble Alpes, Grenoble, \\ France \\ INSERM, U1055 Grenoble, France \\ e-mail: uwe.schlattner@ujf-grenoble.fr \\ T. Wallimann \\ ETH Zürich, Zürich, Switzerland \\ R. Bagur \\ Laboratory of Fundamental and Applied Bioenergetics, Univ. Grenoble Alpes, Grenoble, \\ France
}

INSERM, U1055 Grenoble, France

TIMC-IMAG, Univ. Grenoble Alpes, Grenoble, France

CNRS, UMR5525, Grenoble, France

P.D. Santos

Univ. Bordeaux, Bordeaux, France

Centre de Recherche Cardiothoracique de Bordeaux, Inserm, U1045, Bordeaux, France

LIRYC, L'Institut de rythmologie et modélisation cardiaque, Université de Bordeaux,

Bordeaux, France

F. Boucher

TIMC-IMAG, Univ. Grenoble Alpes, Grenoble, France

CNRS, UMR5525, Grenoble, France 


\begin{abstract}
Integrated mechanisms of regulation of energy metabolism at cellular, tissue, and organ levels are analyzed from a systems biology perspective. These integrated mechanisms comprise the coordinated function of three cycles of mass and energy transfer and conversion: (1) the Randle cycle of substrate supply, (2) the Krebs cycle coupled with energy transformation in mitochondrial oxidative phosphorylation, and (3) the kinase cycles of intracellular energy transfer and signal transduction for regulation of energy fluxes. These cycles are extended and partially governed by information transfer systems like those linked to protein kinase signaling. In the heart, these cycles are closely related to the $\mathrm{Ca}^{2+}$ cycle during excitation-contraction coupling. According to the view of integrated metabolic cycles, the phosphocreatine/creatine kinase system represents a most important subsystem determining the efficiency of regulation of metabolic and energy fluxes in heart, brain, and oxidative skeletal muscles. It carries about $80 \%$ of the energy flux between mitochondria and cytoplasm in heart. The substrate uptake, respiration rate, and energy fluxes are regulated in response to workload via phosphotransfer pathways and $\mathrm{Ca}^{2+}$ cycling. We propose integrated network mechanisms to explain the linear relationship between myocardial oxygen consumption and heart work output under conditions of metabolic stability (metabolic aspect of Frank-Starling's law of the heart). The efficiency of energy transfer, force of contraction, and metabolic regulation of respiration and energy fluxes depend upon the intracellular concentration of total creatine, which is decreased in heart failure. The role of creatine, creatine kinase, and adenylate kinase phosphotransfer and AMP-activated protein kinase (AMPK) signaling systems and their interrelationship with substrate supply and $\mathrm{Ca}^{2+}$ cycles are analyzed. Finally, an introduction to the AMPK signaling network is provided with a particular emphasis on the heart in health and disease.
\end{abstract}

\title{
11.1 Introduction
}

In this chapter, we describe from a systems biology perspective the integration and regulation of substrate and energy supply in living organisms and the role of the creatine/creatine kinase $(\mathrm{Cr} / \mathrm{CK})$ system. Systems biology focuses on the mechanisms of interactions between system components at molecular, cellular,

\footnotetext{
T. Kaambre

Laboratory of Bioenergetics, National Institute of Chemical Physics and Biophysics, Tallinn, Estonia

R. Guzun $(\bowtie)$

Laboratory of Fundamental and Applied Bioenergetics, Univ. Grenoble Alpes, Grenoble, France
}

INSERM, U1055 Grenoble, France

EFCR and Sleep Laboratory, Univ. Hospital of Grenoble (CHU), Grenoble, France e-mail: rita.guzun@chu-grenoble.fr 


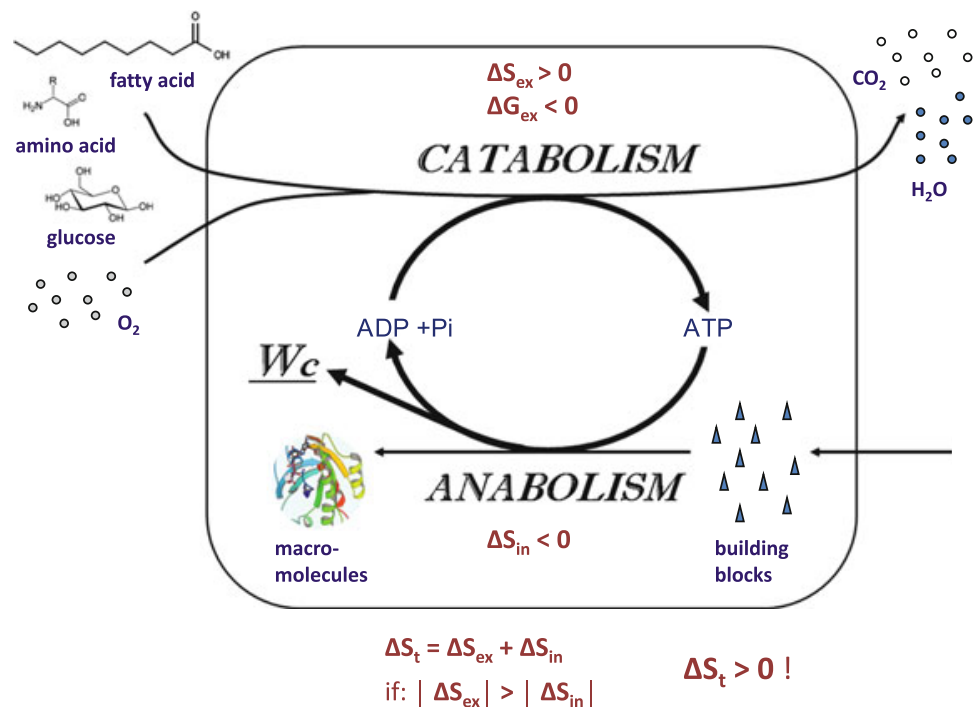

Fig. 11.1 General scheme of cellular metabolism. Catabolic reactions generating ATP (top), through coupling to anabolic reactions (biosynthesis, bottom) using ATP, maintain cell structural organization as an expression of the decrease of internal entropy $\left(\Delta S_{\text {in }}<0\right)$ and are also the source of energy for cellular work $\left(W_{\mathrm{c}}\right)$. Abbreviations: $\Delta S_{e x}$ external entropy, $\Delta S_{i n}$ internal entropy, $\Delta S_{t}$ total entropy, $\Delta G_{e x}$ variatuion of Gibbs free energy. For further details, see text. Adapted from (Saks 2007) with permission

and organ levels, giving rise to biological function. As such, systems biology provides basic mechanistic insights about the principles that govern metabolic behavior in living systems. According to Schrödinger, the metabolic activity of living systems needs a continuous exchange of metabolites with the surroundings as a form of extracting free energy from the medium. This process enables cells and organisms to increase their internal organization such that they are able to perform biological work from anabolic reactions (Schrödinger 1944). An increase of internal order implies a decrease of entropy that should be compensated by an entropy increase in the environment. Catabolic and anabolic reactions are coupled to mediate biological work (e.g., muscle contraction) through processes of free energy conversion involving synthesis and utilization of ATP (Fig. 11.1). Coupling between cellular work, anabolism, and catabolism is achieved by cyclic processes involving mechanisms of feedback regulation. Herein, we introduce the theory of integrated metabolic cycles. Cycles of substrate supply (Randle cycle), intracellular energy conversion (Krebs cycle and mitochondrial oxidative phosphorylation), and phosphotransfer reactions (kinase cycles) constitute conspicuous examples of both substrate and energy provision and feedback regulation (Fig. 11.2). These cycles closely interact with calcium $\left(\mathrm{Ca}^{2+}\right)$ cycling (Fig. 11.2). Among the kinase cycles, a key role is played by the $\mathrm{Cr} / \mathrm{CK}$ system, adenylate kinase, and AMPK in skeletal muscle, heart, brain, and other cell types (Wallimann et al. 1992, 2011; Schlattner et al. 2006a, b; Schlattner and Wallimann 2004; Wallimann 1996, 2007; Saks 


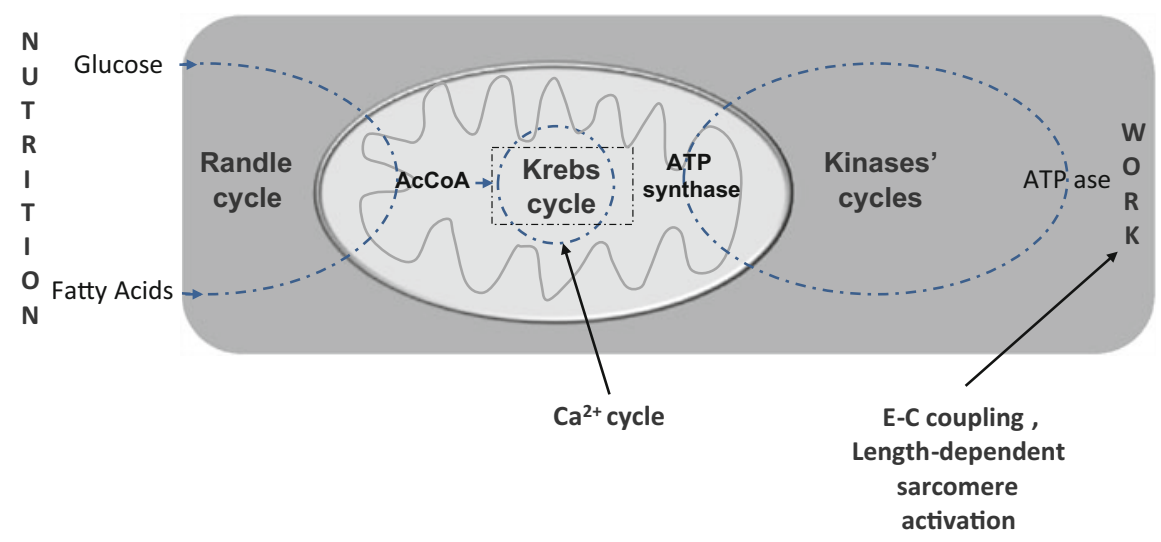

Fig. 11.2 General representation of regulation of energy fluxes via metabolic cycles at the cellular level. The regulatory action that energy transfer cycles, such as the creatine kinase (CK) and adenylate kinase systems (AK), exert on fuel supply is realized through the Randle cycle and energy transforming Krebs cycle, coupled to oxidative phosphorylation. Any decrease in the use of intracellular energy diminishes Krebs cycle activity and tends to favor the accumulation of substrates

et al. 1978, 2007a, 2010, 2012; Saks 2007; Dzeja and Terzic 2003, 2009). In the heart, contraction is initiated by excitation-contraction coupling that includes processes linked to intracellular $\mathrm{Ca}^{2+}$ cycling (Bers 2002; Bers and Despa 2006). Under physiological conditions, contractile force and cardiac work are regulated by ventricular filling and sarcomere length-dependent mechanism (Frank-Starling's law) at constant amplitude of $\mathrm{Ca}^{2+}$ transients. A main regulatory motif of cardiac energy fluxes is represented by metabolic feedback regulation through local changes in $\mathrm{Pi}$, ADP, AMP, $\mathrm{Cr}$, and phosphocreatine ( $\mathrm{PCr}$ ) ratios (Saks et al. 2006a, 2010, 2012; Bose et al. 2003; Dos Santos et al. 2000; Aliev et al. 2012). Under conditions of adrenergic stimulation, cardiac $\mathrm{Ca}^{2+}$ cycling in the cytoplasm and mitochondria becomes most important for energy flux regulation (Balaban 2002; Griffiths and Rutter 2009; Tarasov et al. 2012; Glancy and Balaban 2012). Control and regulation of mitochondrial respiration by both adenine nucleotides and $\mathrm{Ca}^{2+}$ have been analyzed in an integrated model of cardiomyocyte function (Cortassa et al. 2009).

In this work, we aim to analyze regulatory interactions involved in the modulation of energy supply and demand in the network comprised by Randle and Krebs cycles and phosphotransfer pathways in the heart. Contribution of calcium cycling to the regulation of energy supply-demand in the heart has been extensively reviewed elsewhere (Balaban 2002, 2009a, b, 2012; Tarasov et al. 2012; Glancy and Balaban 2012). The synchronization of the mitochondrial network in cardiac cells is treated by Cortassa and Aon in Chap. 5 . 


\subsection{Structural Basis of Functional Organization of Cardiomyocyte Metabolism}

In adult cardiac cells, mitochondria are localized at the A band level of sarcomeres between Z-lines close to T-tubular system and sarcoplasmic reticulum (SR). Estimation of the density distribution of mitochondria relative to their centers showed that neighboring mitochondria in cardiomyocytes are aligned according to a rectangle with distance between centers equal to $1.97 \pm 0.43 \mu \mathrm{m}$ and $1.43 \pm 0.43 \mu \mathrm{m}$ in the longitudinal and transverse direction, respectively (Vendelin et al. 2005). High temporal resolution analysis of mitochondrial dynamics in adult cardiomyocytes (one frame every $400 \mathrm{~ms}$ ) revealed very rapid fluctuation of center positions that did not exceed the limit of the organelle (Beraud et al. 2009). These limited mitochondrial oscillations can be explained by inner membrane conformational changes likely elicited by changes in volume associated with energetic/redox states (Hackenbrock 1968; Mannella 2006). In vivo imaging of mitochondrial dynamics in cardiomyocytes showed separated individual organelles which do not fuse with each other (Gonzalez-Granillo et al. 2012). Figure 11.3 shows confocal images of mitochondria and $\alpha$-actinin distribution in cardiomyocytes from adult rats. In this figure the fluorescence immunolabelling of $\alpha$-actinin is used to mark sarcomeric Z-lines. Individual mitochondria regularly arranged between Z-lines can be visualized by flavoprotein autofluorescence (Fig. 11.3, green). The green fluorescence intensity profile shows the peaks distribution corresponding to mitochondrial fluorescence; the regions of "zero" intensity of $\alpha$-actinin (Fig. 11.3 red) indicate intermyofibrillar localization of mitochondria between Z-lines without apparent fusion/fission (Gonzalez-Granillo et al. 2012). Possibly, fusion can happen in perinuclear mitochondrial clusters (Kuznetsov and Margreiter 2009).

Regular arrangement and limited morphodynamics of mitochondria in adult cardiomyocytes are determined by the cytoskeletal architecture, which includes myofilaments, inter-myofilaments, microtubules, and other structural proteins. Tubulin is one of the constituent cytoskeletal proteins with structural, transport, and metabolic functions (see also Chap. 7). Herein, we will focus on the structural role of $\beta$ isotypes of tubulin. Tubulin is a heterodimeric complex formed by two globular and two C-terminal tails (CTT) of $\alpha$ and $\beta$ proteins. Globular $\alpha$ and $\beta$ proteins can be polymerized into microtubules, while $\alpha$ and $\beta$ CTT can interact with other intracellular structures and proteins. Tubulin has additional binding sites that allow the filaments to join together laterally to form sheets of filaments. About $30 \%$ of tubulins in adult cardiomyocytes are polymerized and $70 \%$ are in the heterodimeric state (Tagawa et al. 1998). These two conformational states of protein are in a dynamic balance driven by polymerization-depolymerization processes (Sackett 2010). A study of the distribution of $\beta$ tubulins by fluorescence confocal microscopy showed that $\beta \mathrm{IV}$ tubulin is polymerized creating a dense mesh of mainly longitudinally and obliquely oriented microtubules. $\beta$ III tubulin co-localizes with alpha-actinine in Z-lines while $\beta \mathrm{I}$ tubulin forms randomly dispersed short polymers 

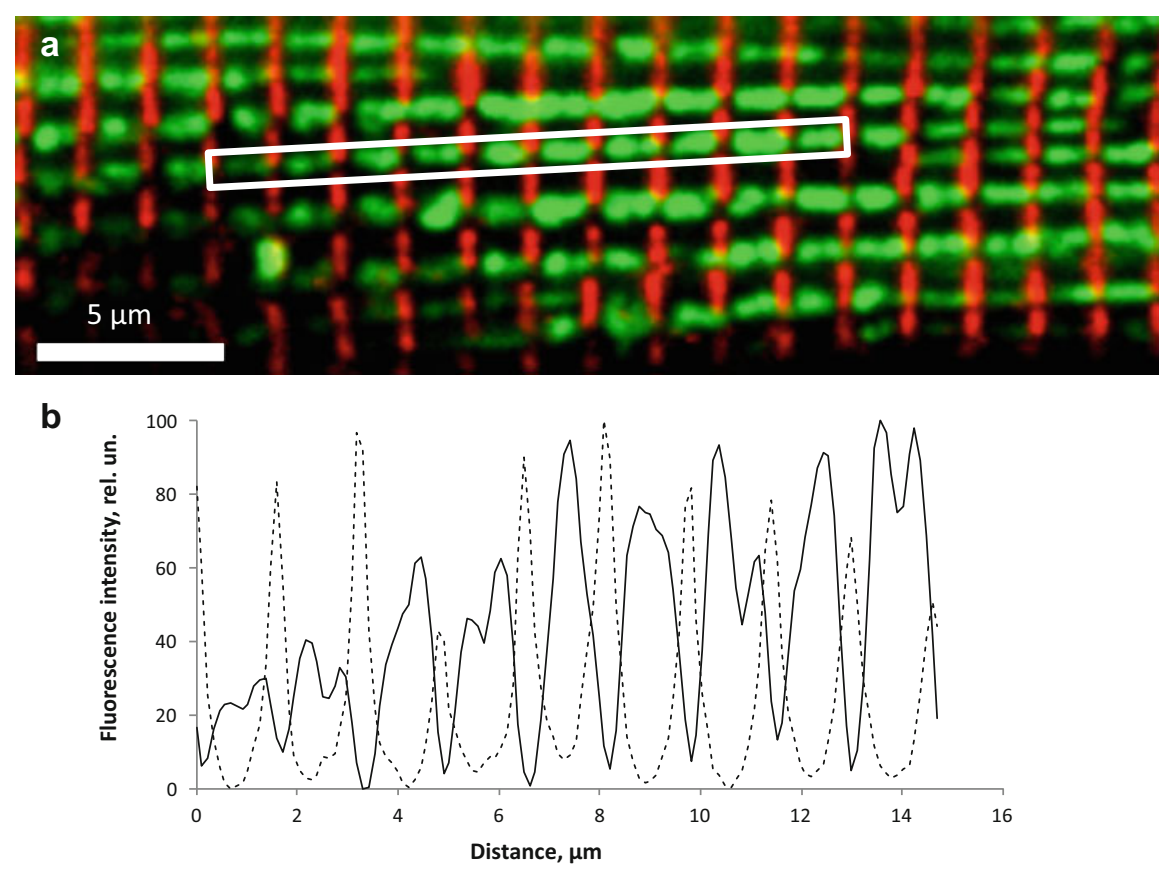

Fig. 11.3 Fluorescence confocal microscopy of mitochondria and alpha-actinin distribution in adult rat cardiomyocyte. (a) Regular distribution of individual mitochondria as visualized by autofluorescence of flavoproteines (green color) in between Z-lines that are labeled with rhodamine immunofluorescent for $\alpha$-actinin (red color). (b) Analysis of fluorescence intensity along a selected line: dotted $=\alpha$-actinin; solid $=$ flavoproteins. Note that peaks of green fluorescence intensity corresponding to mitochondria are seen in the regions of "zero" intensity of red $\alpha$-actinin fluorescence. Reproduced from (Gonzalez-Granillo et al. 2012) with permission

and dimers, and $\beta$ II tubulin co-distributes with mitochondria (Saks et al. 2012; Gonzalez-Granillo et al. 2012; Guzun et al. 2011a, 2012). These findings are in agreement with data published first in 1990 by Saetersdal et al. regarding the link between $\beta$ tubulin and mitochondria as revealed by immunogold labeling (Saetersdal et al. 1990). According to this study, $\beta$ tubulin interacts with mitochondria through the outer membrane (MOM) creating links between the organelle and other cellular structures. The contribution of other cytoskeletal proteins to structural and functional interactions with mitochondria is under intensive investigation. Desmin and plectin are capable of interacting with voltagedependent anion channel (VDAC) at MOM (Capetanaki et al. 2007; Capetenaki 2002; Liobikas et al. 2001; Schroder et al. 2002). The 1b isotype of plectin of cardiomyocytes co-localizes with mitochondria via direct interaction with VDAC, whereas plectin 1d isotype is specifically associated with sarcomeric Z-disks (Schroder et al. 2002).

Recently it has been proposed that the T-tubular system, which represents a network of tubular extensions from the sarcolemma, plays an important role in the 
structural organization of cardiac cell metabolism. The T-tubular system of rat ventricular cells creates a regular arrangement at the level of Z-line and along myofibrils (Fig. 11.4c) (Soeller and Cannell 1999). This system becomes disorganized with time in cardiac cells in culture. The functional role of T-tubules was described to provide a rapid inward spread of electrical excitation and $\mathrm{Ca}^{2+}$ influx that triggers $\mathrm{Ca}^{2+}$ release from the sarcoplasmic reticulum, as well as supply of each mitochondrion with oxygen and substrates. By using electron tomography (Hayashi et al. 2009) identified anatomical couplings between opposing membranes of T-tubules and sarcoplasmic reticulum (SR), these forming so-called Calcium Release Units (CRU). A close localization of mitochondria and CRU favors $\mathrm{Ca}^{2+}$ and metabolite microcompartmentation (Saks et al. 2012). Individual mitochondria localize at the level of the A-band of sarcomeres and at the Z-line they are in close contacts with jSR and the T-tubular system forming CRUs (Fig. 11.4b). This junctional cisterns of arrangement separates mitochondria from each other, also making their fusion unlikely. The 3D reconstruction of the T-tubular system in cardiac cells (Soeller and Cannell 1999) appears as an elaborated and effective system of $\mathrm{Ca}^{2+}$, substrate, and oxygen supply from the extracellular medium. Its discovery about a decade ago profoundly changed our knowledge of the heart cell structure and the implications for metabolic regulation. As a matter of fact, according to this architecture no distinction is possible between intermyofibrillar and subsarcolemmal mitochondria, since both are in close contact with the T-tubular system. This is in agreement with results obtained from kinetic studies (Saks et al. 2012) and the fact that no electrical conduction occurs between individual mitochondria in cardiomyocytes (Beraud et al. 2009; Kuznetsov et al. 2009; Collins and Bootman 2003; Nivala et al. 2011; Zorov et al. 2000). Simultaneous measurements of sarcomere and mitochondrial dimensions in situ along the longitudinal axis of cardiomyocytes identified mitochondria as micronsized spheres localized between sarcomeres and distributed throughout the cell in a crystal-like lattice without any visible fusion. In this organized lattice, transient mitochondrial depolarizations (flickers), elicited by ROS-induced opening of anion channels in the inner membrane, may propagate in cells as depolarization waves (Nivala et al. 2011; Yaniv et al. 2011). However, electron tomographic studies clearly revealed that there is no mitochondrial reticulum in cardiac cells; instead a regular lattice containing 5,000-10,000 single mitochondria seems to prevail (Nivala et al. 2011). In the heart, this forms the structural basis of the mitochondrial network described by Cortassa and Aon in Chap. 5. Taken together, all the data described above indicate that mitochondrial respiration depends upon localized events in their vicinity. These structurally organized functional domains-dubbed Intracellular Energetic Units (ICEUs) (Saks 2007; Saks et al. 2001, 2012) (Fig. 11.5)—comprise sites of ATP hydrolysis (myofibrillar ATPases, sarcoplasmic reticulum ATPase (SERCA), ion pumps) connected to ATP synthesis through phosphotransfer networks. Energy transduction within ICEUs involving the Randle and Krebs cycles of fuel supply and oxidative phosphorylation are governed by energy-demanding reactions. Next, we analyze cardiac energy metabolism from the perspective of regulatory interactions occurring in metabolic cycles. 


\subsection{Substrate Supply and Its Regulation (Randle and Krebs Cycles)}

\subsubsection{Mechanisms of Regulation of Fatty Acids Oxidation in Heart Muscle}

Fatty acids are released from triacylglycerol (TAG) by activated lipoprotein lipase (LPL) and transferred in the cytoplasm bound to proteins. Free fatty acid transfer across mitochondrial membranes consumes ATP involving FFA conversion into an Acyl-CoA derivative and the transport-competent acyl-carnitine form by carnitine palmitoyl transferase (CPT). The MOM-localized CPT1 targeted by malonyl CoA inhibition constitutes an important regulatory step of $\beta$-oxidation of FAs ( $\beta$-FAO) (Fig. 11.4) (Saks et al. 2006b). $\beta$-FAO is linked to the citric acid cycle and oxidative phosphorylation through $\mathrm{NAD}^{+}, \mathrm{FAD}$, and acyl-CoA. The NADH generated by the Krebs cycle and $\beta$-FAO is oxidized in the electron transport chain. Increased ATP utilization elicits ATP synthesis driven by the proton motive force, thus decreasing the NADH/NAD ${ }^{+}$ratio. Oxidation of the NADH pool increases the flux through the Krebs cycle through $\mathrm{NAD}^{+}$-dependent isocitrate and $\alpha$-ketoglutarate deshydrogenases, thus decreasing acetyl-CoA (AcCoA) levels. $\mathrm{NAD}^{+}$can also be reduced in $\beta$-FAO catalyzed by $\beta$-hydroxyacyl-CoA dehydrogenase and in the glycolytic pathway catalyzed by glyceraldehyde phosphate dehydrogenase (GAPDH). However, the transfer of NADH reduction potential from glycolysis towards the mitochondrial matrix via the malate-aspartate shuttle, being slower than direct NAD+ use by $\beta$-FAO, will prioritize the latter one (Kobayashi and Neely 1979). Thus, the GAPDH dependence on cytoplasmic $\mathrm{NADH} / \mathrm{NAD}^{+}$ratio associated with the slow kinetics of malate-aspartate shuttle will rather slow down glycolysis. An increase in the rate of AcCoA utilization by the Krebs cycle will thus increase $\beta$-FAO. An accumulation of AcCoA does not influence significantly the rate of $\beta$-FAO due to the equilibrium constant of the reversible thiolase reaction which is in favor of AcCoA production (Neely and Morgan 1974).

At low ATP demand (decreased workload), the high NADH/NAD ${ }^{+}$ratio slows down the flux through $\mathrm{NAD}^{+}$-dependent dehydrogenases, thus decreasing the rate of AcCoA oxidation through the Krebs cycle. An increased intra-mitochondrial AcCoA level is thought to favor its transfer towards the cytoplasm where it is converted into malonyl-CoA, an inhibitor of CPT-1-controlled FA transport into mitochondria. Malonyl-CoA levels are also controlled by acetyl-coA carboxylase (ACC), a cytosolic enzyme catalyzing conversion of AcCoA into malonyl-CoA, whose inactivation by AMPK during energy stress relieves CPT1 inhibition.

Preferential utilization of FAs involves inhibition of glucose transport, phosphofructokinase (PFK), and pyruvate dehydrogenase (PDH) reactions (Hue and Taegtmeyer 2009; Taegtmeyer 2010; Taegtmeyer et al. 2005). Glucose transport in muscle cells is realized through GLUT4, the expression of which in the sarcolemma is regulated by insulin and other signals. Increased NADH/NAD+ and 


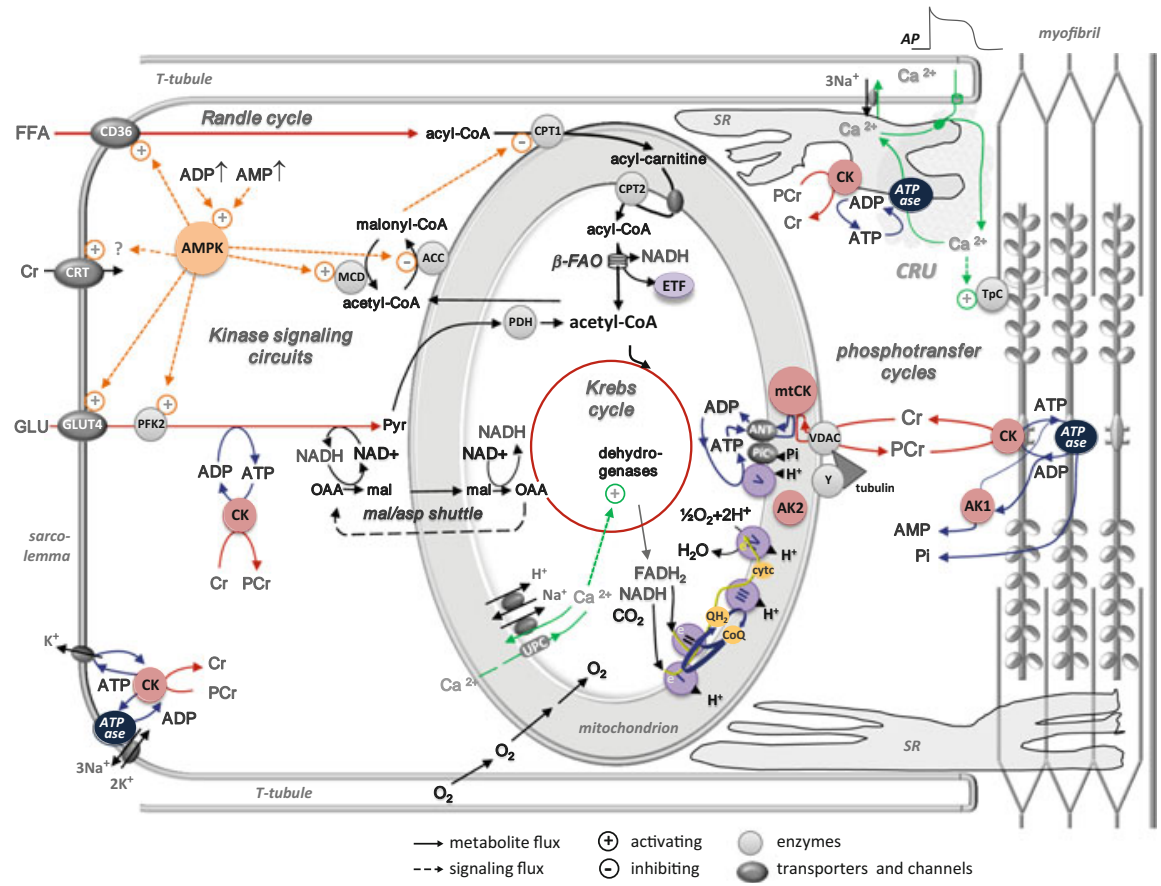

Fig. 11.4 Metabolic cycles and signaling networks in cardiomyocyte-Intracellular Energy Units (iEU). Free fatty acids (FFA, upper left) are taken up by a family of plasma membrane proteins (fatty acid transporter protein, FATP1, fatty acid translocase, CD36), and in the cytoplasm FAs are associated with fatty acid binding protein (FABP). FFAs are esterified to acyl-CoA via fatty acyl$\mathrm{CoA}$ synthetase. The resulting acyl-CoA is then transported into mitochondria via carnitine palmitoyltransferase I (CPT and CPT II). Once inside, acyl-CoA becomes a substrate for the $\beta$-oxidation pathway, resulting in AcCoA production. Each round of $\beta$-oxidation produces 1 molecule of NADH, 1 molecule of $\mathrm{FADH}_{2}$, and 1 molecule of AcCoA. AcCoA enters the Krebs cycle, where it is further oxidized to $\mathrm{CO}_{2}$ with the concomitant generation of 3 molecules of NADH, 1 molecule of FADH 2 and 1 molecule of ATP. Glucose (GLU) is taken up by glucose transporter- 4 (GLUT-4, at the left middle) and enters the Embden-Meyerhof pathway, which converts glucose into 2 molecules of pyruvate (PYR). As a result of these reactions, 2 net ATP and $2 \mathrm{NADH}$ are produced. NADH is transferred into mitochondria via the malate-aspartate shuttle. OAA, oxaloacetate; Glut, glutamate; $\alpha \mathrm{KG}, \alpha$-ketoglutarate; ASP, aspartate; MAL, malate. Most of the metabolic energy derived from glucose can come from the entry of pyruvate into the Krebs cycle and oxidative phosphorylation via AcCoA. NADH and FADH2 issued from both metabolic pathways are oxidized in the respiratory chain. Mitochondrial creatine kinase (mtCK) catalyzes the direct transphosphorylation of intramitochondrial ATP and cytosolic creatine $(\mathrm{Cr})$ into ADP and phosphocreatine (PCr). ADP enters the matrix space to stimulate oxidative phosphorylation, while $\mathrm{PCr}$ is transferred via the cytosolic $\mathrm{Cr} / \mathrm{PCr}$ shuttle to be used in the functional coupling between CK and ATPases (acto-myosin ATPase and ion pumps, black circles). Feedback regulation of substrate supply occurs in the following way: the glucose-fatty acid (Randle) cycle: if glucose and FFAs are both present, FFAs inhibit the transport of glucose across the plasma membrane, and acyl-CoA oxidation increases the mitochondrial ratios of $\mathrm{AcCoA} / \mathrm{CoA}$ and of $\mathrm{NADH} / \mathrm{NAD}+$ which inhibit the pyruvate dehydrogenase (PDH) complex. Citrate from increased production in the Krebs cycle can inhibit phosphofructokinase (PFK). These changes would slow down oxidation of glucose and pyruvate (PYR) and increase glucose-6-phosphate (G6P), which 
AcCoA /CoA ratios inhibit PDH. Their inhibitory effect is realized through pyruvate dehydrogenase kinase (PDK) that phosphorylates and inhibits PDH (Randle 1998). Citrate that escapes oxidation in the Krebs cycle is transported to the cytosol where it inhibits PFK and glycolysis (Hue and Taegtmeyer 2009; Taegtmeyer 2010; Taegtmeyer et al. 2005).

Cell signaling via AMPK provides a parallel control of most of these processes, including substrate uptake via fatty acid and glucose transporters and flux via $\beta$-FAO and glycolysis (see Sect. 5.5). Activation of AMPK during energy stress situations stimulates all these activities.

Physiologically, the significance of the Randle cycle is to ensure the provision of FAs to high-energy demanding organs such as muscle and liver. Also, glucose is directed to organs such as brain, red blood cells, and other tissues dependent upon glucose oxidation and possessing relatively small stores of glycogen.

\subsubsection{Which Substrate Is Better: Reductionism Versus Systems Biology}

Living cells extract and transform energy from different sources distributing them between organs, as a function of their energy needs and metabolic potential. Unfortunately, there is not yet consensus on evaluating the amount of energy that may be extracted from different carbon sources. A reason for this is differences between reductionistic and systems biology type of approaches. The reductionist explanation of the competitive use of different energy sources by distinct organs is based on the oxygen needed to oxidize the different substrates and considerations of coupling of oxidative phosphorylation. All electrons from NADH produced in aerobic catabolism (i.e., from glycolysis and fatty acid oxidation) enter the respiratory chain via complex I, or electrons from $\mathrm{FADH}_{2}$ formed in $\beta$-FAO are carried via electron transferring flavoprotein and complex III (Fig. 11.4), resulting in lower ATP/O ratio. In this way, the yield of 38 ATP for 12 atoms of oxygen consumed $(\mathrm{P} / \mathrm{O}=3.16)$ for glucose $\left(\mathrm{C}_{6} \mathrm{H}_{12} \mathrm{O}_{6}\right)$ oxidation and the yield of 129 ATP for 46 atoms of oxygen consumed $(\mathrm{P} / \mathrm{O}=2.8)$ for palmitic acid $\left(\mathrm{C}_{16} \mathrm{H}_{32} \mathrm{O}_{2}\right)$ oxidation are assumed to be sufficient to conclude that glucose is the preferential fuel for living organisms. This conclusion is further corroborated by measurements of oxygen consumption by direct calorimetry. When one liter of oxygen is used to burn substrates, the amount of energy obtained is $5.19 \mathrm{kcal} / \mathrm{LO}_{2}$ for glucose and $4.81 \mathrm{kcal} / \mathrm{LO}_{2}$ for palmitic acid (Leverve et al. 2006). However, these calculations

Fig. 11.4 (continued) would inhibit hexokinase (HK), and decrease glucose transport. G6P glucose 6-phosphate, $H K$ hexokinase, $P F K$ phosphofructokinase, $G L Y$ glycogen, F1,6diP fructose-1,6-bisphosphate, GAPDH glyceraldehyde 3 phosphate dehydrogenase, 1,3DPG 1,3 diphosphoglycerate. AMPK signaling (orange) controls among others substrate uptake and flux via glycolysis and fatty acid oxidation under conditions of starvation, hypoxia and other triggers of energy stress. For details see text. Modified from (Saks et al. 2012) with permission 
do not take into account that under aerobic physiological conditions oxygen is not a limiting factor for energy metabolism, but instead that there are many other factors to be taken into account in the whole system. And these factors were indeed taken into account by nature. Regarding the fuel supply to such a high-energy demanding organ as is the heart, Clark and collaborators were the first to show that glucose constituted less than $1 / 4$ of the substrates oxidized by the isolated working frog heart (Clark et al. 1937). These authors were not able to figure out which substrate(s) were responsible for consuming the remnant oxygen. In 1954, Bing and collaborators showed that the respiratory quotient $\left(\mathrm{RQ}, \mathrm{VCO}_{2} / \mathrm{VO}_{2}\right)$ in postabsorptive state was about $0.7-0.75$ while studying oxygen utilization during the aerobic metabolism of fats, ketones, and amino acids by human heart (Bing et al. 1954). This ratio was unchanged following overnight fasting but increased above 1 after ingestion of a high fat diet. The authors assumed that this increase could be due to utilization of intramuscular triacylglycerol (TAG) stores (Bing et al. 1954). Similar data were obtained in skeletal muscle. The average respiratory quotient $\left(\mathrm{VCO}_{2} / \mathrm{VO}_{2}\right)$ of muscular tissue taken from de-pancreatized dogs was about 0.7 (Bing et al. 1954).

In the case of working heart, the preferential energy supply by FA can be understood from calculations specifying energy needs to realize work, energy content of different substrates per unit mass, and kinetics of reactions in Randle and Krebs cycles, rather than by oxygen consumed for oxidizing different fuels. A heart contracting with a frequency of $70 \mathrm{bpm}$ exhibits a stroke volume of $0.07 \mathrm{~L}$ (i.e., cardiac output $-5 \mathrm{~L} / \mathrm{min}$ ) that supports a pressure of $13 \mathrm{kPa}$ (equivalent of $120 / 70 \mathrm{~mm} \mathrm{Hg}$ ) and realizes a work equal to $65 \mathrm{~J} / \mathrm{min}$ or $93.6 \mathrm{~kJ} /$ day. ATP hydrolysis in the actomyosin reaction releases about $60 \mathrm{~kJ} / \mathrm{mol}$ under physiological conditions. For the heart to accomplish a work equivalent to $100 \mathrm{~kJ} / \mathrm{day}$ about 2.8 mol of ATP are needed $\left(n=W / \Delta \mathrm{G}_{\mathrm{ATP}}\right.$ corrected for the reaction efficiency that in the case of actomyosin is about $60 \%$ ). This amount of ATP can be obtained from the oxidation of $0.074 \mathrm{~mol}$ glucose or $0.02 \mathrm{~mol}$ of palmitic acid. For glucose, supplemented with an equivalent molecular weight of $10 \mathrm{~mol}$ of water, $26.5 \mathrm{~g}$ glucose should be oxidized by the heart to perform work equivalent to $100 \mathrm{~kJ} / \mathrm{day}$. For palmitic acid only $5.5 \mathrm{~g}$ of this FA are necessary to perform a similar amount of work. Thus, the content of free energy per gram of mass that can be released during oxidation and converted into chemical energy in the form of ATP is much higher for FAs than for carbohydrates due to the much higher content of non-oxidized $-\mathrm{C}-\mathrm{C}-$ and $-\mathrm{C}-\mathrm{H}$ chemical bonds. Depending on the amount of bound water the difference in carbohydrates can range from three- to ninefold (Newsholme and Start 1973) (Fig. 11.5b). Thus, the kinetics of mass transfer in substrate supply is much more favorable when FAs, as compared to glucose, are used as substrates. And this fact explains the choice made by nature: heart and oxidative skeletal muscle clearly prefer FAs as substrates (Fig. 11.5a). Their preferred utilization by heart and oxidative muscle is achieved by multiple regulatory mechanisms involved in the Randle and Krebs cycles (Fig. 11.4).

Randle et al. (1963) were the first to propose the concept of selective supply of FAs over glucose for heart muscle (Randle et al. 1963). The glucose-FA cycle or 

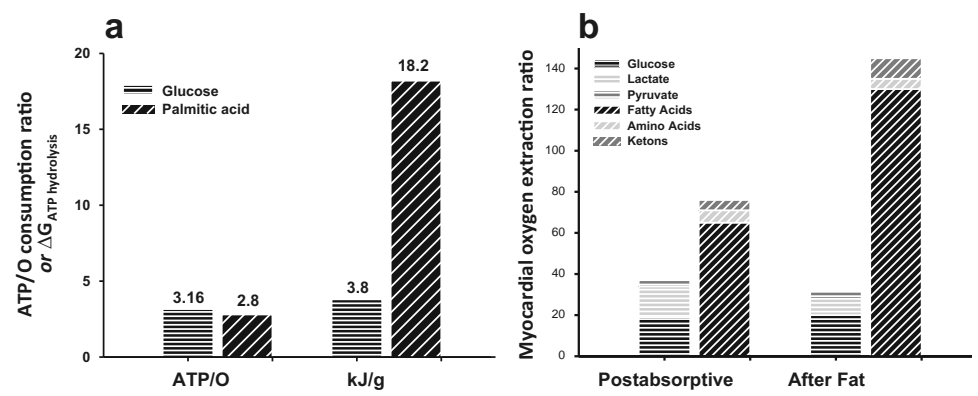

Fig. 11.5 The role of fatty acid oxidation in metabolism. (a) (i) ATP synthesis to oxygen consumption ratio in mitochondria for glucose and palmitate oxidation and (ii) the Gibbs free energy of ATP hydrolysis from the actin-myosin reaction obtained from the oxidation of one gram of glucose in comparison with the oxidation of one gram of palmitate. (b) Comparison of the myocardial oxygen extraction ratio of carbohydrates (glucose, pyruvate, and lactate) and non-carbohydrates (fatty acids, amino acids, ketones) in a post-absorptive state and after ingestion of FAs. In both states FAs oxidation is the prevalent source of energy for the heart [adapted from Bing et al. (1954) with permission]

Randle cycle outlined the restrictions imposed on muscle glucose metabolism by FA oxidation (Randle et al. 1963). Further mechanisms of regulation of the glucose-FA cycle in working heart were described by Neely and Morgan (1974) with new insights being revealed since then (Hue and Taegtmeyer 2009; Taegtmeyer 2010; Taegtmeyer et al. 2005). These mechanisms account for changes in the kinetics of fuels supply, mass transfer, and transformation including glucose transport and glycolysis, FA transport, $\beta$-FAO, and the Krebs cycle in response to variations in respiration rates and $\mathrm{NADH}$ oxidation.

\subsection{Phosphotransfer Pathways (Kinase Cycles)}

\subsubsection{Creatine Biosynthesis and Transmembrane Transport}

Creatine biosynthesis occurs in a two-step reaction; first, in the kidney and in pancreas, the amino acids arginine and glycine are combined to form guanidino acetic acid (GAA) by the enzyme AGAT (arginine-glycine amino-transferase), and second, in the liver, where GAA, taken up from blood serum via GABA-2 (gammaaminobutyric acid transporte) (Tachikawa et al. 2012), is methylated to generate $\mathrm{Cr}$ by GAMT (guanidine-acetic acid methyltransferase) using SAM (S-adenosinemethionine) as a substrate (Wyss and Kaddurah-Daouk 2000). Creatine synthesized in the liver is released into the bloodstream by a still unknown mechanism. Since creatine is not produced in significant amounts in, e.g., heart, brain, skeletal, and smooth muscle, where it plays an important functional role, it has to be imported by these tissues from blood serum, using a specific creatine transporter (CRT) (Beard 
and Braissant 2010). In this way, creatine participates in the regulation of metabolism at the organ level. An increase in total $\mathrm{Cr}$ and $\mathrm{PCr}$ in cells also increases the PCr/ATP ratio and thus energy charge (Wallimann et al. 2011). Mutations in either of the genes coding for AGAT, GAMT (endogenous creatine synthesis), or CRT (creatine transport) in humans lead to the so-called creatine deficiency syndrome with a severe neuromuscular and neurological phenotype including developmental delay of expressive language and cognitive speech, mental retardation, autistic-like behavior, epilepsy, and brain atrophy (for review, see (Stockler et al. 2007)).

\subsubsection{Direct Measurement of Energy Fluxes: Principal Role of the Phosphocreatine Pathway in Energy Transfer in the Heart}

While Cr has been known for 175 years after its discovery by Michel Chevreul, the hypothesis of the PCr pathway was formulated by Samuel Bessman (Bessman and Carpenter 1985; Bessman and Fonyo 1966; Bessman and Geiger 1981) and independently by Martin Klingenberg (1970, 1976, 2008; Wallimann 1975; Turner et al. 1973; Saks et al. 1978) about 50 years ago. An important factual basis of this hypothesis is given by the observation made by Belitzer and Tsybakova (1939), who showed that $\mathrm{Cr}$ addition stimulated respiration in skeletal muscle homogenates, resulting in PCr production (Belitzer and Tsybakova 1939). A fundamental contribution to the existence of a $\mathrm{PCr}$ pathway of energy transfer in heart, muscle, brain, and other tissues was been made by Theo Wallimann's group. They showed that different $\mathrm{CK}$ isoenzymes belong to different compartments, with MtCK in mitochondria and cytosol and MM-CK in myofibrils and the membrane of sarcoplasmic reticulum. They also resolved the atomic structure of CKs and characterized interaction mechanisms with neighboring structures (Wallimann et al. 1992, 2007; Schlattner et al. 1998, 2006a, b; Schlattner and Wallimann 2004; Eder et al. 1999, 2000; Fritz-Wolf et al. 1996). MM-CK was also shown to localize in the sarcolemmal membrane (Saks et al. 1977). Such in vivo compartmentation of CK and ATP in muscle cells represents the cellular basis of the CK cycle, one of the phosphotransfer pathways of energy transport (Wallimann et al. 1992, 2007; Schlattner et al. 2006a, b; Schlattner and Wallimann 2004; Saks 2007, 2008, 2009; Aliev et al. 2012; Saks et al. 2007b). Detailed functional studies combining the use of mathematical modeling with experimental data have shown that within myofibrils, and in the subsarcolemmal area, the diffusion coefficient for ATP is decreased by factor of $10^{5}$ as compared to water solution (Abraham et al. 2002; Alekseev et al. 2012; Selivanov et al. 2004). Diffusion limitations result in ATP compartmentation in cells, where the local ATP and ADP pools are connected by the phosphotransfer pathways. An equally important and fundamental contribution was been made by Dzeja and Terzic groups who measured quantitatively, using an isotope tracer method, energy fluxes between different cellular 
compartments involving kinase cycles (Dzeja and Terzic 2003, 2009; Dzeja et al. 1999; Nemutlu et al. 2012). Most effective and informative in bioenergetic studies of phosphoryl transfer has been the use of ${ }^{18} \mathrm{O}$ transfer (see the Chap. 6). This method is based on the following two reactions: ATP hydrolysis by water molecules containing ${ }^{18} \mathrm{O}$ and ATP resynthesis with formation of $\left[{ }^{18} \mathrm{O}\right] \gamma \mathrm{ATP}$ (Dzeja and Terzic 2009; Nemutlu et al. 2012):

$$
\begin{gathered}
\mathrm{ATP}+\left[{ }^{18} \mathrm{O}\right] \mathrm{H}_{2} \mathrm{O} \rightarrow\left[{ }^{18} \mathrm{O}\right] \mathrm{Pi}+\mathrm{ADP} \\
{\left[{ }^{18} \mathrm{O}\right] \mathrm{Pi}+\mathrm{ADP} \rightarrow\left[{ }^{18} \mathrm{O}\right] \gamma \mathrm{ATP}}
\end{gathered}
$$

Paul Boyer used this method for studying the ATP synthase reaction (Boyer 1997). Inclusion of $\left[{ }^{18} \mathrm{O}\right] \mathrm{Pi}$ into $\left[{ }^{18} \mathrm{O}\right] \gamma \mathrm{ATP}$ in the presence of uncouplers led him to the conclusion of the rotational binding change mechanism of mitochondrial ATP synthesis. Nelson Goldberg, Petras Dzeja, André Terzic, and coworkers have successfully applied this method for studying the kinetics of phosphoryl-transfer reactions and energy fluxes in vivo by measuring the rates of the following reactions (Dzeja and Terzic 2003, 2009; Nemutlu et al. 2012):

Creatine kinase phosphotransfer:

$$
\left[{ }^{18} \mathrm{O}\right] \gamma \mathrm{ATP}+\mathrm{Cr} \rightarrow\left[{ }^{18} \mathrm{O}\right] \mathrm{PCr}+\mathrm{ADP}
$$

Adenylate kinase phosphotransfer:

$$
\left[{ }^{18} \mathrm{O}\right] \gamma \mathrm{ATP}+\mathrm{AMP} \rightarrow\left[{ }^{18} \mathrm{O}\right] \beta \mathrm{ADP}+\mathrm{ADP} \rightarrow\left[{ }^{18} \mathrm{O}\right] \beta \mathrm{ATP}+\mathrm{AMP}
$$

Glycolytic phosphotransfer:

$$
\left[{ }^{18} \mathrm{O}\right] \gamma \mathrm{ATP}+\text { Glucose } \rightarrow\left[{ }^{18} \mathrm{O}\right] \mathrm{G} 6 \mathrm{P}+\mathrm{ADP}
$$

If a direct transfer of ATP from mitochondria to MgATPases happens together with its immediate hydrolysis for contraction as sometimes proposed in the literature, only isotope transfer reactions 1 and 2 could be observed. In an excellent series of studies Dzeja's group showed that in normal cardiac cells about 80-85\% of phosphoryl groups are transferred out from mitochondria by the $\mathrm{PCr}$ flux, and about 10-15\% by adenylate kinase, with a minor contribution by glycolysis (Dzeja et al. 1999). In the heart, these fluxes increase linearly with workload energy demand under conditions of the Frank-Starling law (Saks et al. 2007c). Figure 11.6 shows that PCr fluxes measured experimentally can be quantitatively simulated with a mathematical model of compartmentalized energy transfer (Dos Santos et al. 2000; Aliev et al. 2012; Aliev and Saks 1997; Vendelin et al. 2000). This model was based on the experimental data obtained in studies of mitochondrial PCr synthesis in permeabilized cardiomyocytes. The role of the adenylate kinase system becomes important in hypoxia and pathological situations (Dzeja et al. 1999). 


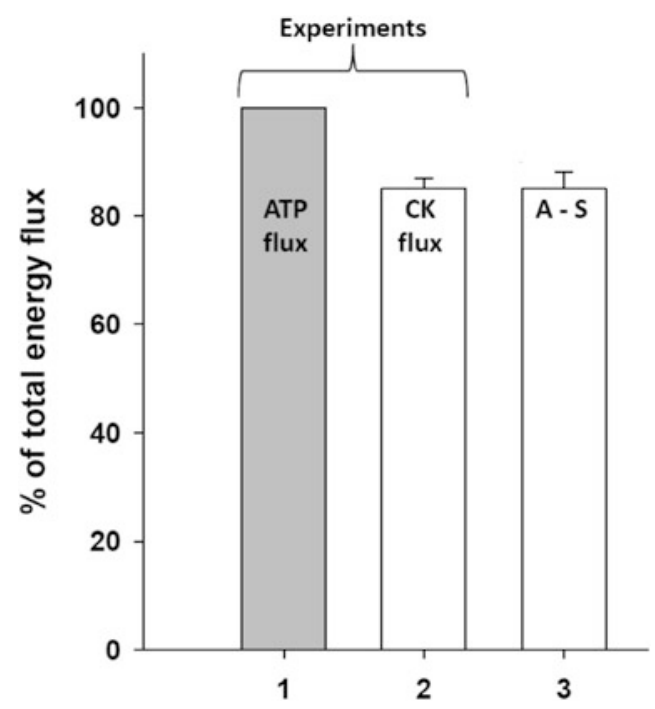

Fig. 11.6 Comparison of experimental data of energy flux measurements with results of simulations by mathematical models. ATP flux: the rate of ATP synthesis in mitochondria; CK flux: energy flux carried into cytoplasm by phosphocreatine measured experimentally by the ${ }^{18} \mathrm{O}$ transfer method [data summarized from Dzeja and Terzic (2003), Dzeja et al. (1996, 2001, 2007, 2011a), Pucar et al. (2001)]; A-S: Aliev and Saks models of compartmentalized energy transfer (Dos Santos et al. 2000; Aliev and Saks 1997). The mathematical model of the compartmentalized energy transfer system in cardiac myocytes includes mitochondrial synthesis of ATP by ATP synthase, $\mathrm{PCr}$ production in the coupled MtCK reaction, the myofibrillar and cytoplasmic $\mathrm{CK}$ reactions, ATP utilization by actomyosin ATPase during the contraction cycle, and diffusional exchange of metabolites between different compartments. The model gives a good fitting with the experimental data, showing that about $85 \%$ of energy produced in mitochondria as ATP flux is transferred out of mitochondria as PCr flux, in agreement with the abundant experimental data reported by Dzeja and colleagues

Recently this method has been used in quantitative studies of metabolic cycles in human health and disease (Dzeja et al. 2011a).

\subsubsection{Intracellular Energetic Units and Mitochondrial Interactosome: Local Signaling and Frank-Starling Law}

In addition to the fundamental structural data from Wallimann and Schlattner and energy flux determinations by Dzeja and Terzic, another important question concerns the cellular mechanisms involved in the function of CKs and other phosphotransfer pathways. This question was addressed by the group of Valdur Saks utilizing permeabilized cells that enable the study of mitochondrial function in their natural environment (Saks et al. 1991, 1998, 2007a, d; Saks and Strumia 
1993). A central bioenergetic question in muscle cells relates to the mechanism of $\mathrm{PCr}$ synthesis in mitochondria. This question arises because the equilibrium and kinetic constants of all $\mathrm{CK}$ isoforms would favor only the resynthesis of MgATP from PCr and MgADP (Saks et al. 2010; Guzun et al. 2009). Kinetic information available is in agreement with the role of MM-CK at the sites of local ATP regeneration in myofibrils and membranes of sarcolemmal and sarcoplasmic reticulum, but this is not the case for PCr synthesis in mitochondria. More insight can be obtained from the classical problem of cardiac physiology - the metabolic aspect of the basic Frank-Starling law of the heart (Saks et al. 2006c, 2012). Discovered in 1914-1926, the Frank-Starling law states that under physiological conditions contractile force, cardiac work, and the rate of oxygen consumption increase manifold with the filling of the left ventricle (Starling and Visscher 1927). Later it was found that this occurs without any changes in the ATP and PCr levels (metabolic stability) and $\mathrm{Ca}^{2+}$ transients (Neely et al. 1972; Balaban et al. 1986). The latter observation excludes any explanation involving a mechanism of control of mitochondrial respiration by changes in intracellular $\mathrm{Ca}^{2+} . \mathrm{A} \mathrm{Ca}^{2+}$-mediated mechanism may be important only in the case of adrenergic activation of the heart (Tarasov et al. 2012; Balaban 2012). Assuming that ATP, ADP, PCr, and Cr are related through equilibrium relationships, the observation of metabolic stability was interpreted to exclude any other explanation of workload dependence of cardiac oxygen consumption than a mechanism involving the control of mitochondrial respiration by ADP or Pi only. The popular assumption of CK equilibrium, as in a mixed bag of enzymes (Wiseman and Kushmerick 1995), however, is in contradiction with the experimental evidence (Saks 2008; Guzun and Saks 2010). This includes recent high-resolution ${ }^{31} \mathrm{P}$ NMR experiments showing that the major part of adenine nucleotides, notably ATP in muscle cells, exists associated with macromolecules and that free ADP may be only transiently present in the cytoplasm (Nabuurs et al. 2010, 2013). We have shown that both high PCr fluxes in the heart detected by Dzeja and collaborators (Dzeja and Terzic 2003, 2009; Dzeja et al. 1999; Nemutlu et al. 2012) and the linear dependence of the rate of oxygen consumption on cardiac work may be explained by local signaling and metabolic channeling of adenine nucleotides in nonequilibrium $\mathrm{CK}$ reactions (Saks et al. 2012; Guzun et al. 2009; Timohhina et al. 2009). Actually, CK can catalyze within the same cell either the forward or the backward reaction depending on in which microcompartment the enzyme is located and where it functions as part of different multienzyme complexes.

Mechanisms involving the interaction of mitochondria and CKs with other cellular structures and multienzyme complexes are central for understanding metabolic stability in the heart. This implies a different perspective in the framework of systems biology. Figure 11.7a shows the localization of the tubulin isotype $\beta I I$ following the pattern of mitochondrial distribution in cardiac cells (Saks et al. 2012; Gonzalez-Granillo et al. 2012; Guzun et al. 2011b, 2012). Tubulin $\beta I I$ is part of the heterodimer tubulin that binds to VDAC in MOM, thus modulating the close probability of this channel specifically so that it is permeated by $\mathrm{Cr}$ or $\mathrm{PCr}$ but limited for ATP or ADP (Guzun et al. 2009; Timohhina et al. 2009). In cardiac 
a

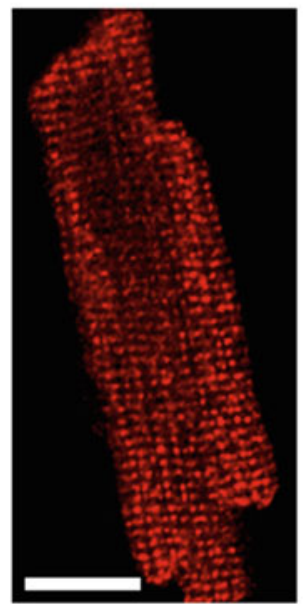

b

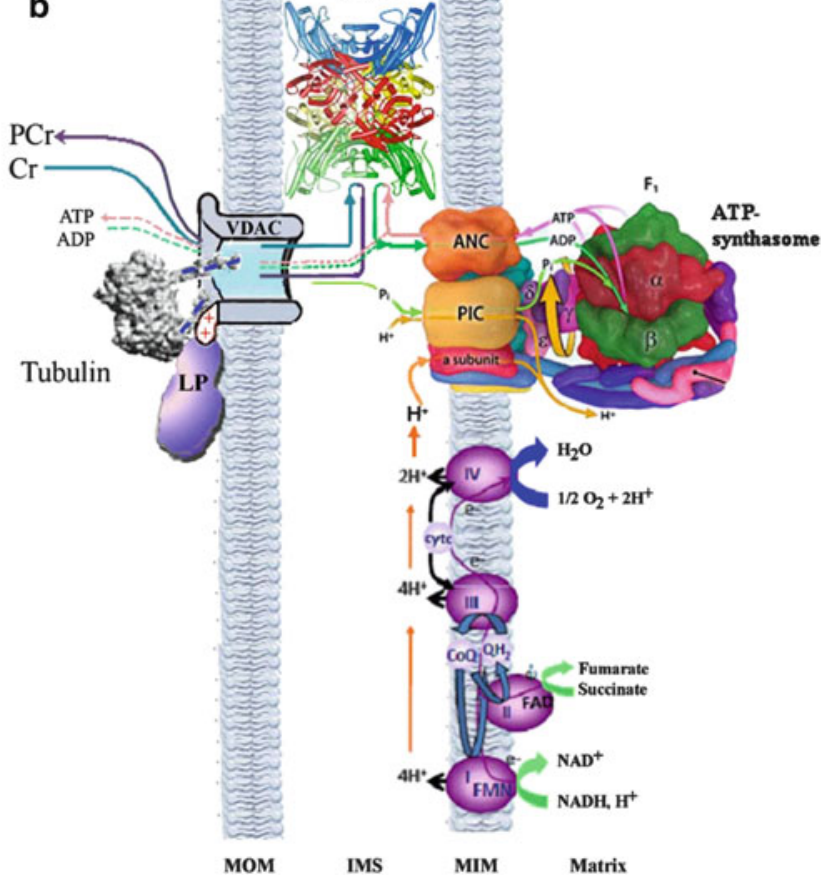

Fig. 11.7 Mitochondrial Interactosome. (a) Confocal image of a cardiomyocyte labeled with MitoTracker Red for mitochondria; scale bar $14 \mu \mathrm{m}$. (b) Scheme depicting the mitochondrial interactosome, a macromolecular complex formed by the ATP synthasome, in turn constituted by ATP synthase (subunits in different colors), adenine nucleotide translocase (ANC, orange), inorganic phosphate carrier (PIC, yellow), coupled to the respiratory complexes (I-IV, purple circles) in the mitochondrial inner membrane (MIM), octameric mitochondrial CK (MtCK, backbone structure with dimers in different color) in the intermembrane space (IMS) and the voltage-dependent anion channel (VDAC, gray-blue) in the mitochondrial outer membrane (MOM) interacting with cytoskeletal proteins tubulin (gray, surface structure representation) and putative linker protein (LP, purple). Metabolite fluxes are indicated by arrows in different colors. For ATP synthase, subunits of the $\mathrm{F}_{1}$ part (greek letters) and $\mathrm{F}_{0}$ part (latin letters) are indicated, as well as the rotation of the rotor (yellow arrow). For the respiratory chain, proton pumping $\left(\mathrm{H}^{+}\right.$, yellow arrows) and some redox centers (FMN, FAD) are indicated, as well as the two electron carriers coenzyme $\mathrm{Q}\left(\mathrm{CoQ} / \mathrm{CoQH}_{2}\right)$ and cytochrome c (cytc). Adapted from (Timohhina et al. 2009) and (Schlattner et al. 2009) with permission. Art work of the ATP synthasome in this figure was reproduced with kind permission from P.L. Pedersen and is the result of the combined efforts of Drs. Young H. Ko and David J. Blum; MtCK structure and membrane topology is reproduced from (Schlattner et al. 2006b) with permission

cells, the heterodimeric tubulin $\alpha \beta I$ and VDAC form a supercomplex with MtCK and the ATP synthasome-the mitochondrial interactosome (MI) (Fig. 11.7b) (Timohhina et al. 2009). Within this supramolecular structure, ATP and ADP cycle between ATP synthasome and MtCK maintaining oxidative phosphorylation effectively coupled to the synthesis of PCr. In the MI, MtCK functions 
unidirectionally toward $\mathrm{PCr}$ synthesis utilizing mitochondrial ATP supplied by ANT (direct channeling). This process moves ADP back into mitochondria, because of the differential permeability of VDAC in interaction with tubulin that impedes ADP release from mitochondria. These coupled reactions of oxidative phosphorylation and $\mathrm{PCr}$ synthesis in MI are effectively regulated by $\mathrm{Cr}$ (Fig. 11.8). In the presence of an extra-mitochondrial ADP trapping system (pyruvate kinase, PK; phosphoenolpyruvate, $\mathrm{PEP}$ ), $\mathrm{Cr}$ addition rapidly increases the respiration rate to its maximal value, revealing a preferential accessibility of the ADP produced by MtCK to matrix ATPase, not to the cytosolic trapping system. Metabolic control analysis of mitochondrial respiration in permeabilized cardiac cells showed high flux control coefficients (FCC) for reactions involving ADP recycling coupled to MtCK and PCr production (Fig. 11.9a). Actually, the sum of control coefficients exceeds the theoretical value for linear systems by a factor of 4 (Tepp et al. 2011). This can be interpreted in terms of MtCK-controlled reactions in MI acting as very effective amplifiers of metabolic signals from cytoplasm (Tepp et al. 2011; Aon and Cortassa 2012). According to Kholodenko, Westerhoff, and their coworkers, the sum of the FCC of the metabolic pathway components exceeding one indicates a direct channeling in the pathway (Moreno-Sanchez et al. 2008). On the contrary, in isolated heart mitochondria and permeabilized cardiac fibers the sum of FCC of respiratory chain complexes, ATP synthase, and metabolite carriers, estimated under conditions of respiration activated by ADP, is close to 1, corresponding to a linear metabolic pathway (Moreno-Sanchez et al. 2008; Kuznetsov et al. 1996; Doussiere et al. 1984; Fell and Thomas 1995; Groen et al. 1982). The high efficiency of energy flux control in MI makes this supercomplex a key site for the feedback of metabolic regulation of mitochondrial respiration in cardiac cells (Saks et al. 2012; Tepp et al. 2011).

Figure $11.9 \mathrm{~b}$ depicts the possible role of both $\mathrm{Cr}$ and $\mathrm{ADP}$ in the control of respiration in situ. Extra- and intra-mitochondrial ADP in the regulation of respiration was studied by MgATP titration in the absence or presence of $\mathrm{Cr}$, i.e., activated MtCK (Saks et al. 2012; Guzun et al. 2009; Guzun and Saks 2010; Timohhina et al. 2009). The influence of mitochondrial ADP alone on respiration was estimated by removing extra-mitochondrial ADP through the PEP-PK trapping system mimicking glycolytic ADP consumption. From Fig. 11.9b we can see that stimulation of the extra-mitochondrial ADP producing system by MgATP alone cannot effectively activate respiration. The high apparent $K_{\mathrm{m}}$ for exogenous $\operatorname{MgATP}(157.8 \pm 40.1 \mu \mathrm{M})$ corresponds to the apparent $K_{\mathrm{m}}$ of myofibrillar ATPase reaction for MgATP. However, when oxidative phosphorylation is stimulated by both extra- and intra-mitochondrial ADP (in the presence of Cr to activate MtCK and MM-CK in myofibrils), the respiration rate increases rapidly up to maximal values and the apparent $K_{\mathrm{m}}$ for ATP decreases from $157.8 \pm 40.1 \mu \mathrm{M}$ to $24.9 \pm 0.8 \mu \mathrm{M}$. Removal of extra-mitochondrial ADP by PEP-PK provokes an increase of $K_{\mathrm{m}}$ for MgATP up to $2.04 \pm 0.10 \mathrm{mM}$. These results show that local endogenous ADP in ICEUs is an important regulatory factor of respiration but only in the presence of $\mathrm{Cr}$ and activated MtCK. The stimulatory effect of respiration by endogenous ADP is strongly amplified by functional coupling of MtCK with ANT 

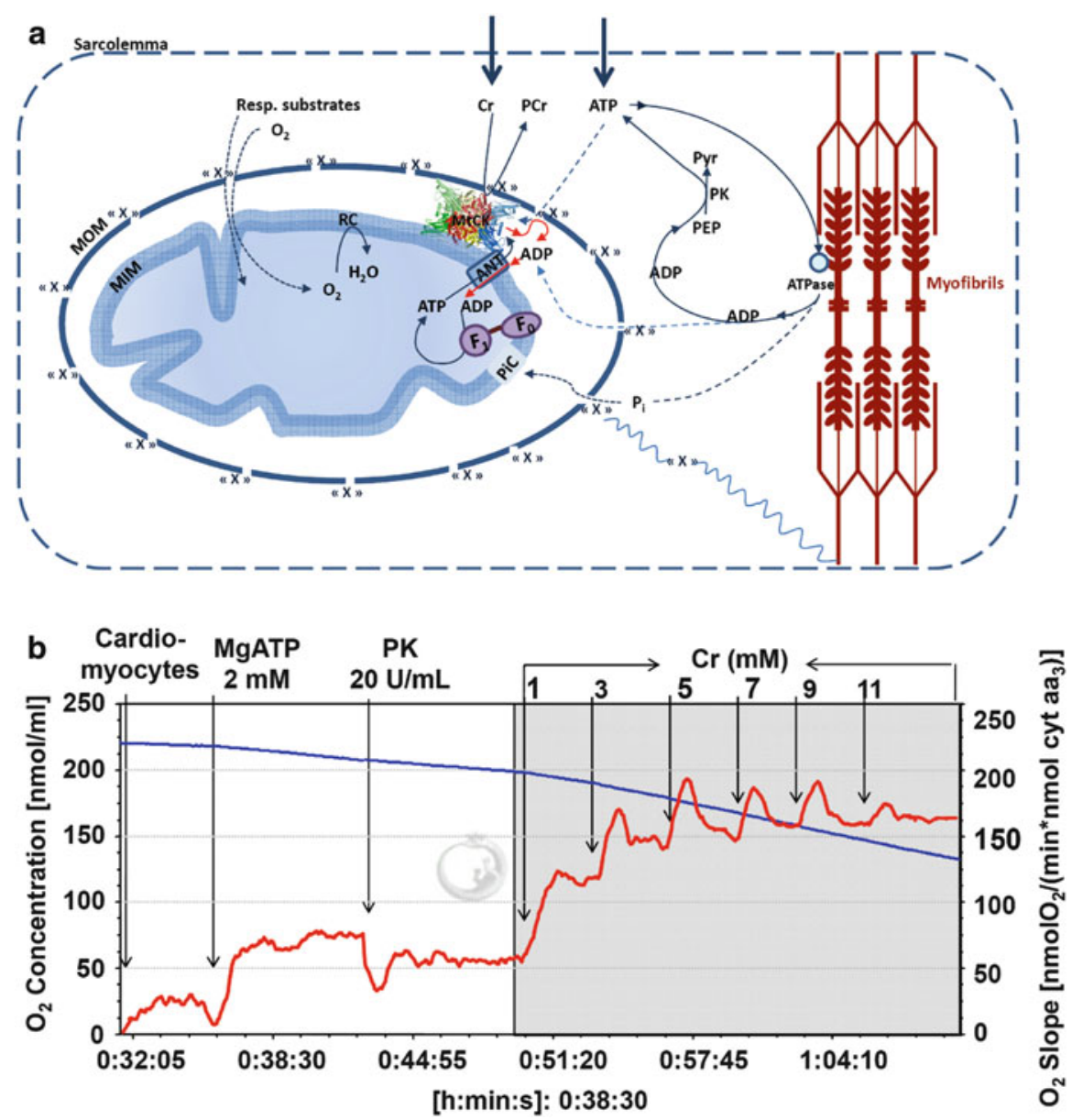

Fig. 11.8 Control of mitochondrial respiration by creatine in permeabilized cardiomyocytes. (a) Schematic representations of an oxygraph experiment and of a mitochondrion in a permeabilized cardiac cell, surrounded by cytoskeletal proteins and myofibrils. First, added ATP is hydrolyzed by cellular ATPases and the ADP produced stimulates respiration. Phosphoenolpyruvate (PEP) and pyruvate kinase (PK) continuously trap extra-mitochondrial ADP to regenerate ATP. Stepwise addition of $\mathrm{Cr}$ in the presence of ATP stimulates mitochondrial creatine kinase (MtCK) that controls respiration through continuous intra-mitochondrial re-cycling of ADP from ATP. (b) Oxygraph recording of $\mathrm{Cr}$ stimulated respiration. This experiment enables the estimation of the apparent affinity of MtCK for $\mathrm{Cr}$. The left scale and the blue trace indicate the oxygen concentration $\left(\mathrm{nmol} \mathrm{O}_{2} \mathrm{ml}^{-1}\right)$ in the experimental milieu. The right scale and the red trace denote the rate of oxygen uptake (in nmol $\mathrm{O}_{2} \mathrm{~min}^{-1} \mathrm{nmol}^{-1}$ cyt. aa3). Adapted from (Guzun et al. 2009) with permission

that increases adenine nucleotides recycling within the MI (Saks et al. 2012; Guzun et al. 2009; Timohhina et al. 2009; Jacobus and Saks 1982). The loss of Cr-stimulated respiration in transgenic MtCK-knockout mice confirms the central role of MtCK in respiration regulation (Kay et al. 2000). 

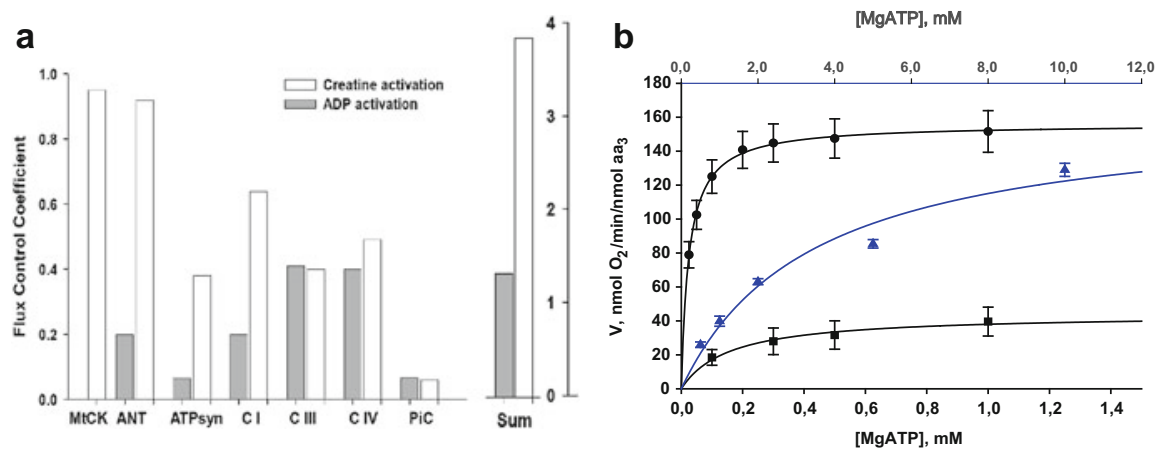

Fig. 11.9 The energy flux control in permeabilized cardiomyocytes: creatine stimulation of mitochondrial respiration. (a) Flux control coefficients for MtCK, adenine nucleotide translocase (ANT), ATP synthasome (ATPsyn), respiratory complexes I (C I), III (C III), IV (C IV), and inorganic phosphate carrier $(\mathrm{PiC})$. The right panel shows the sum of flux control coefficients. Reproduced from (Tepp et al. 2011) with permission. (b) The role of endogenous ADP produced in MgATPase reactions at different concentrations of MgATP in the regulation of mitochondrial respiration in permeabilized cardiomyocytes under different conditions: (square)-without ADP trapping system (PEP-PK) and in the absence of Cr; ( filled circle) - without PEP-PK system but in the presence of $20 \mathrm{mM} \mathrm{Cr}$ (i.e., activated MtCK); (triangle) - in the presence of both trapping system for free ADP and $20 \mathrm{mM}$ Cr. Reproduced from (Timohhina et al. 2009) with permission

Taken together this information allows explaining the linear relationship existing between oxygen consumption and cardiac work by local metabolic feedback signaling within ICUEs (Saks et al. 2010, 2012; Aliev et al. 2012) (Fig. 11.10). Direct flux determination and mathematical modeling show that not more than $10 \%$ of free energy is transported out of mitochondria by ATP flux needed to equilibrate the information-carrying flux of ADP into mitochondria. According to this model, ADP released from actomyosin cross-bridges stimulates the local MM-CK reaction in the myofibrillar space within ICEUs while at the same time forms a concentration gradient towards mitochondria (Fig. 11.10a-c) (Dos Santos et al. 2000; Aliev et al. 2012; Aliev and Saks 1997; Vendelin et al. 2000). The amplitude of displacement of MM-CK from equilibrium, as well as cyclic changes in ADP, is proportionally increased with workload (Fig. 11.10b, c). The rephosphorylation of ADP in the MM-CK reaction increases locally the $\mathrm{Cr} / \mathrm{PCr}$ ratio that is transferred towards $\mathrm{MtCK}$ via the $\mathrm{CK} / \mathrm{PCr}$ shuttle. Regulation of VDAC permeability by $\beta \mathrm{II}$ tubulin is a key element mediating the linear response of mitochondrial respiration to local signaling within ICEUs. When MOM is permeable, as in isolated mitochondria, modulation of respiration is impossible because of saturating ADP concentrations used under these conditions. The latter exceeds manifold the apparent affinity of oxidative phosphorylation for free ADP $\left(K_{\mathrm{m}}{ }^{\text {app }} \mathrm{ADP}=7.9 \pm 1.6 \mu \mathrm{M}\right)$, even in diastolic phase (about $\left.40 \mu \mathrm{M}\right)$ (Fig. 11.11a). On the contrary, when ADP diffusion is restricted at the level of 
a
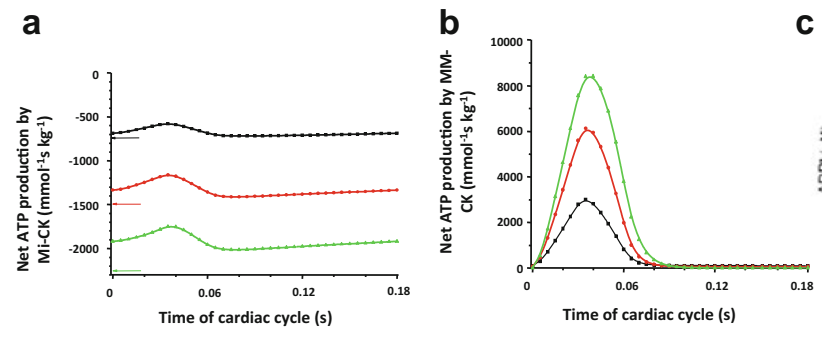

C

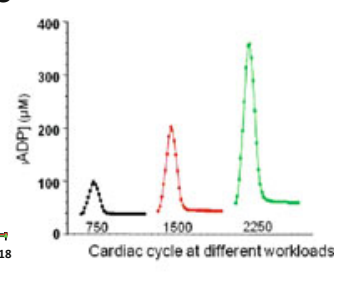

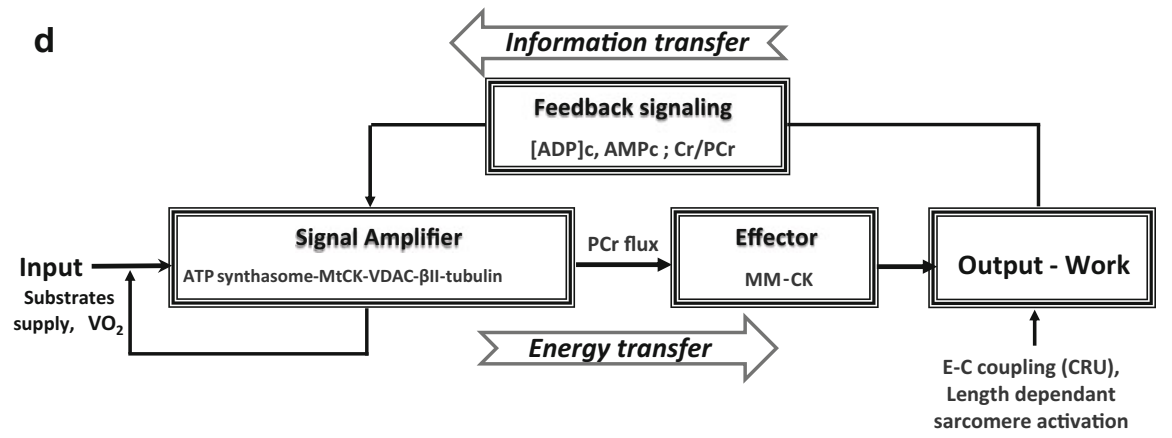

Fig. 11.10 Mechanisms of regulation of mitochondrial respiration controlled by MtCK and of energy fluxes in cardiac muscle cells. (a-c) Results from a mathematical model of cardiac energy metabolism (Vendelin-Aliev-Saks-Dos Santos model). (a,b) Calculated net PCr production rates in nonequilibrium steady state MtCK reaction (a) and cyclic changes in rates of ATP regeneration in nonequilibrium myofibrillar MM-CK reaction (b) during contraction cycles at different workloads corresponding to oscillations of [ADP]c indicated in Fig. 11.11. (c) Mathematically modeled oscillations of ADP concentrations in the core of myofibrils over cardiac cycle at workloads equivalent to 750 (black), 1,500 (red) and 2,250 (green) $\mu \mathrm{mol} \mathrm{ATP} \mathrm{s}{ }^{-1} \mathrm{~kg}^{-1}$. According to this model, the ATP cyclically produced during contractions (b) is associated with cyclical oscillations of ADP and Pi concentrations in myofibrils (c) and subsequent $\mathrm{PCr}$ production in the MtCK reaction (a). Reproduced from (Dos Santos et al. 2000; Aliev et al. 2012; Aliev and Saks 1997; Vendelin et al. 2000) with permission. (d) Schematic representation of feedback metabolic signaling in regulation of energy metabolism within ICEUs in cardiac cells. Due to the nonequilibrium MtCK and cyclic MM-CK reactions, intracellular ATP utilization (output) and mitochondrial ATP regeneration (input) are linked via cyclic fluctuations of cytosolic ADP and $\mathrm{Cr} / \mathrm{PCr}$. See the text for explanation

MOM, as in mitochondria in situ, the apparent $K_{\mathrm{m}}$ for free ADP increases to about $370.75 \pm 30.57 \mu \mathrm{M}$ and the respiration rate becomes almost linearly dependent on local ADP concentration. Under these conditions, the initial respiratory rate can be approximated by its linear dependence on ADP within the range of values corresponding to the increase in workload (Fig. 11.11b) (Guzun et al. 2009; Timohhina et al. 2009). Thus, cyclic changes in local ADP concentrations within the myofibrillar space of ICEUs become an effective regulatory signal due to (1) the nonequilibrium state of CK reactions, (2) the restricted VDAC permeability to metabolites elicited by association with $\beta$ II tubulin, and (3) the presence of 
a

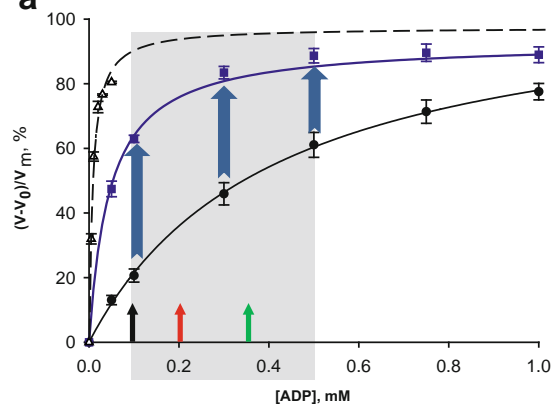

b

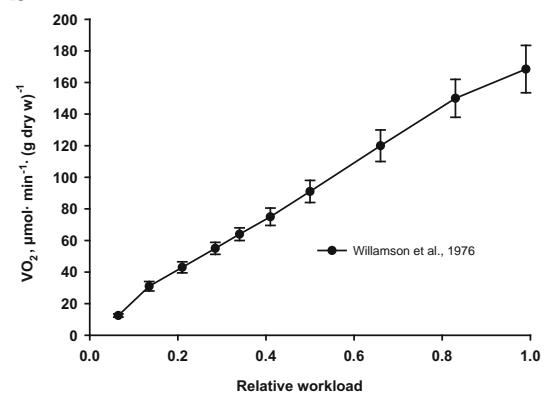

Fig. 11.11 The role of restriction of ADP diffusion in the regulation of mitochondrial respiration. (a) Kinetic analysis of ADP-activated respiration. The ADP concentrations corresponding to mathematically modeled fluctuations of ADP by Michaelis-Menten graph representation with colored small arrows (black, red and green), contained in the area of physiological cytosolic ADP concentration (indicated by a gray box). When MOM is permeable, as in isolated mitochondria $(\Delta$, $K_{\mathrm{m}}{ }^{\text {app }} \mathrm{ADP}-7.9 \pm 1.6 \mu \mathrm{M}$ ), the regulation of respiration is impossible because of a saturated ADP concentration for the minimal workload. When the ADP diffusion is restricted at the level of $\mathrm{MOM}$, as in mitochondria in permeabilized cardiomyocytes (circle, $K_{\mathrm{m}}^{\text {app ADP- }}$ $370.75 \pm 30.57 \mu \mathrm{M})$, the respiration rates become linearly dependant on ADP concentrations, in fact also on heart workloads in accordance with the Frank-Starling law (b). This linear dependence under physiological conditions can be amplified by creatine (see large blue arrows in a) in the presence of activated MtCK (Square, $K_{\mathrm{m}}{ }^{\text {app ADP }}-50.24 \pm 7.98 \mu \mathrm{M}$ ). Reproduced from (Guzun et al. 2009) with permission. (b) The metabolic aspect of the Frank-Starling's law of the heart is expressed by linear dependence between the increase of left ventricular end-diastolic volume and the increase of respiration rates in the absence of measurable changes in the intracellular ATP and $\mathrm{PCr}$ content. Reproduced from (Saks et al. 2006c) with permission

Cr. When these conditions are fulfilled, activation of the coupled MtCK within MI by $\mathrm{Cr}$ induces ADP/ATP recycling and increases respiration rate, thus amplifying the effect of cytoplasmic ADP; under these conditions, the apparent $K_{\mathrm{m}}$ for ADP becomes equal to $50.24 \pm 7.98 \mu \mathrm{M}$ (Fig. 11.11a). These data suggest that modulation of respiration by local changes in ADP concentration, under condition of restriction of adenine nucleotide diffusion across mitochondrial membranes, is mediated by the structural organization of the MI. The MtCK reaction amplifies the ADP signal due to its functional coupling with ATP Synthasome (Fig. 11.7), thus increasing the steady-state rate of adenine nucleotides cycling in mitochondria and the rate of respiration. The coupled reactions of muscle type MM-CK in myofibrils and MtCK in mitochondria perform under nonequilibrium conditions and proceed in opposite directions (Fig. 11.10a-c) (Saks et al. 2012; Guzun et al. 2009; Guzun and Saks 2010; Timohhina et al. 2009). This mode of function results in separation of energy fluxes (mass and energy transfer by $\mathrm{PCr}$ ) and signaling (information transfer by oscillations of cytosolic ADP concentrations, $\mathrm{Pi}$ and $\mathrm{PCr} / \mathrm{Cr}$ ratio) that is amplified within the MI. As a result, reactions catalyzed by different isoforms of compartmentalized $\mathrm{CK}$ tend to maintain the intracellular metabolic stability. The separation of energy and information transfer is illustrated 
by the scheme depicted in Fig. 11.10d. This scheme shows feedback regulation of respiration in vivo according to Norbert Wiener's cybernetic principles (Saks et al. 2012; Guzun and Saks 2010): the usage of ATP (or release of free energy of ATP hydrolysis, $\Delta \mathrm{G}_{\mathrm{ATP}}$, to perform work, marked as output) and ATP regeneration (or extraction of $\Delta \mathrm{G}_{\mathrm{ATP}}$ from substrates by oxidative phosphorylation, denoted as input) are interconnected via the feedback signaling through oscillations of cytoplasmic concentrations of ADP, AMP, $\mathrm{Pi}$, and $\mathrm{Cr} / \mathrm{PCr}$ amplified within $\mathrm{MI}$. In this framework, the role of $\beta$ II tubulin in association with MOM in cardiomyocytes would be to induce the linear response of mitochondrial respiration to workloaddependent metabolic signals. This elegant feedback mechanism of regulation of respiration on a beat-to-beat basis ensures metabolic stability necessary for normal heart function and explains well the metabolic aspect of the Frank-Starling's law of the heart (Saks 2007; Saks et al. 2006a, 2012). Importantly, recycling of adenine nucleotides within MI when coupled to PCr production significantly decreases ROS levels ensuring maximal efficiency of free energy transduction in mitochondria while inhibiting permeability transition pore opening, thus protecting the heart under stress conditions (Schlattner et al. 2006b; Meyer et al. 2006).

While the mechanisms described above represent local signaling within ICEUs, important mechanisms of synchronization of mitochondrial activity between ICEUs and their integration into structurally and functionally organized cellular systems are described by Cortassa and Aon in Chap. 5. The role of $\mathrm{Ca}^{2+}$ cycle in maintaining high respiratory activity of mitochondria within ICEUs has been described by Balaban's group and studied by mathematical modeling by Cortassaet al. (2009).

\subsubsection{Intracellular Creatine Concentration as a Regulatory Factor in Heart Energetics}

Many experimental and clinical studies have shown that intracellular Cr concentration is an important factor, determining the efficiency of intracellular energy transfer in heart cells (Saks et al. 1978, 2012; Wyss and Kaddurah-Daouk 2000; Nascimben et al. 1996). The results of an earlier work of ours published more than 30 years ago are reproduced in Fig. 11.12. This experiment shows that removal of $\mathrm{Cr}$ from the frog heart cells results in decreased $\mathrm{PCr}$ content and diminished contractile force; all parameters return to their initial value after restoration of $\mathrm{Cr}$ content (Saks et al. 1978). Similar results were recently reported by (Nabuurs et al. 2013) by assessing morphological, metabolic, and functional consequences of systemic $\mathrm{Cr}$ depletion in skeletal muscle. These data were obtained in a mouse model deficient in $L$-arginine:glycine amidino transferase $\left(\mathrm{AGAT}^{-/-}\right.$) which catalyzes the first step of $\mathrm{Cr}$ biosynthesis. In this work, systemic $\mathrm{Cr}$ depletion resulted in mitochondrial dysfunction and intracellular energy deficiency, as well as structural and physiological abnormalities. In vivo magnetic resonance 
Fig. 11.12 The role of Creatine in the regulation of contraction in frog heart. After $8 \mathrm{~h}$ of perfusion without creatine, frog heart strips assume a hypodynamic state with decreased contractile force (FC) and lowered $\mathrm{Cr}$ and $\mathrm{PCr}$ levels. Addition of $20 \mathrm{mM}$ Cr to the perfusate restored to normal the values of all these variables. Reproduced with permission from (Saks et al. 1978)

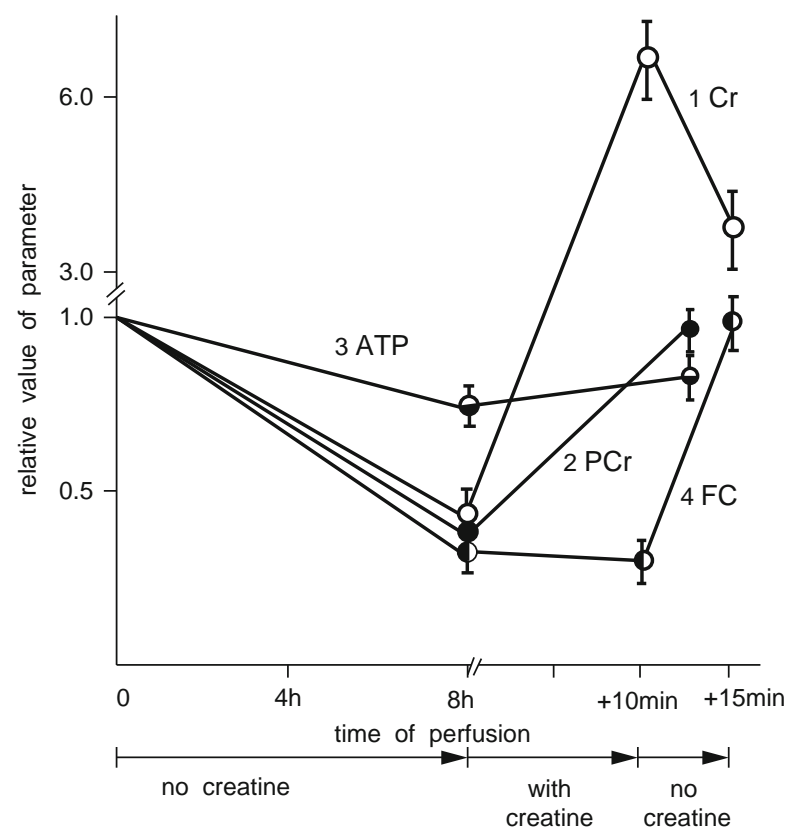

spectroscopy showed a near-complete absence of $\mathrm{Cr}$ and $\mathrm{PCr}$ in resting hind limb muscle of $\mathrm{AGAT}^{-/-}$mice. Compared to wild type, the inorganic phosphate/ $\beta$-ATP ratio was increased fourfold, while ATP levels were reduced to nearly half and overall mitochondrial content was increased. The Cr-deficient $\mathrm{AGAT}^{-1-}$ mice presented with significantly reduced grip strength and suffered from severe muscle atrophy. Oral $\mathrm{Cr}$ administration led to rapid accumulation in skeletal muscle (faster than in brain) and reversed all muscle abnormalities revealing that the condition of the $\mathrm{AGAT}^{-/-}$mice can be switched between $\mathrm{Cr}$-deficient and normal simply by dietary manipulation. The consequences of AGAT deficiency were more pronounced than those of muscle-specific CK deficiency (Nabuurs et al. 2013), which suggests a multifaceted involvement of $\mathrm{Cr}$ in addition to its role in the $\mathrm{PCr}-\mathrm{CK}$ system and in muscle energy homeostasis, as, e.g., by direct effects on biomembranes (Tokarska-Schlattner et al. 2012). It was also shown by the group of Stefan Neubauer in Oxford that a moderate elevation of total $\mathrm{Cr}$ levels in the heart by approximately $50 \%$ in transgenic mice overexpressing the $\mathrm{Cr}$ transporter (CRT) conveyed significant protection and improved recovery of the hearts upon experimental induction of ischemia/reperfusion (Lygate et al. 2012). In one of their most important work the Neubauer's group has shown that a decrease of PCr content in the heart of patients with dilated cardiomyopathy is accompanied with significantly increased mortality rates (Neubauer 2007).

The role of altered phosphotransfer pathways in heart pathology of animal models, as well as human patients, is well documented and has been described in 
a number of reviews (Ingwall and Weiss 2004; Ingwall 2006; Ventura-Clapier et al. 2002, 2004). Most recently, two younger Chinese patients with acute myocardial infarction and presenting with muscle MM-CK deficiency have been diagnosed with somatic mutations in the M-CK gene. These mutants at amino acid E79 prevent correct folding and dimerization of M-CK. In parallel, correct targeting of the enzyme to subcellular structures is hampered and enzymatic CK activity dramatically lowered (Wu et al. 2013). These data with human cardiac infarction patients have shown that active dimeric MM-CK together with its substrates $\mathrm{Cr}$ and $\mathrm{PCr}$ are important for normal heart function.

Thus, the current opinion, supported by a host of data derived from different experimental approaches and provided by a number of different independent laboratories, is that $\mathrm{Cr}$ and $\mathrm{PCr}$ together with microcompartmentalized $\mathrm{CK}$ isoforms are physiologically essential for normal body function, specifically for optimal performance of skeletal and heart muscle, brain, neuronal cells, skin, retina and auditory cell, spermatozoa, and other cells of intermittant high-energy requirements (Wallimann et al. 1992, 2011). This fundamental hypothesis is strongly supported by the more or less severe phenotypes observed in double and single CK isoenzyme knockout mice, respectively (Steeghs et al. 1997; Streijger et al. 2005; Heerschap et al. 2007), as well as by the phenotypes of AGAT and GAMT knockout mice, presenting with disturbed energy metabolism body weight control, hampered fertility, muscular dystrophy, and cognitive and behavioral impairment, etc. (Nabuurs et al. 2013; Schmidt et al. 2004; ten Hove et al. 2005; Torremans et al. 2005).

In a most recent, provocative publication, entitled "Life without creatine", Lygate and colleagues purport that the phenotype of the GAMT knockout mouse was basically "normal". Specifically, they do not find a skeletal or cardiac muscle phenotype (Lygate et al. 2013). This contradicts the phenotype of the same transgenic mouse described earlier (Schmidt et al. 2004; ten Hove et al. 2005; Kan et al. 2005). Most importantly it is in contrast to the AGAT knockout creatine deficiency mouse (Nabuurs et al. 2013). This latter AGAT knockout mouse, in contrast to the GAMT knockout mouse, does not synthesize guanidine acetate (GAA), which in the GAMT knockout skeletal muscle was shown to be phosphorylated by CK to form an alternative energy-rich phosphagen, phosphoGAA, which still can be utilized as high-energy phosphagen, albeit at lower efficiency (Heerschap et al. 2007). Thus, it will be most important to reevaluate cardiac energy metabolism and heart phenotype in the GAMT knockout mouse to completely rule out any compensatory effects of the high concentrations of phospho-GAA accumulated in these knockout mice and to rule out a still possible contribution of phospho-GAA as an still alternative energy source. Corresponding experiments with the pure creatine deficiency AGAT knockout, presenting with a rather severe phenotype that is reversible by simple creatine supplementation (Nabuurs et al. 2013), are warranted and should provide some answers to these pending questions. To get a physiologically more meaningful answer to the true function of $\mathrm{CK}$ in heart it will be paramount to stress the heart to maximal performance and work output, where one would expect to see the true effects of creatine deficiency also in this organ. 
In conclusion, until the enigma of the results provided by (Lygate et al. 2013) (see above) is solved, all available data still indicate that the CK system together with $\mathrm{PCr}$ and $\mathrm{Cr}$ is central to the regulatory mechanisms of metabolic and energy fluxes in those cells under intermitantly fluctuating high-energy requirements, including the heart (Taegtmeyer and Ingwall 2013).

\subsection{The Signaling Network of AMP-Activated Protein Kinase (AMPK) in the Heart}

\subsubsection{Protein Kinase Signaling Networks in Metabolic Control of Cardiac Function}

Metabolic cycles as described before provide immediate metabolic feedback for changes in energy input (nutrient supply) and energy output (workload). They are particularly important in the heart, an organ that maintains a high degree of metabolic stability and a particularly well-controlled energy homeostasis. An additional layer of regulation, which ascertains this metabolic stability, is achieved by information transfer via protein kinase signaling. All major protein kinase pathways were shown to play important roles in the heart, controlling contraction force, contractility, and heart rate in particular during cardiac development, under prolonged strong stimulation, and under emerging pathological conditions.

The possibly best studied example is the cyclic adenosine nucleotide (cAMP)dependent protein kinase A (PKA) (Taylor et al. 2008), together with its homologous cGMP-dependent protein kinase G (PKG) (Takimoto 2012). Their control of cardiac contraction strength, ion fluxes, and hypertrophy relies on a precise spatiotemporal regulation of substrate phosphorylation. In case of PKA, A-kinase anchoring proteins (AKAPs) and cyclic nucleotide phosphodiesterases (PDEs) play a major role in this spatiotemporal organization and the occurrence of cAMP microdomains (Edwards et al. 2012; Mika et al. 2012; Diviani et al. 2013). This emphasizes the importance of cellular localization and organization for protein kinase-mediated information fluxes, as already outlined above for cardiac CK isoenzymes.

Also some other protein kinase signaling pathways have to be considered as relevant for cardiac metabolism. Protein kinase B (PKB or Akt) is an essential component of the growth response of an organism to nutritional input. In the heart, it participates in the regulation of myocyte growth under physiological conditions (Walsh 2006; Hers et al. 2011). PKC isoforms regulate cardiac contraction and hypertrophic responses, as well as other signaling pathways in more pathological situations such as ischemia and reperfusion injuries (Steinberg 2012). While calcium-regulated PKD is a more recent addition to the kinome, less well studied in respect to the cardiovascular system (Avkiran et al. 2008), members of the 
mitogen-activated protein kinase (MAPK) family are prominent regulators of cardiac function with both protective and detrimental effects (Rose et al. 2010).

The protein kinase most relevant in the context of metabolic stability and energy homeostasis, however, is AMP-activated protein kinase (AMPK). It has often been described as a major "signaling hub," "fuel gauge," "metabolic sensor," or "metabolic master switch" because it plays a central role in sensing and regulating energy homeostasis at the cellular, organ, and whole-body level (Winder and Hardie 1999; Hardie and Carling 1997). Activation of AMPK is triggered by a diverse array of signals linked to limited energy availability in physiological and pathological situations, including extracellular (e.g., hormones, cytokines, nutrients) and intracellular stimuli (e.g., AMP, ADP) (Hardie et al. 2012a). Activation involves covalent phosphorylations and allosteric binding of AMP or ADP that cooperate in a complex manner. In general, these regulations are coordinated to activate AMPK in situations of energy deficits and aim at compensating ATP loss via accelerated catabolism and inhibited anabolism. However, pleiotropic control exerted by AMPK affects not only metabolic pathways but also other physiological functions like cell growth and proliferation, cell polarity and motility, apoptosis, autophagy, and central appetite control by regulating enzyme activities and gene transcription. This has made the kinase also a prime pharmacological target for treating metabolic disorders or possibly also cancer (Hardie 2007; Zhang et al. 2009; Finckenberg and Mervaala 2010; Inoki et al. 2012; Srivastava et al. 2012).

Although earlier work on AMPK mainly focused on tissues like liver and skeletal muscle, more recent research has revealed novel molecular mechanisms of AMPK regulation and downstream action that are relevant also to cardiovascular function. Activation of the AMPK pathway plays a particularly important role in the myocardial response to pathological stimuli like ischemia-reperfusion (Kudo et al. 1995; Russell et al. 2004), pressure overload (Tian et al. 2001; Kim et al. 2012), or heart failure (Sasaki et al. 2009). Pharmacological activation of AMPK also holds promise as a therapeutic strategy for treating cardiovascular diseases (e.g., Sasaki et al. 2009; Calvert et al. 2008; Shinmura et al. 2007). The following paragraphs will briefly summarize the key elements of AMPK signaling with an emphasis on metabolic regulation in the heart. For more complete reviews of this issue, the reader is referred to some excellent recent overviews dedicated to general AMPK signaling (Hardie et al. 2012a; Inoki et al. 2012; Carling et al. 2012; Oakhill et al. 2012) or AMPK functions in the heart (Zaha and Young 2012; Harada et al. 2012; Ahn et al. 2012; Horman et al. 2012) and other organs [see e.g., a recent review series in Mol Cell Endocrinol (Steinberg 2013)]. Thus, AMPK signaling may constitute a fourth module for a systems description of the cardiac metabolic network. 


\subsubsection{Network Elements: AMPK Isoforms and Their Distribution in Cells and Tissues}

AMPK is an evolutionary conserved and ubiquitously expressed serine/threonine kinase that presents complex structural and functional features. Structurally, it occurs in vertebrates as an obligatory heterotrimeric complex composed of one catalytic subunit $(\alpha)$ and two regulatory subunits $(\beta$ and $\gamma)$. As a first layer of complexity, all subunits exist in form of different isoforms $(\alpha 1, \alpha 2, \beta 1, \beta 2, \gamma 1, \gamma 2$, and $\gamma 3$ ) and splice variants (of $\gamma 2$ and $\gamma 3$ ), generating multiple heterotrimeric complexes. The precise physiological significance of these isoforms is not yet entirely clear. However, there is some evidence that they determine intracellular distribution, protein recognition, or tissue-specific functions of AMPK, all of which could provide selectivity for specific subsets of substrates within the ever increasing list of AMPK substrates (Hardie et al. 2012a, b; Carling et al. 2012).

\subsubsection{Subcellular Localization}

The subcellular distribution and recruitment of AMPK to specific sites are likely an important factor for its signaling function, but so far only few details are known, in particular in heart. AMPK is generally observed as a soluble complex with diffuse cytosolic localization, but at least $\alpha 2$-containing complexes in their activated form can translocate into the nucleus to phosphorylate important substrates (e.g., transcription factors, histones, histone deacetylases) as seen, e.g., after exercise in skeletal muscle (McGee et al. 2003, 2008; Suzuki et al. 2007; McGee and Hargreaves 2008). Minor but important portions of AMPK may associate with cellular structures like specific membranes, where processes are regulated by AMPK (e.g., ion channel activity, cell polarity, or cell junction formation) (Forcet and Billaud 2007; Andersen and Rasmussen 2012; Nakano and Takashima 2012). Myristoylation of the AMPK $\beta$-subunit can localize the kinase complex to membranes and increases its activability, possibly favoring activation of membrane-bound complexes (Suzuki et al. 2007; Oakhill et al. 2010).

AMPK may also be recruited into specific complexes via interaction with its upstream kinases, downstream substrates, or more general scaffolding proteins. However, the AMPK interactome is only partially known so far from some targeted and non-biased interaction studies conducted by us and others (e.g., Ewing et al. 2007; Moreno et al. 2009; Behrends et al. 2010; Klaus et al. 2012), and more research is needed on this issue, in particular in the heart. AMPK interaction with LKB1, its major upstream kinase in the heart, could localize AMPK to places of LKB1 localization, including the mitochondrial surface or E-cadherin in adherens junctions (Sebbagh et al. 2009). Scaffolding proteins can provide specificity in cell signaling by isolating activated kinases from bulk signaling and directing the information flow into specific pathways. In heart, for example, AMPK competes with p38 MAPK for binding to the scaffolding protein 
TAK-1-binding protein-1, thus blunting p38 activation during ischemia (Li et al. 2005). Mitochondrial VDAC may represent yet another anchor protein recruiting AMPK to this organelle (Strogolova et al. 2012). There is also some evidence that AMPK subunit isoforms determine specific protein interactions. The $\beta$-subunit may in some cases confer substrate specificity, as seen with the yeast and plant orthologues (Vincent and Carlson 1999; Polge et al. 2008), but also putative mammalian AMPK interactors (IntAct database, (Kerrien et al. 2012)). We recently found the $\beta 2$-isoform interacting with $\mathrm{Mu}$ - and Pi-type glutathione transferases (GSTs) to favor glutathionylation of the $\alpha$-subunit (Klaus et al. 2013). However, in case of fumarate hydratase $(\mathrm{FH})$, we identified a specific interaction with $\alpha 2$-containing AMPK complexes (Klaus et al. 2012).

\subsubsection{Expression Patterns}

AMPK isoforms also show some differences in their tissue- and developmentalspecific expression patterns, also in heart, although the physiological significance is still uncertain. While the $\alpha 1 \beta 1 \gamma 1$ complex is probably the most abundant in most cell types, differences seem to occur in the amount of additional isoforms like $\alpha 2$ and $\gamma 3$ in skeletal muscle or $\beta 2$ and a specific intermediate length $\gamma 2$ splice variant $(\gamma 2-3 B)$ in the heart (Stapleton et al. 1996; Thornton et al. 1998; Li et al. 2006; Pinter et al. 2012). There are also pathological and developmental changes in cardiac AMPK expression. The $\alpha 2, \beta 2$, and $\gamma 2$ isoforms are all upregulated by pressure overload or heart failure in rodents, although in patients rather the content of $\alpha 1, \beta 1$, and $\gamma 2$ (an intermediate form) increases with different forms of cardiomyopathy (Tian et al. 2001; Kim et al. 2012). During embryonic development in rodents, $\gamma 1$ increases while high levels of $\gamma 3$ disappear, and the embryonically predominant full-length $\gamma 2$ form is replaced by $\gamma 2-3 B$ in heart, but by short $\gamma 2 \mathrm{~b}$ in other tissues (Pinter et al. 2012). These developmental and tissue particularities may also explain why $\gamma 2$ gene mutations in the CBS domains cause heriditary hypertrophic cardiomyopathy (see below) but no other pathological symptoms. Full-length $\gamma 2$ and $\gamma 2-3 B$ share an N-terminal domain with unknown function that could localize the AMPK complex to specific compartments or signaling pathways (Pinter et al. 2012). Total AMPK activity increases after birth, contributing to the switch to predominant use of fatty acids (Makinde et al. 1997). AMPK levels may also be determined by ubiquitin-dependent mechanisms (Qi et al. 2008; Moreno et al. 2010), but its role in the heart is not known.

\subsubsection{Network Elements: Molecular Structure of AMPK}

Given the interest in AMPK as a putative drug target in metabolic diseases, recent years have seen intense efforts to elucidate the molecular structure of AMPK. 
By solving several X-ray structures for AMPK domains and truncated core complexes, the topology of the heterotrimer, the conserved global fold of large parts of the subunits, and the putative activation mechanisms could be deduced (Townley and Shapiro 2007; Amodeo et al. 2007; Xiao et al. 2007, 2011; Chen et al. 2009; Oakhill et al. 2011). However, a high-resolution structure of full-length heterotrimeric complex in both active and inactive states is still lacking. The so far most complete X-ray structure covers most of the $\alpha 1$-subunit except a C-terminal linker region (although not all of the sequence present is well resolved in the electron density map), the C-terminal domain of the $\beta 2$-subunit, and the entire $\gamma 1$-subunit (Xiao et al. 2007, 2011).

\subsubsection{1 $\alpha-$ Subunit}

The catalytic $\alpha$-subunit contains an $\mathrm{N}$-terminal serine-threonine kinase domain with an activation loop carrying the critical Thr172 residue. Phosphorylation of this residue by upstream kinases is essential for AMPK activation and often used as an indicator for AMPK activity (Hawley et al. 1996). The C-terminal $\alpha$-domain carries the motif interacting with the $\beta$-subunit and further structural determinants that are involved in AMPK activation. These include an autoinhibitory domain (AID) and loop(s) contacting the $\gamma$-subunit (called $\alpha$-hook or $\alpha$-RIM1 and $\alpha$-RIM2) (Xiao et al. 2007; Chen et al. 2009, 2013a; Pang et al. 2007). Their exact roles are, however, disputed and further structural studies will be necessary to delineate their function in autoinhibition and $\alpha-\gamma$ communication. Earlier in vitro studies suggested that the $\alpha 2$ subunit has a higher sensitivity to allosteric activation by AMP (Salt et al. 1998).

\subsubsection{2 $\beta$-Subunit}

The regulatory $\beta$-subunit is often described as a scaffold for $\alpha$ - and $\gamma$-subunits, a function that indeed is provided by the $\mathrm{C}$-terminal domain. The $\mathrm{N}$-terminal domain whose structure is not entirely resolved at molecular resolution carries additional regulatory elements. A glycogen-binding domain (GBD) seems to provide regulation of AMPK by glucose $\alpha 1-6$-branched glycogen that inhibits AMPK activation (Polekhina et al. 2003; McBride et al. 2009). The N-terminal $\beta$-domain may also be involved in protein interactions of AMPK (see above).

\subsubsection{3 $\gamma$-Subunit}

While $\alpha$ - and $\beta$-isoforms are very homologous, $\gamma$-subunits and their splice variants differ in length. They all share the C-terminal part that consists of four cystathionine $\beta$ synthetase (CBS) domains that are arranged in tandem in so-called Bateman domains (Bateman 1997). The symmetrical structure of this 
domain theoretically provides four binding sites for adenylates [referred to as sites 1-4 (Kemp et al. 2007; Hardie et al. 2011)], but only sites 1, 3, and 4 can be occupied in the mammalian enzyme, while site 2 is nonfunctional. The precise role of these sites is still unclear. Initial evidence suggested that site 4 binds AMP tightly in a non-exchangeable manner, while site 1 is a high-affinity site for AMP involved in allosteric activation (see below) and site 3 represents a lower affinity site (binding AMP, ADP, and ATP) more involved in regulating $\alpha$-Thr172 phosphorylation (Xiao et al. 2007). A more recent study suggests that also site 4 can bind ATP (and causes site 3 to be empty) and that both sites 3 and 4 may play a role in allosteric activation (Chen et al. 2012). The $\gamma 2$ - and $\gamma 3$-isoforms contain $\mathrm{N}$-terminal extensions that are subject to truncation by RNA splicing and whose molecular structure and function are currently unknown. Mutations in the CBS domains of the AMPK $\gamma 2$ subunit, expressed at particularly high levels in heart, cause the Wolff-Parkinson-White (WPW) syndrome, a hereditary cardiomyopathy of varying severity, involving cardiac hypertrophy, contractile dysfunction, and arrhythmias. Mutations impair adenylate binding and thus AMPK activation (Scott et al. 2004; Burwinkel et al. 2005), but the major cause for the cardiomyopathy is the increased AMP-independent basal AMPK activity. This leads to higher glucose uptake, accumulation of glycogen in cardiac myocytes, and finally impairment of normal heart muscle development (Burwinkel et al. 2005; Davies et al. 2006).

\subsubsection{Network Connectivity: AMPK Input Signals and Upstream Regulation}

AMPK integrates various intra- and extracellular signals and maintains cross talk with other signaling pathways, all related to the cellular energy and nutrient state. This makes the kinase a central signaling hub in sensing and regulating cellular energetics and ATP-dependent functions. Indeed, most recent research revealed that AMPK activation is much more complex than initially anticipated and depends on multiple covalent modifications and allosteric effectors (Fig. 11.13). AMPK regulation also evolved from a more simple state as, e.g., in the yeast AMPK homologues that lack allosteric activation by AMP (see below) to the more complex regulation present in mammals.

\subsubsection{Covalent Regulation by Phosphorylation}

The phosphorylation state at $\alpha$-Thr172 defines the primary activation of AMPK. This is determined by the balance of different upstream kinases and phosphatases. There are potentially three mammalian AMPK upstream kinases, with the major one in most cell types, including heart, being Liver Kinase B1 (LKB1, also called 


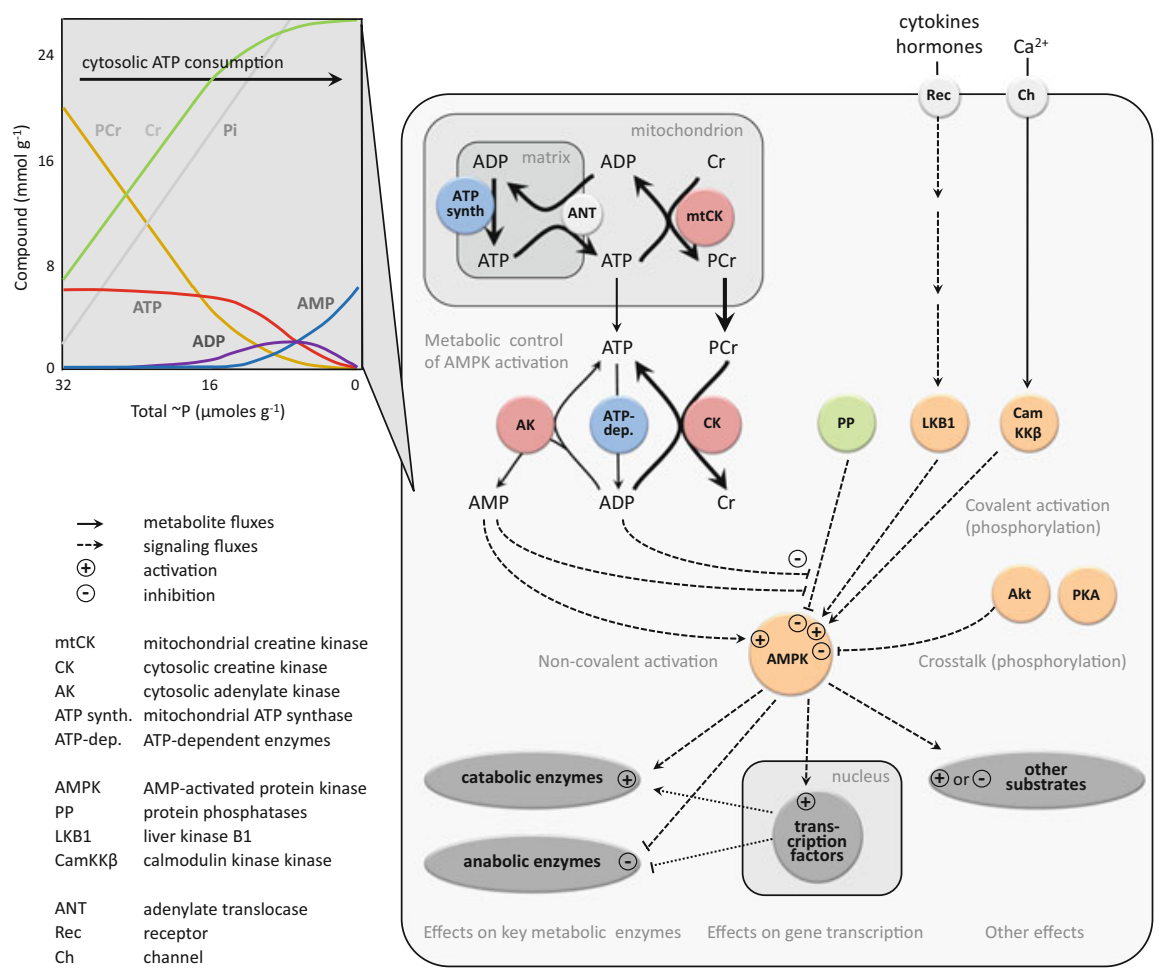

Fig. 11.13 AMPK signaling. Large scheme: Activation of AMPK by intra- and extracellular metabolic and endocrine signals and major fields of downstream signaling. Activation of AMPK is determined by upstream kinases (covalent activation by LKB1, CamKK $\beta$, inhibition by Akt and PKA) and phosphatases. They mediate mainly extracellular signals carrying, e.g., information on the energy and nutrient state of the cellular environment and the entire organism (endocrine signals). Covalent activation also depends on some intracellular parameters $\left(\mathrm{Ca}^{2+}\right.$, possibly also ROS/RNS). As a second layer of regulation, AMPK is activated by ADP and in particular AMP (allosteric regulation), both acting as second messengers of cellular energy stress. This signaling is linked to conversion of nucleotides via the adenylate kinase (AK) and creatine kinase (CK) reactions. Activated AMPK compensates for ATP loss by accelerating catabolism, inhibiting anabolism, and further effects on cell motility, growth, proliferation, and others, via regulation of key enzymes and transcription factors. For further details see text. Insert: Connection of AMPK signaling and phosphotransfer reactions (CK and $A K$ ) (Neumann et al. 2003). Global cellular concentration changes of phosphocreatine [PCr] and adenine nucleotides ([ATP], [ADP] and [AMP]), inorganic phosphate [Pi], and creatine [Cr], calculated from the reactions of $\mathrm{CK}, \mathrm{AK}$, and a generalized ATPase at decreasing "high-energy" phosphates (corresponding to a transition from rest to high work-load). Note that with "high-energy" phosphate consumption, [ATP] remains constant until more than $80 \%$ of the PCr pool is consumed. Only then, there is a transient increase in [ADP] and finally [AMP] starts to rise dramatically. The exponential rise in [AMP] makes this nucleotide an ideal second messenger for a lowered cellular energy state. This simplified model assumes that the $\mathrm{CK}$ and $\mathrm{AK}$ reactions work at equilibrium (which is unlikely to be true in vivo) and does not account for specific subcellular localizations of $\mathrm{CK}$ and $\mathrm{AK}$ 
STK11). LKB1 is upstream of an entire family of 12 other AMPK-related kinases in the human kinome, and like AMPK forms heterotrimers with two accessory subunits, STRAD $\alpha / \beta$ and MO25 $\alpha / \beta$ (Hawley et al. 2003; Woods et al. 2003). LKB1 has originally been identified as a tumor suppressor whose inactivating mutations lead to the Peutz-Jeghers syndrome, an inherited susceptibility to different human cancers (Alessi et al. 2006). However, LKB1 seems to mostly exhibit constitutive activity and may thus not be the limiting step in AMPK activation. An alternative upstream kinase much less expressed in heart is $\mathrm{Ca}^{2+} /$ calmodulindependent protein kinase kinase $\beta(\mathrm{CamKK} \beta)$ that mediates $\mathrm{Ca}^{2+}$-dependent AMPK activation (Hawley et al. 2005; Hurley et al. 2005; Woods et al. 2005). Although such CamKK $\beta$-mediated AMPK activation might anticipate an increasing energy turnover that accompanies a rise in cytosolic $\mathrm{Ca}^{2+}$ during muscle contraction, its role in the heart is not well understood. More recently, the transforming growth factor- $\beta$-activated kinase-1 (TAK1) that phosphorylates the yeast AMPK homologue Snf1 was proposed as an AMPK upstream kinase (Momcilovic et al. 2006; Xie et al. 2006a). Although TAK-1 is present in heart, it is not activated during ischemia and it is unclear whether it acts via direct AMPK phosphorylation (Xie et al. 2006a).

Protein phosphatases are possibly the more critical parameter governing the $\alpha$-Thr172 phosphorylation state, and this may also apply to the heart. However, their identity and regulatory role in vivo remain to be confirmed. Both seem to depend on cell type and/or stimulus. Different phosphatases can act on AMPK, including PP1, PP2A, and PP2C in vitro (Davies et al. 1995), as well as PP1-R6 in MIN6 beta cells (Garcia-Haro et al. 2010) and metal-dependent phosphatase PPM1E/F in HEK-293 cells in vivo (Voss et al. 2011). In heart and endothelial cells, expression levels PP2C and 2A, respectively, correlate with AMPK activation (Wang and Unger 2005; Wu et al. 2007).

The $\alpha$-Thr172 phosphorylation state is further negatively controlled by hierarchical phosphorylation at other sites in the AMPK heterotrimer. Phosphorylation at $\alpha 1-S e r 485(\alpha 2-S e r 491)$ by PKA or at $\alpha$-Ser173 by PKB/Akt reduces $\alpha$-Thr172 phosphorylation (Hurley et al. 2006; Horman et al. 2006; Djouder et al. 2010). Further phosphorylation sites were identified in both $\alpha$ - and $\beta$-subunits, many of them targeted by autophosphorylation, but their functional role remains uncertain.

\subsubsection{Non-Covalent Allosteric Regulation by AMP and ADP}

The activation of AMPK by low cellular energy state is triggered by increased concentrations of AMP and, as discovered more recently, also of ADP, since the kinase can sense AMP/ATP and ADP/ATP concentration ratios (Xiao et al. 2011; Oakhill et al. 2011). In many cell types and in particular in heart, breakdown of ATP to ADP at the onset of high workload or cellular stress has only minor immediate effects on ATP levels. Due to the energy buffer and transfer function of the $\mathrm{Cr} / \mathrm{CK}$ system (see above), global and local ATP is rapidly replenished (Wallimann et al. 2011; Neumann et al. 2003). Thus, ATP is not a very suitable signal for 
indicating developing energy deficits. However, minor decreases in ATP levels lead to more pronounced relative increases in free ADP and even more in AMP due to the adenylate kinase (AK) reaction (Fig. 11.13). Under these conditions, AK uses two ADP to regenerate ATP and AMP, thus increasing AMP concentrations from the sub-micromolar range under resting conditions to the lower micromolar range (Frederich and Balschi 2002). To lesser extent, AMP levels also depend on pyrophosphates (cleaving the $\beta$-phosphate bond of ATP) and the activity of AMP degradation pathways [AMP-deaminase and $5^{\prime}$-nucleotidase, whose inhibition may be useful to activate AMPK (Kulkarni et al. 2011)]. As a consequence, a decrease in ATP levels by only $10 \%$ translates into a 10- to 100-fold increase in AMP, making AMP an ideal second messenger of energy stress (Fig. 11.13, upper left). Regulation of AMPK activation by the balance between ATP, ADP, and AMP concentrations resembles to what was put forward by Atkinson 40 years ago as “energy charge" regulation (Xiao et al. 2011; Oakhill et al. 2011; Atkinson 1968; Hardie and Hawley 2001).

The molecular basis of allosteric AMPK activation is not yet fully understood, but certainly involves multiple interconnected mechanisms. The nucleotide ratios are sensed at the $\gamma$-subunit binding sites (sites 1, 3, and 4), which possess high affinity for AMP and ADP, but less for ATP in its major, $\mathrm{Mg}^{2+}$-complexed form. AMP or ADP binding to AMPK has several consequences: (1) it makes $\alpha$-Thr172 a better substrate for phosphorylation, (2) it protects P- $\alpha$-Thr172 from dephosphorylation, and (3), only in case of AMP, it exerts direct allosteric activation of AMPK (Xiao et al. 2011; Oakhill et al. 2011; Davies et al. 1995; Suter et al. 2006). All these effects require close communication between the AMP-binding $\gamma$ - and the catalytic $\alpha$-subunit. The three adenylate binding sites participate differentially in these mechanisms. Diverging models have been proposed that involve different structural elements of the $\alpha$-subunit (Xiao et al. 2011; Chen et al. 2013a). We and our collaborators have proposed that all these mechanisms involve an AMP(or ADP)- induced conformational switch within the full-length AMPK complex that is not seen in the X-ray structures of AMPK core complexes solved so far (Chen et al. 2009, 2012; Riek et al. 2008; Zhu et al. 2011).

\subsubsection{Other Covalent and Non-Covalent Regulations}

An increasing number of additional secondary protein modifications adds to the complex scheme of AMPK activation. Myristoylation at Gly 2 in the $\beta$-subunit increases the sensitivity of AMPK for allosteric activation and promotes Thr172 phosphorylation (Oakhill et al. 2010). Acetylation of $\alpha$-subunits is determined by the reciprocal actions of the acetylase p300 and the histone deacetylase 1. AMPK deacetylation promotes its activation via LKB1 interaction (Lin et al. 2012). LKB1 itself is also regulated by acetylation, since deacetylated LKB1 shifts from nucleus to the cytosol, where it forms active complexes with STRAD (Lan et al. 2008). Thus, acetylation is a potentially important factor for activating the LKB1-AMPK pathway (Ruderman et al. 2010), but its role in the heart has not been examined so 
far. Glutathionylation at Cys299 and Cys304 in the $\alpha$-subunit activates the kinase under oxidative conditions in cellular models and is favored by binding to certain GST isoforms (Klaus et al. 2013; Zmijewski et al. 2010). This latter mechanism may be part of a more general redox regulation of the kinase (Han et al. 2010; Jeon et al. 2012). ROS and RNS activate AMPK, but it is unclear whether this happens via increases in [ADP] and [AMP], or whether noncanonical mechanisms at the level of AMPK (like glutathionylation) or upstream kinases play a role. Vice versa, AMPK regulates NADPH homeostasis and an entire battery of ROS-detoxifying enzymes. Another non-covalent allosteric regulator is glycogen as well as other synthetic branched oligosaccharides that inhibit AMPK activity by binding to the $\beta$-GBD domain (McBride et al. 2009).

\subsubsection{Upstream Regulation in Cardiac (Patho) Physiology}

In the heart, AMPK activity is increased by a wide array of signals acting via upstream kinases and modulation of adenylate levels under both pathological and physiological stress and involving various hormones and cytokines (Zaha and Young 2012). Classical physiological stimuli of AMPK are exercise or hypoxia. Both also occur in the heart (Coven et al. 2003; Musi et al. 2005; Frederich et al. 2005) and promote the metabolism of glucose and fatty acids via different downstream targets (see below). However, it is unclear whether this activation is due to altered energy state as in skeletal muscle or rather relies on alternative upstream signaling. AMPK is also involved in the adaptive response of the heart to caloric restriction (Chen et al. 2013b), but nutrient effects in the heart may be more complex (Clark et al. 2004). Possibly, within the physiological range, the role of cardiomyocyte AMPK is different from other cell types, because of the remarkable metabolic stability of this organ maintained by multiple other mechanisms, including the metabolic cycles outlined before.

As pathological stimulus, ischemia is the best studied in form of both no-flow and partial ischemia in isolated perfused animal hearts, as well as regional ischemia due to coronary ligation in vivo (Russell et al. 2004; Kudo et al. 1996; Wang et al. 2009; Paiva et al. 2011; Kim et al. 2011a), for a review, see (Young 2008). They both lead to rapid and lasting AMPK activation. As already mentioned, besides energetic stress, oxidative stress may be a determinant of such activation, acting through different forms of ROS (Sartoretto et al. 2011; Zou et al. 2002). In endothelial cells, it is rather peroxynitrite formation that affects AMPK via the protein kinase $\mathrm{C} \zeta-\mathrm{LKB} 1$ axis (Zou et al. 2004; Xie et al. 2006b), while in other non-excitable cells it may be rather a ROS-induced $\mathrm{Ca}^{2+}$ release that triggers the CamKK $\beta$ axis (Mungai et al. 2011). ROS-facilitated glutathionylation of AMPK (see above) as observed in cellular systems represents yet another direct activation mechanism, but still has to be verified in cardiomyocytes (Klaus et al. 2013; Zmijewski et al. 2010). However, the signaling function of ROS may be lost at more intense oxidative stress that simply inactivates AMPK. In models of cardiotoxicity induced by the anticancer drug doxorubicine, AMPK has been 
found inactivated in most cases, despite pronounced oxidative, energetic, and genotoxic stress (Tokarska-Schlattner et al. 2005; Gratia et al. 2012). This is probably due to activation of PKB/Akt via DNA-damage signaling kinases that induce the inhibitory cross talk via AMPK $\alpha 1-S e r 485$ phosphorylation. In other situations, also LKB1 may become inactivated (Dolinsky et al. 2009). Stress resulting from many but not all forms of pressure overload also results in AMPK activation, mainly increasing glucose uptake and glycolysis (Tian et al. 2001; Li et al. 2007; Allard et al. 2007; Zhang et al. 2008), as well as changing the gene expression profile (Hu et al. 2011).

Information about the cellular environment and whole-body energy and nutrient state is connected to AMPK signaling via endocrine, paracrine, and autocrine mechanisms. These include a diverse array of hormones and cytokines identified in noncardiac cells that act via largely unknown cellular signaling cascades on AMPK upstream kinases, including adiponectin (Shibata et al. 2004), leptin (Minokoshi et al. 2004), resistin (Kang et al. 2011), ghrelin (Kola et al. 2005), IL6 (Kelly et al. 2004), and CNTF (Watt et al. 2006). Regulation of AMPK by these factors partially depends on the tissue. While in peripheral tissues leptin activates and ghrelin inhibits AMPK in the regulation of fatty acid oxidation and glucose uptake, their effects in hypothalamus are different, since they inhibit (leptin) or stimulate (ghrelin) AMPK-controlled food intake [for reviews see (Kahn et al. 2005; Steinberg and Kemp 2009)]. In the heart, AMPK seems to be involved in the positive effects of adiponectin for cardioprotection during ischemia and for reduced cardiac hypertrophy (Shibata et al. 2004, 2005). For example, AMPK limits accumulation and densification of microtubules that occur in response to hypertrophic stress (Fassett et al. 2013). Also leptin may modulate AMPK in the heart, since impaired leptin signaling correlates with reduced AMPK activation and metabolic defects or reduced postconditioning after ischemia (McGaffin et al. 2009; Bouhidel et al. 2008). Proinflammatory cytokines like IL-6 rather reduce AMPK protein and activation (Ko et al. 2009), although there may be opposite effects in specific tissues like skeletal muscle due to a specific autocrine-paracrine effect (Kelly et al. 2004). Other cytokines with functions in the heart include macrophage migration inhibitory factor (MIF), which is involved in AMPK activation during ischemia and hypoxia and its decrease with age in mice seems to reduce AMPK activation during ischemia (Miller et al. 2008; Ma et al. 2010).

\subsubsection{Evolution of Cellular Homeostasis Signaling Circuits}

From a phylogenetic perspective, it is interesting to note that AMPK homologues evolved early with eukaryotic life. However, yeast homologues of AMPK lack the direct allosteric AMP-activation, although they already possess the ADP-regulation of the $\alpha$-Thr172 phosphorylation state (Mayer et al. 2011). Since such lower eukaryotes neither express a $\mathrm{CK} / \mathrm{PCr}$ system, it can be concluded that they still tolerate larger fluctuations in energy state. It seems that those more sophisticated regulatory circuits evolved only with multicellular life. It will be interesting to 
examine when during metazoan evolution AMP has been established as a second messenger for energy stress and activation of AMPK. Creatine kinase and other closely homologous phosphagen kinases have emerged quite early at the dawn of the radiation of metazoans (Ellington 2001; Ellington and Suzuki 2007). Recently, besides identifying arginine kinase in unicellular organisms, a novel taurocyamine phosphagen kinase has been identified even in a unicellular protist (Uda et al. 2013).

In addition, at least in vertebrates a crosstalk has evolved between AMPK signaling and the Cr/CK system (Neumann et al. 2003; Ju et al. 2012). Although AMPK is not directly activated by $\mathrm{Cr}$ as postulated earlier (Ponticos et al. 1998; Ingwall 2002; Taylor et al. 2006), the $\mathrm{PCr} / \mathrm{Cr}$ ratio will also determine cellular ATP/ADP ratios via the CK reaction and thus indirectly AMPK activation, as well. Knockdown of cytosolic CK activates AMPK (Li et al. 2013), and similar control of AMPK signaling is observed when manipulating the cellular levels of adenylate kinase isoenzymes (Dzeja et al. 2011b). Such indirect mechanisms may also cause the additional AMPK activation observed after $\mathrm{Cr}$ supplementation in cellular models of skeletal muscle (Ceddia and Sweeney 2004), in the muscles of patients undergoing exercise programs in different pathological settings (Alves et al. 2012), and in Huntington disease models (Mochel et al. 2012), although these findings need further investigation.

Vice versa, AMPK complexes interact with cytosolic CKs and are able to phosphorylate them (Ponticos et al. 1998; Dieni and Storey 2009). Since this does not affect CK enzyme activity, at least in rodents (Ingwall 2002; Taylor et al. 2006) this phosphosphorylation remained enigmatic. Our most recent unpublished data indicate that BB-CK phosphorylation by AMPK may determine subcellular localization of this enzyme which is known to partially associate with ATP-requiring cellular structures and ATPases. In myocytes, active AMPK may also increase cellular Cr uptake by positively acting on Cr transporter (Alves et al. 2012; Darrabie et al. 2011), while an inverse effect was found in kidney epithelial cells (Li et al. 2010). If the latter cells are under energy stress, either physiological or pathological, this mechanism would prevent them to spend additional energy required for $\mathrm{Cr}$ uptake from the glomerular filtrate.

\subsubsection{Network Connectivity: AMPK Output Signals and Downstream Regulation}

AMPK integrates a large number of signals from inside and outside the cell that carry information on the nutrient and energy state from the cellular to organism level with the aim to mount a coordinated response (Fig. 11.13). This response includes compensation for ATP loss by stimulating catabolic and inhibiting several anabolic pathways, but also control of many other energy-related biological checkpoints in cell growth and proliferation, cell motility and polarity, apoptosis, 
autophagy, and central functions like appetite control. To date, about 50 AMPK substrates have been described in different tissues, including metabolic enzymes, transcription (co)factors, and other cellular signaling elements. They all are activated or inactivated by phosphorylation at Thr or Ser residues within a more or less conserved AMPK recognition motif. We will give here only some examples pertinent to heart; more complete descriptions can be found in recent reviews (Hardie et al. 2012a, b; Carling et al. 2012; Steinberg and Kemp 2009).

\subsubsection{Metabolic Pathways}

AMPK control of cellular substrate uptake, transport, and metabolism is the historically best described and possibly most important function of AMPK, also in the heart, since it is critical for ATP generation (Fig. 11.5). Activated AMPK stimulates cellular glucose and fatty acid uptake via translocation of GLUT4 (Kurth-Kraczek et al. 1999; Yamaguchi et al. 2005) and FAT/CD36 (van Oort et al. 2009), respectively, to the plasma membrane, involving among others phosphorylation of the Rab-GTPase activating protein TBC1D1 (Frosig et al. 2010). The subsequent substrate flux via glycolysis is increased by phosphorylation and activation of 6-phosphofructosekinase-2 (PFK2), whose product fructose-2,6-bisphosphate is an allosteric activator of the glycolytic enzyme 6-phosphofructokinase-1 (Marsin et al. 2000) and in long term by stimulation of hexokinase II (HKII) transcription (Stoppani et al. 2002). Substrate flux via fatty acid $\beta$-oxidation is increased by inhibition of mitochondria-associated acetyl-CoA carboxylase (ACC2), whose product malonyl-CoA is an allosteric inhibitor of carnitine palmitoyltransferase 1 (CPT1), the rate-limiting enzyme for of mitochondrial fatty acid import and oxidation (Merrill et al. 1997). At the same time, inhibition of cytosolic ACC1 will repress ATP-consuming fatty acid synthesis for which malonyl-CoA is the precursor (Davies et al. 1992). In other organs with multiple anabolic functions like liver, several other anabolic pathways like gluconeogenesis or triglyceride and cholesterol synthesis are inhibited (Bultot et al. 2012; Muoio et al. 1999; Clarke and Hardie 1990).

Active AMPK also affects gene expression of many of these metabolic enzymes by phosphorylation of transcription (co)factors and histone deacetylases (HDACs). Activation of peroxisome proliferator-activated receptor gamma co-activator-1 alpha (PGC-1 $\alpha$ ) increases the expression of nuclear-encoded mitochondrial genes that favor mitochondrial biogenesis (Irrcher et al. 2003; Jager et al. 2007), and further catabolic genes including substrate transporters (e.g., GLUT4). Mainly in the liver, expression of several genes in anabolic lipogenesis (e.g., ACC1) and gluconeogenesis is reduced via inhibition of ChREBP or SREBP (Kawaguchi et al. 2002; Li et al. 2011) and CRTC2 or class II HDACs (Koo et al. 2005; Mihaylova et al. 2011), respectively. Cellular redox regulation by AMPK also occurs mainly at the transcriptional level. AMPK directly phosphorylates transcription factor FOXO3, which increases transcription of many genes, mainly in oxidative stress defense (Greer et al. 2007) and activates, possibly more indirectly, class 
III deacetylase SIRT1, which deacetylates and thus activates FOXO1/3 and PGC-1 $\alpha$ (Canto et al. 2009).

\subsubsection{Protein Metabolism, Cell Growth, and Proliferation}

AMPK also acts via cross talk with other major cellular signaling hubs. The most important may be the mammalian target of rapamycin complex 1 (mTORC1) which is inhibited by activated AMPK via multiple mechanisms, including phosphorylation of tuberous sclerosis complex protein-2 (TSC2) (Inoki et al. 2003) upstream of mTORC1, or direct phosphorylating the mTORC1 subunit Raptor (Gwinn et al. 2008). This reduces the multiple TORC1 functions in stimulation of protein biosynthesis and cell cycle (Kwiatkowski and Manning 2005) and inhibition of autophagy (Meijer and Codogno 2007). Autophagy is also directly stimulated by AMPK-induced phosphorylation of the protein kinase ULK1 (Kim et al. 2011b; Egan et al. 2011). AMPK further reduces protein synthesis more indirectly by inhibiting eukaryotic elongation factor 2 kinase (eEF2K) (Browne et al. 2004) and downregulating ribosomal RNA (Hoppe et al. 2009) and several cyclins (Wang et al. 2002). Phosphorylation of the tumor suppressor p53 and the cyclindependent kinase inhibitor p27 $7^{\mathrm{KIP} 1}$ will both contribute to cell cycle arrest and eventual autophagy (Imamura et al. 2001; Jones et al. 2005; Liang et al. 2007). AMPK also stimulates protein-ubiquitination and proteasome-dependent degradation (Viana et al. 2008; Solaz-Fuster et al. 2008).

\subsubsection{Cell Contractility, Dynamics, and Shape}

AMPK phosphorylates cardiac troponin I (cTnI) during ischemia and thus increases its calcium sensitivity, suggesting that AMPK activation improves myocyte contraction (Oliveira et al. 2012a). Cellular models also suggest that AMPK controls microtubule dynamics through phosphorylation of the microtubule plus end protein CLIP-170 (Nakano et al. 2010) and dynamics of cells and in particular of the mitotic spindle via different indirect mechanisms that increase phosphorylation of the non-muscle myosin regulatory light chain (MRLC) (Lee et al. 2007; Banko et al. 2011).

\subsubsection{Cellular Ion Homeostasis}

The maintenance of ion gradients across cell membranes and intracellular ion homeostasis are further highly energy-demanding processes. Thus it is little surprising that AMPK, like $\mathrm{CK}$, might also regulate these processes. Indeed, different ion transporters are inhibited by AMPK, directly or indirectly, including cystic fibrosis transmembrane conductance regulator Cl-channel (CFTR) (Hallows et al. 2003) and ATP-sensitive potassium (KATP) channel (Kir6.2) (Chang 
et al. 2009), and several more cell-type specific ion transporters, like epithelial $\mathrm{Na}^{+}$ channel (eNaC) (Carattino et al. 2005), renal $\mathrm{Na}^{+}-\mathrm{K}^{+}-2 \mathrm{Cl}^{-}$cotransporter $(\mathrm{NKCC} 2)$ (Fraser et al. 2007), and neuronal voltage-gated, delayed rectifier $\mathrm{K}^{+}$channel (Kv2.1), whose phosphorylation reduces the frequency of highly energy-consuming action potentials (Ikematsu et al. 2011).

\subsubsection{Modeling Signaling Networks in Heart and Beyond}

Given the complexity and interconnectivity of cell signaling networks, only recently emerging systems biology approaches hold promises for understanding and predicting the higher order properties and behavior of such networks (Arkin and Schaffer (2011) and following papers of this Cell Leading Edge Review series). However, the mathematical modeling necessary for such systems approaches is still in its infancy. Modeling needs a solid base of both quantitative and qualitative data, including the spatiotemporal component as outlined above. So far, both bottom-up and top-down systems approaches have been applied to obtain comprehensive databases of protein kinase signaling. Typically, bottom-up, hypothesis-, or model-driven approaches were used to study the role of individual components, also facilitating first studies of dynamic systems properties. More recently, with the broad availability of "omics" approaches, more top-down so-called hypothesis-free studies have mapped interactomes and phosphoproteomes of protein kinases, mainly in yeast (Breitkreutz et al. 2010; Bensimon et al. 2012; Oliveira et al. 2012b). Such large-scale data are necessary to construct first network models needed to advance mathematical modeling in this field. Indeed, progress is also made in the computational methodology and the mathematical description of signaling pathways (Frey et al. 2008; Ideker et al. 2011; Telesco and Radhakrishnan 2012). However, similar modeling approaches with mammalian cells, in particular under physiological and pathological conditions relevant to humans, are still scarce (Benedict et al. 2011; Basak et al. 2012; Rogne and Tasken 2013), except a strong history of modeling in cardiac electrophysiology (Amanfu and Saucerman 2011). Such models would be highly valuable for in silico drug target identification, drug screening, and development (Benedict et al. 2011). Important steps in such approaches are (1) to establish a network structure, (2) to obtain quantitative dynamic datasets for basic systems properties, (3) to generate dynamic mathematical models, and (4) to test and iteratively improve the models by prediction and experimental verification of systems perturbations (Frey et al. 2008). First models also including AMPK signaling are currently emerging (Marcus 2008; Sonntag et al. 2012), but sustained interdisciplinary efforts in the field will be necessary to obtain models that allow meaningful predictions of AMPK systems behavior.

Acknowledgments The authors would like to thank all group members involved in work cited in this review. Work of the contributing groups was funded among others by EU FP6 and FP7 programs (contract LSHM-CT-2004-005272 EXGENESIS to U.S.; by reintegration grants 
ANTHRAWES, 041870; ANTHRAPLUS, 249202 to M.T.S.), the French Agence Nationale de Recherche ("chaire d'excellence" to U.S., project ANR N RA0000C407 to V.S. and R.G.), and by the National Council of Science and Technology of Mexico (CONACYT).

\section{References}

Abraham MR, Selivanov VA, Hodgson DM, Pucar D, Zingman LV, Wieringa B et al. (2002) Coupling of cell energetics with membrane metabolic sensing. Integrative signaling through creatine kinase phosphotransfer disrupted by M-CK gene knock-out. J Biol Chem 277 (27):24427-34. doi:10.1074/jbc.M201777200

Ahn YJ, Kim H, Lim H, Lee M, Kang Y, Moon S et al. (2012) AMP-activated protein kinase: implications on ischemic diseases. BMB Rep 45(9):489-95

Alekseev AE, Reyes S, Selivanov VA, Dzeja PP, Terzic A (2012) Compartmentation of membrane processes and nucleotide dynamics in diffusion-restricted cardiac cell microenvironment. $\mathrm{J}$ Mol Cell Cardiol 52(2):401-9. doi:10.1016/j.yjmcc.2011.06.007

Alessi DR, Sakamoto K, Bayascas JR (2006) LKB1-dependent signaling pathways. Annu Rev Biochem 75:137-63. doi:10.1146/annurev.biochem.75.103004.142702

Aliev MK, Saks VA (1997) Compartmentalized energy transfer in cardiomyocytes: use of mathematical modeling for analysis of in vivo regulation of respiration. Biophys $\mathrm{J} 73$ (1):428-45

Aliev M, Guzun R, Karu-Varikmaa M, Kaambre T, Wallimann T, Saks V (2012) Molecular system bioenergics of the heart: experimental studies of metabolic compartmentation and energy fluxes versus computer modeling. Int J Mol Sci 12(12):9296-331. doi:10.3390/ ijms12129296

Allard MF, Parsons HL, Saeedi R, Wambolt RB, Brownsey R (2007) AMPK and metabolic adaptation by the heart to pressure overload. Am J Physiol Heart Circ Physiol 292(1): H140-8. doi:10.1152/ajpheart.00424.2006

Alves CR, Ferreira JC, de Siqueira-Filho MA, Carvalho CR, Lancha AH Jr, Gualano B (2012) Creatine-induced glucose uptake in type 2 diabetes: a role for AMPK-alpha? Amino Acids 43 (4):1803-7. doi:10.1007/s00726-012-1246-6

Amanfu RK, Saucerman JJ (2011) Cardiac models in drug discovery and development: a review. Crit Rev Biomed Eng 39(5):379-95

Amodeo GA, Rudolph MJ, Tong L (2007) Crystal structure of the heterotrimer core of Saccharomyces cerevisiae AMPK homologue SNF1. Nature 449(7161):492-5. doi:10.1038/ nature 06127

Andersen MN, Rasmussen HB (2012) AMPK: A regulator of ion channels. Commun Integr Biol 5 (5):480-4. doi:10.4161/cib.21200

Aon MA, Cortassa S (2012) Mitochondrial network energetics in the heart. Wiley Interdiscip Rev Syst Biol Med 4(6):599-613. doi:10.1002/wsbm.1188

Arkin AP, Schaffer DV (2011) Network news: innovations in 21st century systems biology. Cell 144(6):844-9. doi:10.1016/j.cell.2011.03.008

Atkinson DE (1968) The energy charge of the adenylate pool as a regulatory parameter. Interaction with feedback modifiers. Biochemistry 7(11):4030-4

Avkiran M, Rowland AJ, Cuello F, Haworth RS (2008) Protein kinase d in the cardiovascular system: emerging roles in health and disease. Circ Res 102(2):157-63. doi:10.1161/ CIRCRESAHA.107.168211

Balaban RS (2002) Cardiac energy metabolism homeostasis: role of cytosolic calcium. J Mol Cell Cardiol 34(10):1259-71

Balaban RS (2009a) Domestication of the cardiac mitochondrion for energy conversion. J Mol Cell Cardiol 46:832-41. doi:10.1016/yjmcc.2009.02.018 
Balaban RS (2009b) The role of $\mathrm{Ca}^{2+}$ signaling in the coordination of mitochondrial ATP production with cardiac work. Biochim Biophys Acta 1787(11):1334-41. doi:10.1016/j. bbabio.2009.05.011

Balaban RS (2012) Perspectives on: SGP symposium on mitochondrial physiology and medicine: metabolic homeostasis of the heart. J Gen Physiol 139(6):407-14. doi:10.1085/jgp.201210783

Balaban RS, Kantor HL, Katz LA, Briggs RW (1986) Relation between work and phosphate metabolite in the in vivo paced mammalian heart. Science (New York) 232(4754):1121-3

Banko MR, Allen JJ, Schaffer BE, Wilker EW, Tsou P, White JL et al. (2011) Chemical genetic screen for AMPKalpha2 substrates uncovers a network of proteins involved in mitosis. Mol Cell 44(6):878-92. doi:10.1016/j.molcel.2011.11.005

Basak S, Behar M, Hoffmann A (2012) Lessons from mathematically modeling the NF-kappaB pathway. Immunol Rev 246(1):221-38. doi:10.1111/j.1600-065X.2011.01092.x

Bateman A (1997) The structure of a domain common to archaebacteria and the homocystinuria disease protein. Trends Biochem Sci 22(1):12-3

Beard E, Braissant O (2010) Synthesis and transport of creatine in the CNS: importance for cerebral functions. J Neurochem 115(2):297-313. doi:10.1111/j.1471-4159.2010.06935.x

Behrends C, Sowa ME, Gygi SP, Harper JW (2010) Network organization of the human autophagy system. Nature 466(7302):68-76. doi:10.1038/nature09204

Belitzer VA, Tsybakova ET (1939) About mechanism of phosphorylation, respiratory coupling. Biokhimiya 4:516-34

Benedict KF, Mac Gabhann F, Amanfu RK, Chavali AK, Gianchandani EP, Glaw LS et al. (2011) Systems analysis of small signaling modules relevant to eight human diseases. Ann Biomed Eng 39(2):621-35. doi:10.1007/s10439-010-0208-y

Bensimon A, Heck AJ, Aebersold R (2012) Mass spectrometry-based proteomics and network biology. Annu Rev Biochem 81:379-405. doi:10.1146/annurev-biochem-072909-100424

Beraud N, Pelloux S, Usson Y, Kuznetsov AV, Ronot X, Tourneur Y et al. (2009) Mitochondrial dynamics in heart cells: very low amplitude high frequency fluctuations in adult cardiomyocytes and flow motion in non beating Hl-1 cells. J Bioenerg Biomembr 41 (2):195-214

Bers DM (2002) Cardiac excitation-contraction coupling. Nature 415(6868):198-205

Bers DM, Despa S (2006) Cardiac myocytes $\mathrm{Ca}^{2+}$ and $\mathrm{Na}^{+}$regulation in normal and failing hearts. J Pharmacol Sci 100(5):315-22

Bessman SP, Carpenter CL (1985) The creatine-creatine phosphate energy shuttle. Annu Rev Biochem 54:831-62

Bessman SP, Fonyo A (1966) The possible role of the mitochondrial bound creatine kinase in regulation of mitochondrial respiration. Biochem Biophys Res Commun 22(5):597-602

Bessman SP, Geiger PJ (1981) Transport of energy in muscle: the phosphorylcreatine shuttle. Science 211(4481):448-52

Bing RJ, Siegel A, Ungar I, Gilbert M (1954) Metabolism of the human heart. II. Studies on fat, ketone and amino acid metabolism. Am J Med 16(4):504-15

Bose S, French S, Evans FJ, Joubert F, Balaban RS (2003) Metabolic network control of oxidative phosphorylation: multiple roles of inorganic phosphate. J Biol Chem 278(40):39155-65

Bouhidel O, Pons S, Souktani R, Zini R, Berdeaux A, Ghaleh B (2008) Myocardial ischemic postconditioning against ischemia-reperfusion is impaired in ob/ob mice. Am J Physiol Heart Circ Physiol 295(4):H1580-6. doi:10.1152/ajpheart.00379.2008

Boyer PD (1997) The ATP, synthase - a splendid molecular machine. Annu Rev Biochem 66:717-49

Breitkreutz A, Choi H, Sharom JR, Boucher L, Neduva V, Larsen B et al. (2010) A global protein kinase and phosphatase interaction network in yeast. Science 328(5981):1043-6. doi:10.1126/ science. 1176495

Browne GJ, Finn SG, Proud CG (2004) Stimulation of the AMP-activated protein kinase leads to activation of eukaryotic elongation factor 2 kinase and to its phosphorylation at a novel site, serine 398. J Biol Chem 279(13):12220-31. doi:10.1074/jbc.M309773200 
Bultot L, Guigas B, Von Wilamowitz-Moellendorff A, Maisin L, Vertommen D, Hussain N et al. (2012) AMP-activated protein kinase phosphorylates and inactivates liver glycogen synthase. Biochem J 443(1):193-203. doi:10.1042/BJ20112026

Burwinkel B, Scott JW, Buhrer C, van Landeghem FK, Cox GF, Wilson CJ et al. (2005) Fatal congenital heart glycogenosis caused by a recurrent activating R531Q mutation in the gamma 2-subunit of AMP-activated protein kinase (PRKAG2), not by phosphorylase kinase deficiency. Am J Hum Genet 76(6):1034-49. doi:10.1086/430840

Calvert JW, Gundewar S, Jha S, Greer JJ, Bestermann WH, Tian R et al. (2008) Acute metformin therapy confers cardioprotection against myocardial infarction via AMPK-eNOS-mediated signaling. Diabetes 57(3):696-705. doi:10.2337/db07-1098

Canto C, Gerhart-Hines Z, Feige JN, Lagouge M, Noriega L, Milne JC et al. (2009) AMPK regulates energy expenditure by modulating NAD+ metabolism and SIRT1 activity. Nature 458(7241):1056-60. doi:10.1038/nature07813

Capetanaki Y, Bloch RJ, Kouloumenta A, Mavroidis M, Psarras S (2007) Muscle intermediate filaments and their links to membranes and membranous organelles. Exp Cell Res 313 (10):2063-76

Capetenaki Y (2002) Desmin cytoskeleton: a potential regulator of muscle mitochondrial behaviour and function. Trends Cardiovasc Med 12(8):339-48

Carattino MD, Edinger RS, Grieser HJ, Wise R, Neumann D, Schlattner U et al. (2005) Epithelial sodium channel inhibition by AMP-activated protein kinase in oocytes and polarized renal epithelial cells. J Biol Chem 280(18):17608-16. doi:10.1074/jbc.M501770200

Carling D, Thornton C, Woods A, Sanders MJ (2012) AMP-activated protein kinase: new regulation, new roles? Biochem J 445(1):11-27. doi:10.1042/BJ20120546

Ceddia RB, Sweeney G (2004) Creatine supplementation increases glucose oxidation and AMPK phosphorylation and reduces lactate production in L6 rat skeletal muscle cells. J Physiol 555 (Pt 2):409-21. doi:10.1113/jphysiol.2003.056291

Chang TJ, Chen WP, Yang C, Lu PH, Liang YC, Su MJ et al. (2009) Serine-385 phosphorylation of inwardly rectifying $\mathrm{K}^{+}$channel subunit (Kir6.2) by AMP-dependent protein kinase plays a key role in rosiglitazone-induced closure of the K(ATP) channel and insulin secretion in rats. Diabetologia 52(6):1112-21

Chen L, Jiao ZH, Zheng LS, Zhang YY, Xie ST, Wang ZX et al. (2009) Structural insight into the autoinhibition mechanism of AMP-activated protein kinase. Nature 459(7250):1146-9. doi:10.1038/nature 08075

Chen L, Wang J, Zhang YY, Yan SF, Neumann D, Schlattner U et al. (2012) AMP-activated protein kinase undergoes nucleotide-dependent conformational changes. Nat Struct Mol Biol 19(7):716-8. doi:10.1038/nsmb.2319

Chen L, Xin FJ, Wang J, Hu J, Zhang YY, Wan S, Cao LS, Lu C, Li P, Yan SF, Neumann D, Schlattner U, Xia B, Wang ZX, Wu JW (2013a) Conserved regulatory elements in AMPK. Nature 498:E8-E10

Chen K, Kobayashi S, Xu X, Viollet B, Liang Q (2013b) AMP activated protein kinase is indispensable for myocardial adaptation to caloric restriction in mice. PLoS One 8(3): e59682. doi:10.1371/journal.pone.0059682

Clark AJ, Gaddie R, Stewart CP (1937) The aerobic metabolism of the isolated frog's heart poisoned by iodoacetic acid. J Physiol 90(3):335-46

Clark H, Carling D, Saggerson D (2004) Covalent activation of heart AMP-activated protein kinase in response to physiological concentrations of long-chain fatty acids. Eur J Biochem 271 (11):2215-24. doi:10.1111/j.1432-1033

Clarke PR, Hardie DG (1990) Regulation of HMG-CoA reductase: identification of the site phosphorylated by the AMP-activated protein kinase in vitro and in intact rat liver. EMBO J 9(8):2439-46

Collins TJ, Bootman MD (2003) Mitochondria are morphologically heterogeneous within cells. J Exp Biol 206(Pt 12):1993-2000 
Cortassa S, O'Rourke B, Winslow RL, Aon MA (2009) Control and regulation of mitochondrial energetics in an integrated model of cardiomyocyte function. Biophys J 96(6):2466-78

Coven DL, Hu X, Cong L, Bergeron R, Shulman GI, Hardie DG et al. (2003) Physiological role of AMP-activated protein kinase in the heart: graded activation during exercise. Am J Physiol Endocrinol Metab 285(3):E629-36. doi:10.1152/ajpendo.00171.2003

Darrabie MD, Arciniegas AJ, Mishra R, Bowles DE, Jacobs DO, Santacruz L (2011) AMPK and substrate availability regulate creatine transport in cultured cardiomyocytes. Am J Physiol Endocrinol Metab 300(5):E870-6. doi:10.1152/ajpendo.00554.2010

Davies SP, Carling D, Munday MR, Hardie DG (1992) Diurnal rhythm of phosphorylation of rat liver acetyl-CoA carboxylase by the AMP-activated protein kinase, demonstrated using freezeclamping. Effects of high fat diets. Eur J Biochem 203(3):615-23

Davies SP, Helps NR, Cohen PT, Hardie DG (1995) 5'-AMP inhibits dephosphorylation, as well as promoting phosphorylation, of the AMP-activated protein kinase. Studies using bacterially expressed human protein phosphatase-2C alpha and native bovine protein phosphatase-2AC. FEBS Lett 377(3):421-5

Davies JK, Wells DJ, Liu K, Whitrow HR, Daniel TD, Grignani R et al. (2006) Characterization of the role of gamma2 R531G mutation in AMP-activated protein kinase in cardiac hypertrophy and Wolff-Parkinson-White syndrome. Am J Physiol Heart Circ Physiol 290(5):H1942-51. doi:10.1152/ajpheart.01020.2005

Dieni CA, Storey KB (2009) Creatine kinase regulation by reversible phosphorylation in frog muscle. Comp Biochem Physiol B Biochem Mol Biol 152(4):405-12. doi:10.1016/j. cbpb.2009.01.012

Diviani D, Maric D, Perez Lopez I, Cavin S, Del Vescovo CD (2013) A-kinase anchoring proteins: Molecular regulators of the cardiac stress response. Biochim Biophys Acta 1833(4):901-8. doi:10.1016/j.bbamcr.2012.07.014

Djouder N, Tuerk RD, Suter M, Salvioni P, Thali RF, Scholz R et al. (2010) PKA phosphorylates and inactivates AMPKalpha to promote efficient lipolysis. EMBO J 29(2):469-81. doi:10.1038/emboj.2009.339

Dolinsky VW, Chan AY, Robillard Frayne I, Light PE, Des Rosiers C, Dyck JR (2009) Resveratrol prevents the prohypertrophic effects of oxidative stress on LKB1. Circulation 119 (12):1643-52. doi:10.1161/CIRCULATIONAHA.108.787440

Dos Santos P, Aliev MK, Diolez P, Duclos F, Besse P, Bonoron-Adele S et al. (2000) Metabolic control of contractile performance in isolated perfused rat heart. Analysis of experimental data by reaction:diffusion mathematical model. J Mol Cell Cardiol 32(9):1703-34

Doussiere J, Ligeti E, Brandolin G, Vignais PV (1984) Control of oxidative phosphorylation in rat heart mitochondria. The role of the adenine nucleotide carrier. Biochim Biophys Acta 766 (2):492-500

Dzeja PP, Terzic A (2003) Phosphotransfer networks and cellular energetics. J Exp Biol 206 (Pt 12):2039-47

Dzeja P, Terzic A (2009) Adenylate kinase and AMP signaling networks: metabolic monitoring, signal communication and body energy sensing. Int J Mol Sci 10(4):1729-72

Dzeja PP, Zeleznikar RJ, Goldberg ND (1996) Suppression of creatine kinase-catalyzed phosphotransfer results in increased phosphoryl transfer by adenylate kinase in intact skeletal muscle. J Biol Chem 271(22):12847-51

Dzeja PP, Vitkevicius KT, Redfield MM, Burnett JC, Terzic A (1999) Adenylate kinase-catalyzed phosphotransfer in the myocardium: increased contribution in heart failure. Circ Res 84 (10):1137-43

Dzeja PP, Holmuhamedov EL, Ozcan C, Pucar D, Jahangir A, Terzic A (2001) Mitochondria: gateway for cytoprotection. Circ Res 89(9):744-6

Dzeja PP, Bast P, Pucar D, Wieringa B, Terzic A (2007) Defective metabolic signaling in adenylate kinase AK1 gene knock-out hearts compromises post-ischemic coronary reflow. J Biol Chem 282(43):31366-72. doi:10.1074/jbc.M705268200 
Dzeja PP, Hoyer K, Tian R, Zhang S, Nemutlu E, Spindler M et al. (2011a) Rearrangement of energetic and substrate utilization networks compensate for chronic myocardial creatine kinase deficiency. J Physiol 589(Pt 21):5193-211. doi:10.1113/jphysiol.2011.212829

Dzeja PP, Chung S, Faustino RS, Behfar A, Terzic A (2011b) Developmental enhancement of adenylate kinase-AMPK metabolic signaling axis supports stem cell cardiac differentiation. PLoS One 6(4):e19300. doi:10.1371/journal.pone.0019300

Eder M, Schlattner U, Becker A, Wallimann T, Kabsch W, Fritz-Wolf K (1999) Crystal structure of brain-type creatine kinase at 1.41 A resolution. Protein Sci 8(11):2258-69

Eder M, Fritz-Wolf K, Kabsch W, Wallimann T, Schlattner U (2000) Crystal structure of human ubiquitous mitochondrial creatine kinase. Proteins 39(3):216-25. doi:10.1002/(SICI)10970134(20000515)39

Edwards HV, Christian F, Baillie GS (2012) cAMP: novel concepts in compartmentalised signalling. Semin Cell Dev Biol 23(2):181-90. doi:10.1016/j.semcdb.2011.09.005

Egan DF, Shackelford DB, Mihaylova MM, Gelino S, Kohnz RA, Mair W et al. (2011) Phosphorylation of ULK1 (hATG1) by AMP-activated protein kinase connects energy sensing to mitophagy. Science 331(6016):456-61. doi:10.1126/science.1196371

Ellington WR (2001) Evolution and physiological roles of phosphagen systems. Annu Rev Physiol 63:289-325. doi:10.1146/annurev.physiol.63.1.289

Ellington WR, Suzuki T (2007) Early evolution of the creatine kinase gene family and the capacity for creatine biosynthesis and membrane transport. Subcell Biochem 46:17-26

Ewing RM, Chu P, Elisma F, Li H, Taylor P, Climie S et al. (2007) Large-scale mapping of human protein-protein interactions by mass spectrometry. Mol Syst Biol 3:89. doi:10.1038/ msb4100134

Fassett JT, Hu X, Xu X, Lu Z, Zhang P, Chen Y et al. (2013) AMPK attenuates microtubule proliferation in cardiac hypertrophy. Am J Physiol Heart Circ Physiol 304(5):H749-58. doi:10.1152/ajpheart.00935.2011

Fell DA, Thomas S (1995) Physiological control of metabolic flux: the requirement for multisite modulation. Biochem J 311(Pt 1):35-9

Finckenberg P, Mervaala E (2010) Novel regulators and drug targets of cardiac hypertrophy. J Hypertens 28(Suppl 1):S33-8. doi:10.1097/01.hjh.0000388492.73954.0b

Forcet C, Billaud M (2007) Dialogue between LKB1 and AMPK: a hot topic at the cellular pole. Sci STKE 2007(404):pe51. doi:10.1126/stke.4042007pe51

Fraser SA, Gimenez I, Cook N, Jennings I, Katerelos M, Katsis F et al. (2007) Regulation of the renal-specific $\mathrm{Na}^{+}-\mathrm{K}^{+}-2 \mathrm{Cl}^{-}$co-transporter $\mathrm{NKCC} 2$ by AMP-activated protein kinase (AMPK). Biochem J 405(1):85-93. doi:10.1042/BJ20061850

Frederich M, Balschi JA (2002) The relationship between AMP-activated protein kinase activity and AMP concentration in the isolated perfused rat heart. J Biol Chem 277(3):1928-32. doi:10.1074/jbc.M107128200

Frederich M, Zhang L, Balschi JA (2005) Hypoxia and AMP independently regulate AMP-activated protein kinase activity in heart. Am J Physiol Heart Circ Physiol 288(5): H2412-21. doi:10.1152/ajpheart.00558.2004

Frey S, Millat T, Hohmann S, Wolkenhauer O (2008) How quantitative measures unravel design principles in multi-stage phosphorylation cascades. J Theor Biol 254(1):27-36. doi:10.1016/j. jtbi.2008.04.037

Fritz-Wolf K, Schnyder T, Wallimann T, Kabsch W (1996) Structure of mitochondrial creatine kinase. Nature 381(6580):341-5. doi:10.1038/381341a0

Frosig C, Pehmoller C, Birk JB, Richter EA, Wojtaszewski JF (2010) Exercise-induced TBC1D1 Ser237 phosphorylation and 14-3-3 protein binding capacity in human skeletal muscle. J Physiol 588(Pt 22):4539-48. doi:10.1113/jphysiol.2010.194811

Garcia-Haro L, Garcia-Gimeno MA, Neumann D, Beullens M, Bollen M, Sanz P (2010) The PP1-R6 protein phosphatase holoenzyme is involved in the glucose-induced dephosphorylation and inactivation of AMP-activated protein kinase, a key regulator of insulin secretion, in MIN6 beta cells. FASEB J 24(12):5080-91. doi:10.1096/fj.10-166306 
Glancy B, Balaban RS (2012) Role of mitochondrial $\mathrm{Ca}^{2+}$ in the regulation of cellular energetics. Biochemistry 51(14):2959-73. doi:10.1021/bi2018909

Gonzalez-Granillo M, Grichine A, Guzun R, Usson Y, Tepp K, Chekulayev V, Shevchuk I, KaruVarikmaa M, Kuznetsov AV, Grimm M, Saks V, Kaambre T (2012) Studies of the role of tubulin beta II isotype in regulation of mitochondrial respiration in intracellular energetic units in cardiac cells. J Mol Cell Cardiol 52:437-47

Gratia S, Kay L, Potenza L, Seffouh A, Novel-Chate V, Schnebelen C et al. (2012) Inhibition of AMPK signalling by doxorubicin: at the crossroads of the cardiac responses to energetic, oxidative, and genotoxic stress. Cardiovasc Res 95(3):290-9. doi:10.1093/cvr/cvs134

Greer EL, Oskoui PR, Banko MR, Maniar JM, Gygi MP, Gygi SP et al. (2007) The energy sensor AMP-activated protein kinase directly regulates the mammalian FOXO3 transcription factor. J Biol Chem 282(41):30107-19. doi:10.1074/jbc.M705325200

Griffiths EJ, Rutter GA (2009) Mitochondrial calcium as a key regulator of mitochondrial ATP production in mammalian cells. Biochim Biophys Acta 1787:1324-33

Groen AK, Wanders RJ, Westerhoff HV, van der Meer R, Tager JM (1982) Quantification of the contribution of various steps to the control of mitochondrial respiration. J Biol Chem 257 (6):2754-7

Guzun R, Saks V (2010) Application of the principles of systems biology and Wiener's cybernetics for analysis of regulation of energy fluxes in muscle cells in vivo. Int J Mol Sci 11 (3):982-1019

Guzun R, Timohhina N, Tepp K, Monge C, Kaambre T, Sikk P et al. (2009) Regulation of respiration controlled by mitochondrial creatine kinase in permeabilized cardiac cells in situ. Importance of system level properties. Biochim Biophys Acta 1787(9):1089-105. doi:10.1016/ j.bbabio.2009.03.024

Guzun R, Karu-Varikmaa M, Gonzalez-Granillo M, Kuznetsov AV, Michel L, Cottet-Rousselle C et al. (2011a) Mitochondria-cytoskeleton interaction: distribution of beta-tubulins in cardiomyocytes and HL-1 cells. Biochim Biophys Acta 1807(4):458-69

Guzun R, Timohhina N, Tepp K, Gonzalez-Granillo M, Shevchuk I, Chekulayev V, Kuznetsov AV, Kaambre T, Saks VA (2011b) Systems bioenergetics of creatine kinase networks: physiological roles of creatine and phosphocreatine in regulation of cardiac cell function. Amino Acids 40:1333-48

Guzun R, Gonzalez-Granillo M, Karu-Varikmaa M, Grichine A, Usson Y, Kaambre T et al. (2012) Regulation of respiration in muscle cells in vivo by VDAC through interaction with the cytoskeleton and MtCK within mitochondrial interactosome. Biochim Biophys Acta 1818 (6):1545-54. doi:10.1016/j.bbamem.2011.12.034

Gwinn DM, Shackelford DB, Egan DF, Mihaylova MM, Mery A, Vasquez DS et al. (2008) AMPK phosphorylation of raptor mediates a metabolic checkpoint. Mol Cell 30(2):214-26. doi:10.1016/j.molcel.2008.03.003

Hackenbrock CR (1968) Chemical and physical fixation of isolated mitochondria in low-energy and high-energy states. Proc Natl Acad Sci USA 61(2):598-605

Hallows KR, McCane JE, Kemp BE, Witters LA, Foskett JK (2003) Regulation of channel gating by AMP-activated protein kinase modulates cystic fibrosis transmembrane conductance regulator activity in lung submucosal cells. J Biol Chem 278(2):998-1004. doi:10.1074/jbc. M210621200

Han Y, Wang Q, Song P, Zhu Y, Zou MH (2010) Redox regulation of the AMP-activated protein kinase. PLoS One 5(11):e15420. doi:10.1371/journal.pone.0015420

Harada M, Nattel SN, Nattel S (2012) AMP-activated protein kinase: potential role in cardiac electrophysiology and arrhythmias. Circ Arrhythm Electrophysiol 5(4):860-7. doi:10.1161/ CIRCEP.112.972265

Hardie DG (2007) AMP-activated protein kinase as a drug target. Annu Rev Pharmacol Toxicol 47:185-210. doi:10.1146/annurev.pharmtox.47.120505.105304

Hardie DG, Carling D (1997) The AMP-activated protein kinase-fuel gauge of the mammalian cell? Eur J Biochem 246(2):259-73 
Hardie DG, Hawley SA (2001) AMP-activated protein kinase: the energy charge hypothesis revisited. Bioessays 23(12):1112-9. doi:10.1002/bies.10009

Hardie DG, Carling D, Gamblin SJ (2011) AMP-activated protein kinase: also regulated by ADP? Trends Biochem Sci 36(9):470-7. doi:10.1016/j.tibs.2011.06.004

Hardie DG, Ross FA, Hawley SA (2012a) AMPK: a nutrient and energy sensor that maintains energy homeostasis. Nat Rev Mol Cell Biol 13(4):251-62. doi:10.1038/nrm3311

Hardie DG, Ross FA, Hawley SA (2012b) AMP-activated protein kinase: a target for drugs both ancient and modern. Chem Biol 19(10):1222-36. doi:10.1016/j.chembiol.2012.08.019

Hawley SA, Davison M, Woods A, Davies SP, Beri RK, Carling D et al. (1996) Characterization of the AMP-activated protein kinase kinase from rat liver and identification of threonine 172 as the major site at which it phosphorylates AMP-activated protein kinase. J Biol Chem 271 (44):27879-87

Hawley SA, Boudeau J, Reid JL, Mustard KJ, Udd L, Makela TP et al. (2003) Complexes between the LKB1 tumor suppressor, STRAD alpha/beta and MO25 alpha/beta are upstream kinases in the AMP-activated protein kinase cascade. J Biol 2(4):28. doi:10.1186/1475-4924-2-28

Hawley SA, Pan DA, Mustard KJ, Ross L, Bain J, Edelman AM et al. (2005) Calmodulindependent protein kinase kinase-beta is an alternative upstream kinase for AMP-activated protein kinase. Cell Metab 2(1):9-19. doi:10.1016/j.cmet.2005.05.009

Hayashi T, Martone ME, Yu Z, Thor A, Doi M, Holst MJ et al. (2009) Three-dimensional electron microscopy reveals new details of membrane systems for $\mathrm{Ca}^{2+}$ signaling in the heart. J Cell Sci 122(Pt 7):1005-13. doi:10.1242/jcs.028175

Heerschap A, Kan HE, Nabuurs CI, Renema WK, Isbrandt D, Wieringa B (2007) In vivo magnetic resonance spectroscopy of transgenic mice with altered expression of guanidinoacetate methyltransferase and creatine kinase isoenzymes. Subcell Biochem 46:119-48

Hers I, Vincent EE, Tavare JM (2011) Akt signalling in health and disease. Cell Signal 23 (10):1515-27. doi:10.1016/j.cellsig.2011.05.004

Hoppe S, Bierhoff H, Cado I, Weber A, Tiebe M, Grummt I et al. (2009) AMP-activated protein kinase adapts rRNA synthesis to cellular energy supply. Proc Natl Acad Sci USA 106 (42):17781-6. doi:10.1073/pnas.0909873106

Horman S, Vertommen D, Heath R, Neumann D, Mouton V, Woods A et al. (2006) Insulin antagonizes ischemia-induced Thr172 phosphorylation of AMP-activated protein kinase alpha-subunits in heart via hierarchical phosphorylation of Ser485/491. J Biol Chem 281 (9):5335-40. doi:10.1074/jbc.M506850200

Horman S, Beauloye C, Vanoverschelde JL, Bertrand L (2012) AMP-activated protein kinase in the control of cardiac metabolism and remodeling. Curr Heart Fail Rep 9(3):164-73. doi:10.1007/s11897-012-0102-z

Hu X, Xu X, Lu Z, Zhang P, Fassett J, Zhang Y et al. (2011) AMP activated protein kinase-alpha2 regulates expression of estrogen-related receptor-alpha, a metabolic transcription factor related to heart failure development. Hypertension 58(4):696-703. doi:10.1161/HYPERTENSIONAHA.111.174128

Hue L, Taegtmeyer H (2009) The Randle cycle revisited: a new head for an old hat. Am J Physiol Endocrinol Metab 297(3):E578-91

Hurley RL, Anderson KA, Franzone JM, Kemp BE, Means AR, Witters LA (2005) The $\mathrm{Ca}^{2+}$ / calmodulin-dependent protein kinase kinases are AMP-activated protein kinase kinases. J Biol Chem 280(32):29060-6. doi:10.1074/jbc.M503824200

Hurley RL, Barre LK, Wood SD, Anderson KA, Kemp BE, Means AR et al. (2006) Regulation of AMP-activated protein kinase by multisite phosphorylation in response to agents that elevate cellular cAMP. J Biol Chem 281(48):36662-72. doi:10.1074/jbc.M606676200

Ideker T, Dutkowski J, Hood L (2011) Boosting signal-to-noise in complex biology: prior knowledge is power. Cell 144(6):860-3. doi:10.1016/j.cell.2011.03.007

Ikematsu N, Dallas ML, Ross FA, Lewis RW, Rafferty JN, David JA et al. (2011) Phosphorylation of the voltage-gated potassium channel Kv2.1 by AMP-activated protein kinase regulates membrane excitability. Proc Natl Acad Sci USA 108(44):18132-7 
Imamura K, Ogura T, Kishimoto A, Kaminishi M, Esumi H (2001) Cell cycle regulation via p53 phosphorylation by a 5'-AMP activated protein kinase activator, 5-aminoimidazole4-carboxamide-1-beta-D-ribofuranoside, in a human hepatocellular carcinoma cell line. Biochem Biophys Res Commun 287(2):562-7. doi:10.1006/bbrc.2001.5627

Ingwall JS (2002) Is creatine kinase a target for AMP-activated protein kinase in the heart? J Mol Cell Cardiol 34(9):1111-20

Ingwall JS (2006) On the hypothesis that the failing heart is energy starved: lessons learned from the metabolism of ATP and creatine. Curr Hypertens Rep 8(6):457-64

Ingwall JS, Weiss RG (2004) Is the failing heart energy starved? On using chemical energy to support cardiac function. Circ Res 95(2):135-45

Inoki K, Zhu T, Guan KL (2003) TSC2 mediates cellular energy response to control cell growth and survival. Cell 115(5):577-90

Inoki K, Kim J, Guan KL (2012) AMPK and mTOR in cellular energy homeostasis and drug targets. Annu Rev Pharmacol Toxicol 52:381-400. doi:10.1146/annurev-pharmtox-010611134537

Irrcher I, Adhihetty PJ, Sheehan T, Joseph AM, Hood DA (2003) PPARgamma coactivator-1alpha expression during thyroid hormone- and contractile activity-induced mitochondrial adaptations. Am J Physiol Cell Physiol 284(6):C1669-77. doi:10.1152/ajpcell.00409.2002

Jacobus WE, Saks VA (1982) Creatine kinase of heart mitochondria: changes in its kinetic properties induced by coupling to oxidative phosphorylation. Arch Biochem Biophys 219 (1):167-78

Jager S, Handschin C, St-Pierre J, Spiegelman BM (2007) AMP-activated protein kinase (AMPK) action in skeletal muscle via direct phosphorylation of PGC-1alpha. Proc Natl Acad Sci USA 104(29):12017-22. doi:10.1073/pnas.0705070104

Jeon SM, Chandel NS, Hay N (2012) AMPK regulates NADPH homeostasis to promote tumour cell survival during energy stress. Nature 485(7400):661-5. doi:10.1038/nature11066

Jones RG, Plas DR, Kubek S, Buzzai M, Mu J, Xu Y et al. (2005) AMP-activated protein kinase induces a p53-dependent metabolic checkpoint. Mol Cell 18(3):283-93. doi:10.1016/j. molcel.2005.03.027

Ju TC, Lin YS, Chern Y (2012) Energy dysfunction in Huntington's disease: insights from PGC-1alpha, AMPK, and CKB. Cell Mol Life Sci 69(24):4107-20. doi:10.1007/s00018-012$1025-2$

Kahn BB, Alquier T, Carling D, Hardie DG (2005) AMP-activated protein kinase: ancient energy gauge provides clues to modern understanding of metabolism. Cell Metab 1(1):15-25

Kan HE, Buse-Pot TE, Peco R, Isbrandt D, Heerschap A, de Haan A (2005) Lower force and impaired performance during high-intensity electrical stimulation in skeletal muscle of GAMT-deficient knockout mice. Am J Physiol Cell Physiol 289(1):C113-9. doi:10.1152/ ajpcell.00040.2005

Kang S, Chemaly ER, Hajjar RJ, Lebeche D (2011) Resistin promotes cardiac hypertrophy via the AMP-activated protein kinase/mammalian target of rapamycin (AMPK/mTOR) and c-Jun $\mathrm{N}$-terminal kinase/insulin receptor substrate 1 (JNK/IRS1) pathways. J Biol Chem 286 (21):18465-73. doi:10.1074/jbc.M110.200022

Kawaguchi T, Osatomi K, Yamashita H, Kabashima T, Uyeda K (2002) Mechanism for fatty acid "sparing" effect on glucose-induced transcription: regulation of carbohydrate-responsive element-binding protein by AMP-activated protein kinase. J Biol Chem 277(6):3829-35. doi:10.1074/jbc.M107895200

Kay L, Nicolay K, Wieringa B, Saks V, Wallimann T (2000) Direct evidence for the control of mitochondrial respiration by mitochondrial creatine kinase in oxidative muscle cells in situ. J Biol Chem 275(10):6937-44

Kelly M, Keller C, Avilucea PR, Keller P, Luo Z, Xiang X et al. (2004) AMPK activity is diminished in tissues of IL-6 knockout mice: the effect of exercise. Biochem Biophys Res Commun 320(2):449-54. doi:10.1016/j.bbrc.2004.05.188 
Kemp BE, Oakhill JS, Scott JW (2007) AMPK structure and regulation from three angles. Structure 15(10):1161-3. doi:10.1016/j.str.2007.09.006

Kerrien S, Aranda B, Breuza L, Bridge A, Broackes-Carter F, Chen C et al. (2012) The IntAct molecular interaction database in 2012. Nucleic Acids Res 40(Database issue):D841-6. doi:10.1093/nar/gkr1088

Kim AS, Miller EJ, Wright TM, Li J, Qi D, Atsina K et al. (2011a) A small molecule AMPK activator protects the heart against ischemia-reperfusion injury. J Mol Cell Cardiol 51 (1):24-32. doi:10.1016/j.yjmcc.2011.03.003

Kim J, Kundu M, Viollet B, Guan KL (2011b) AMPK and mTOR regulate autophagy through direct phosphorylation of Ulk1. Nat Cell Biol 13(2):132-41. doi:10.1038/ncb2152

Kim M, Shen M, Ngoy S, Karamanlidis G, Liao R, Tian R (2012) AMPK isoform expression in the normal and failing hearts. J Mol Cell Cardiol 52(5):1066-73. doi:10.1016/j.yjmcc.2012.01.016

Klaus A, Polge C, Zorman S, Auchli Y, Brunisholz R, Schlattner U (2012) A two-dimensional screen for AMPK substrates identifies tumor suppressor fumarate hydratase as a preferential AMPKalpha2 substrate. J Proteomics 75(11):3304-13. doi:10.1016/j.jprot.2012.03.040

Klaus A, Zorman S, Berthier A, Polge C, Ramirez-Rios S, Michelland S et al. (2013) Glutathione S-transferases interact with AMP-activated protein kinase: evidence for S-glutathionylation and activation in vitro. PLoS One 8:e62497

Klingenberg M (1970) Mitochondria metabolite transport. FEBS Lett 6(3):145-54

Klingenberg M (1976) The state of ADP or ATP fixed to the mitochondria by bongkrekate. Eur J Biochem/FEBS 65(2):601-5

Klingenberg M (2008) The ADP, and ATP transport in mitochondria and its carrier. Biochim Biophys Acta 1778(10):1978-2021

Ko HJ, Zhang Z, Jung DY, Jun JY, Ma Z, Jones KE et al. (2009) Nutrient stress activates inflammation and reduces glucose metabolism by suppressing AMP-activated protein kinase in the heart. Diabetes 58(11):2536-46. doi:10.2337/db08-1361

Kobayashi K, Neely JR (1979) Control of maximum rates of glycolysis in rat cardiac muscle. Circ Res 44(2):166-75

Kola B, Hubina E, Tucci SA, Kirkham TC, Garcia EA, Mitchell SE et al. (2005) Cannabinoids and ghrelin have both central and peripheral metabolic and cardiac effects via AMP-activated protein kinase. J Biol Chem 280(26):25196-201. doi:10.1074/jbc.C500175200

Koo SH, Flechner L, Qi L, Zhang X, Screaton RA, Jeffries S et al. (2005) The CREB coactivator TORC2 is a key regulator of fasting glucose metabolism. Nature 437(7062):1109-11. doi: 10.1038 /nature 03967

Kudo N, Barr AJ, Barr RL, Desai S, Lopaschuk GD (1995) High rates of fatty acid oxidation during reperfusion of ischemic hearts are associated with a decrease in malonyl-CoA levels due to an increase in 5'-AMP-activated protein kinase inhibition of acetyl-CoA carboxylase. J Biol Chem 270(29): 17513-20

Kudo N, Gillespie JG, Kung L, Witters LA, Schulz R, Clanachan AS et al. (1996) Characterization of $5^{\prime}$ AMP-activated protein kinase activity in the heart and its role in inhibiting acetyl-CoA carboxylase during reperfusion following ischemia. Biochim Biophys Acta 1301(1-2):67-75

Kulkarni SS, Karlsson HK, Szekeres F, Chibalin AV, Krook A, Zierath JR (2011) Suppression of 5'-nucleotidase enzymes promotes AMP-activated protein kinase (AMPK) phosphorylation and metabolism in human and mouse skeletal muscle. J Biol Chem 286(40):34567-74. doi:10.1074/jbc.M111.268292

Kurth-Kraczek EJ, Hirshman MF, Goodyear LJ, Winder WW (1999) 5' AMP-activated protein kinase activation causes GLUT4 translocation in skeletal muscle. Diabetes 48(8):1667-71

Kuznetsov AV, Margreiter R (2009) Heterogeneity of mitochondria and mitochondrial function within cells as another level of mitochondrial complexity. Int J Mol Sci 10(4):1911-29

Kuznetsov AV, Clark JF, Winkler K, Kunz WS (1996) Increase of flux control of cytochrome c oxidase in copper-deficient mottled brindled mice. J Biol Chem 271(1):283-8 
Kuznetsov AV, Hermann M, Troppmair J, Margreiter R, Hengster P (2009) Complex patterns of mitochondrial dynamics in human pancreatic cells revealed by fluorescent confocal imaging. $\mathrm{J}$ Cell Mol Med 14:417-25

Kwiatkowski DJ, Manning BD (2005) Tuberous sclerosis: a GAP at the crossroads of multiple signaling pathways. Hum Mol Genet 14(Spec No. 2):R251-8. doi:10.1093/hmg/ddi260

Lan F, Cacicedo JM, Ruderman N, Ido Y (2008) SIRT1 modulation of the acetylation status, cytosolic localization, and activity of LKB1. Possible role in AMP-activated protein kinase activation. J Biol Chem 283(41):27628-27635. doi:10.1074/jbc.M805711200

Lee JH, Koh H, Kim M, Kim Y, Lee SY, Karess RE et al. (2007) Energy-dependent regulation of cell structure by AMP-activated protein kinase. Nature 447(7147):1017-20. doi:10.1038/ nature 05828

Leverve X, Fontaine E, Peronnet F, (eds) (2006) Bioénergétique. Traité de nutrition artificielle de l'adulte: Springer

Li J, Miller EJ, Ninomiya-Tsuji J, Russell RR 3rd, Young LH (2005) AMP-activated protein kinase activates $\mathrm{p} 38$ mitogen-activated protein kinase by increasing recruitment of p38 MAPK to TAB1 in the ischemic heart. Circ Res 97(9):872-9. doi:10.1161/01. RES.0000187458.77026.10

Li J, Coven DL, Miller EJ, Hu X, Young ME, Carling D et al. (2006) Activation of AMPK alphaand gamma-isoform complexes in the intact ischemic rat heart. Am J Physiol Heart Circ Physiol 291(4):H1927-34. doi:10.1152/ajpheart.00251.2006

Li HL, Yin R, Chen D, Liu D, Wang D, Yang Q et al. (2007) Long-term activation of adenosine monophosphate-activated protein kinase attenuates pressure-overload-induced cardiac hypertrophy. J Cell Biochem 100(5):1086-99. doi:10.1002/jcb.21197

Li H, Thali RF, Smolak C, Gong F, Alzamora R, Wallimann T et al. (2010) Regulation of the creatine transporter by AMP-activated protein kinase in kidney epithelial cells. Am J Physiol Renal Physiol 299(1):F167-77. doi:10.1152/ajprenal.00162.2010

Li Y, Xu S, Mihaylova MM, Zheng B, Hou X, Jiang B et al. (2011) AMPK phosphorylates and inhibits SREBP activity to attenuate hepatic steatosis and atherosclerosis in diet-induced insulin-resistant mice. Cell Metab 13(4):376-88. doi:10.1016/j.cmet.2011.03.009

Li XH, Chen XJ, Ou WB, Zhang Q, Lv ZR, Zhan Y et al. (2013) Knockdown of creatine kinase B inhibits ovarian cancer progression by decreasing glycolysis. Int J Biochem Cell Biol 45 (5):979-86. doi:10.1016/j.biocel.2013.02.003

Liang J, Shao SH, Xu ZX, Hennessy B, Ding Z, Larrea M et al. (2007) The energy sensing LKB1AMPK pathway regulates p27(kip1) phosphorylation mediating the decision to enter autophagy or apoptosis. Nat Cell Biol 9(2):218-24. doi:10.1038/ncb1537

Lin YY, Kiihl S, Suhail Y, Liu SY, Chou YH, Kuang Z, Lu JY, Khor CN, Lin CL, Bader JS, Irizarry R, Boeke JD (2012) Functional dissection of lysine deacetylases reveals that HDAC1 and p300 regulate AMPK. Nature 482(7384):251-255. doi:10.1038/nature10804

Liobikas J, Kopustinskiene DM, Toleikis A (2001) What controls the outer mitochondrial membrane permeability for ADP: facts for and against the role of oncotic pressure. Biochim Biophys Acta 1505(2-3):220-5

Lygate CA, Bohl S, ten Hove M, Faller KM, Ostrowski PJ, Zervou S et al. (2012) Moderate elevation of intracellular creatine by targeting the creatine transporter protects mice from acute myocardial infarction. Cardiovasc Res 96(3):466-75. doi:10.1093/cvr/cvs272

Lygate CA, Aksentijevic D, Dawson D, Ten Hove M, Phillips D, de Bono JP et al. (2013) Living without creatine: unchanged exercise capacity and response to chronic myocardial infarction in creatine-deficient mice. Circ Res 112(6):945-55. doi:10.1161/CIRCRESAHA.112.300725

Ma H, Wang J, Thomas DP, Tong C, Leng L, Wang W et al. (2010) Impaired macrophage migration inhibitory factor-AMP-activated protein kinase activation and ischemic recovery in the senescent heart. Circulation 122(3):282-92. doi:10.1161/CIRCULATIONAHA.110.953208

Makinde AO, Gamble J, Lopaschuk GD (1997) Upregulation of 5'-AMP-activated protein kinase is responsible for the increase in myocardial fatty acid oxidation rates following birth in the newborn rabbit. Circ Res 80(4):482-9 
Mannella CA (2006) Structure and dynamics of the mitochondrial inner membrane cristae. Biochim Biophys Acta 1763(5-6):542-8. doi:10.1016/j.bbamcr.2006.04.006

Marcus FB (2008) Bioinformatics and systems biology - collaborative research and resources. Springer, Berlin, Heidelberg

Marsin AS, Bertrand L, Rider MH, Deprez J, Beauloye C, Vincent MF et al. (2000) Phosphorylation and activation of heart PFK-2 by AMPK has a role in the stimulation of glycolysis during ischaemia. Curr Biol 10(20):1247-55

Mayer FV, Heath R, Underwood E, Sanders MJ, Carmena D, McCartney RR et al. (2011) ADP regulates SNF1, the Saccharomyces cerevisiae homolog of AMP-activated protein kinase. Cell Metab 14(5):707-14. doi:10.1016/j.cmet.2011.09.009

McBride A, Ghilagaber S, Nikolaev A, Hardie DG (2009) The glycogen-binding domain on the AMPK beta subunit allows the kinase to act as a glycogen sensor. Cell Metab 9(1):23-34. doi:10.1016/j.cmet.2008.11.008

McGaffin KR, Moravec CS, McTiernan CF (2009) Leptin signaling in the failing and mechanically unloaded human heart. Circ Heart Fail 2(6):676-83. doi:10.1161/ CIRCHEARTFAILURE.109.869909

McGee SL, Hargreaves M (2008) AMPK and transcriptional regulation. Front Biosci 13:3022-33

McGee SL, Howlett KF, Starkie RL, Cameron-Smith D, Kemp BE, Hargreaves M (2003) Exercise increases nuclear AMPK alpha2 in human skeletal muscle. Diabetes 52(4):926-8

McGee SL, van Denderen BJ, Howlett KF, Mollica J, Schertzer JD, Kemp BE et al. (2008) AMP-activated protein kinase regulates GLUT4 transcription by phosphorylating histone deacetylase 5. Diabetes 57(4):860-7. doi:10.2337/db07-0843

Meijer AJ, Codogno P (2007) AMP-activated protein kinase and autophagy. Autophagy 3 (3):238-40

Merrill GF, Kurth EJ, Hardie DG, Winder WW (1997) AICA riboside increases AMP-activated protein kinase, fatty acid oxidation, and glucose uptake in rat muscle. Am J Physiol 273(6 Pt 1): E1107-12

Meyer LE, Machado LB, Santiago AP, Da-Silva WS, De Felice FG, Holub O et al. (2006) Mitochondrial creatine kinase activity prevents reactive oxygen species generation: antioxidant role of mitochondrial kinase-dependent ADP re-cycling activity. J Biol Chem 281 (49):37361-71. doi:10.1074/jbc.M604123200

Mihaylova MM, Vasquez DS, Ravnskjaer K, Denechaud PD, Yu RT, Alvarez JG et al. (2011) Class IIa histone deacetylases are hormone-activated regulators of FOXO and mammalian glucose homeostasis. Cell 145(4):607-21. doi:10.1016/j.cell.2011.03.043

Mika D, Leroy J, Vandecasteele G, Fischmeister R (2012) PDEs create local domains of cAMP signaling. J Mol Cell Cardiol 52(2):323-9. doi:10.1016/j.yjmcc.2011.08.016

Miller EJ, Li J, Leng L, McDonald C, Atsumi T, Bucala R et al. (2008) Macrophage migration inhibitory factor stimulates AMP-activated protein kinase in the ischaemic heart. Nature 451 (7178):578-82. doi:10.1038/nature06504

Minokoshi Y, Alquier T, Furukawa N, Kim YB, Lee A, Xue B et al. (2004) AMP-kinase regulates food intake by responding to hormonal and nutrient signals in the hypothalamus. Nature 428 (6982):569-74. doi:10.1038/nature02440

Mochel F, Durant B, Meng X, O'Callaghan J, Yu H, Brouillet E et al. (2012) Early alterations of brain cellular energy homeostasis in Huntington disease models. J Biol Chem 287(2):1361-70. doi:10.1074/jbc.M111.309849

Momcilovic M, Hong SP, Carlson M (2006) Mammalian TAK1 activates Snf1 protein kinase in yeast and phosphorylates AMP-activated protein kinase in vitro. J Biol Chem 281 (35):25336-43. doi:10.1074/jbc.M604399200

Moreno D, Viana R, Sanz P (2009) Two-hybrid analysis identifies PSMD11, a non-ATPase subunit of the proteasome, as a novel interaction partner of AMP-activated protein kinase. Int J Biochem Cell Biol 41(12):2431-9. doi:10.1016/j.biocel.2009.07.002

Moreno D, Towler MC, Hardie DG, Knecht E, Sanz P (2010) The laforin-malin complex, involved in Lafora disease, promotes the incorporation of K63-linked ubiquitin chains into 
AMP-activated protein kinase beta subunits. Mol Biol Cell 21(15):2578-88. doi:10.1091/mbc. E10-03-0227

Moreno-Sanchez R, Saavedra E, Rodriguez-Enriquez S, Olin-Sandoval V (2008) Metabolic control analysis: a tool for designing strategies to manipulate metabolic pathways. J Biomed Biotechnol 2008:597913

Mungai PT, Waypa GB, Jairaman A, Prakriya M, Dokic D, Ball MK et al. (2011) Hypoxia triggers AMPK activation through reactive oxygen species-mediated activation of calcium releaseactivated calcium channels. Mol Cell Biol 31(17):3531-45. doi:10.1128/MCB.05124-11

Muoio DM, Seefeld K, Witters LA, Coleman RA (1999) AMP-activated kinase reciprocally regulates triacylglycerol synthesis and fatty acid oxidation in liver and muscle: evidence that sn-glycerol-3-phosphate acyltransferase is a novel target. Biochem J 338(Pt 3):783-91

Musi N, Hirshman MF, Arad M, Xing Y, Fujii N, Pomerleau J et al. (2005) Functional role of AMP-activated protein kinase in the heart during exercise. FEBS Lett 579(10):2045-50. doi:10.1016/j.febslet.2005.02.052

Nabuurs C, Huijbregts B, Wieringa B, Hilbers CW, Heerschap A (2010) 31P saturation transfer spectroscopy predicts differential intracellular macromolecular association of ATP and ADP in skeletal muscle. J Biol Chem 285(51):39588-96. doi:10.1074/jbc.M110.164665

Nabuurs CI, Choe CU, Veltien A, Kan HE, van Loon LJ, Rodenburg RJ et al. (2013) Disturbed energy metabolism and muscular dystrophy caused by pure creatine deficiency are reversible by creatine intake. J Physiol 591(Pt 2):571-92. doi:10.1113/jphysiol.2012.241760

Nakano A, Takashima S (2012) LKB1 and AMP-activated protein kinase: regulators of cell polarity. Genes Cells 17(9):737-47. doi:10.1111/j.1365-2443.2012.01629.x

Nakano A, Kato H, Watanabe T, Min KD, Yamazaki S, Asano Y et al. (2010) AMPK controls the speed of microtubule polymerization and directional cell migration through CLIP-170 phosphorylation. Nat Cell Biol 12(6):583-90. doi:10.1038/ncb2060

Nascimben L, Ingwall JS, Pauletto P, Friedrich J, Gwathmey JK, Saks V et al. (1996) Creatine kinase system in failing and nonfailing human myocardium. Circulation 94(8):1894-901

Neely J, Morgan H (1974) Relationship between carbohydrate and lipid metabolism and the energy balance of heart muscle. Annu Rev Physiol 63:413-59

Neely JR, Denton RM, England PJ, Randle PJ (1972) The effects of increased heart work on the tricarboxylate cycle and its interactions with glycolysis in the perfused rat heart. Biochem J 128 (1):147-59

Nemutlu E, Zhang S, Gupta A, Juranic NO, Macura SI, Terzic A et al. (2012) Dynamic phosphometabolomic profiling of human tissues and transgenic models by 18O-assisted (3)(1)P NMR and mass spectrometry. Physiol Genomics 44(7):386-402. doi:10.1152/physiolgenomics.00152.2011

Neubauer S (2007) The failing heart-an engine out of fuel. N Engl J Med 356(11):1140-51

Neumann D, Schlattner U, Wallimann T (2003) A molecular approach to the concerted action of kinases involved in energy homoeostasis. Biochem Soc Trans 31(Pt 1):169-74. doi:10.1042/

Newsholme EA, Start C (1973) Regulation in metabolism. Wiley, London

Nivala M, Korge P, Weiss JN, Qu Z (2011) Linking flickering to waves and whole-cell oscillations in a mitochondrial network model. Biophys J 101(9):2102-11. doi:10.1016/j.bpj.2011.09.038

Oakhill JS, Chen ZP, Scott JW, Steel R, Castelli LA, Ling N et al. (2010) beta-Subunit myristoylation is the gatekeeper for initiating metabolic stress sensing by AMP-activated protein kinase (AMPK). Proc Natl Acad Sci USA 107(45):19237-41. doi:10.1073/ pnas. 1009705107

Oakhill JS, Steel R, Chen ZP, Scott JW, Ling N, Tam S et al. (2011) AMPK is a direct adenylate charge-regulated protein kinase. Science 332(6036):1433-5. doi:10.1126/science.1200094

Oakhill JS, Scott JW, Kemp BE (2012) AMPK functions as an adenylate charge-regulated protein kinase. Trends Endocrinol Metab 23(3):125-32. doi:10.1016/j.tem.2011.12.006

Oliveira SM, Zhang YH, Solis RS, Isackson H, Bellahcene M, Yavari A et al. (2012a) AMP-activated protein kinase phosphorylates cardiac troponin I and alters contractility of murine ventricular myocytes. Circ Res 110(9):1192-201. doi:10.1161/ CIRCRESAHA. 111.259952 
Oliveira AP, Ludwig C, Picotti P, Kogadeeva M, Aebersold R, Sauer U (2012b) Regulation of yeast central metabolism by enzyme phosphorylation. Mol Syst Biol 8:623. doi:10.1038/ msb.2012.55

Paiva MA, Rutter-Locher Z, Goncalves LM, Providencia LA, Davidson SM, Yellon DM et al. (2011) Enhancing AMPK activation during ischemia protects the diabetic heart against reperfusion injury. Am J Physiol Heart Circ Physiol 300(6):H2123-34. doi:10.1152/ ajpheart.00707.2010

Pang T, Xiong B, Li JY, Qiu BY, Jin GZ, Shen JK et al. (2007) Conserved alpha-helix acts as autoinhibitory sequence in AMP-activated protein kinase alpha subunits. J Biol Chem 282 (1):495-506. doi:10.1074/jbc.M605790200

Pinter K, Grignani RT, Czibik G, Farza H, Watkins H, Redwood C (2012) Embryonic expression of AMPK gamma subunits and the identification of a novel gamma2 transcript variant in adult heart. J Mol Cell Cardiol 53(3):342-9. doi:10.1016/j.yjmcc.2012.05.017

Polekhina G, Gupta A, Michell BJ, van Denderen B, Murthy S, Feil SC et al. (2003) AMPK beta subunit targets metabolic stress sensing to glycogen. Curr Biol 13(10):867-71

Polge C, Jossier M, Crozet P, Gissot L, Thomas M (2008) Beta-subunits of the SnRK1 complexes share a common ancestral function together with expression and function specificities; physical interaction with nitrate reductase specifically occurs via AKINbeta1-subunit. Plant Physiol 148 (3):1570-82. doi:10.1104/pp. 108.123026

Ponticos M, Lu QL, Morgan JE, Hardie DG, Partridge TA, Carling D (1998) Dual regulation of the AMP-activated protein kinase provides a novel mechanism for the control of creatine kinase in skeletal muscle. EMBO J 17(6):1688-99. doi:10.1093/emboj/17.6.1688

Pucar D, Dzeja PP, Bast P, Juranic N, Macura S, Terzic A (2001) Cellular energetics in the preconditioned state: protective role for phosphotransfer reactions captured by $18 \mathrm{O}$-assisted 31P NMR. J Biol Chem 276(48):44812-9. doi:10.1074/jbc.M104425200

Qi J, Gong J, Zhao T, Zhao J, Lam P, Ye J et al. (2008) Downregulation of AMP-activated protein kinase by Cidea-mediated ubiquitination and degradation in brown adipose tissue. EMBO J 27 (11):1537-48. doi:10.1038/emboj.2008.92

Randle PJ (1998) Regulatory interactions between lipids and carbohydrates: the glucose fatty acid cycle after 35 years. Diabetes Metab Rev 14(4):263-83

Randle PJ, Garland PB, Hales CN, Newsholme EA (1963) The glucose fatty-acid cycle. Its role in insulin sensitivity and the metabolic disturbances of diabetes mellitus. Lancet 1(7285):785-9

Riek U, Scholz R, Konarev P, Rufer A, Suter M, Nazabal A et al. (2008) Structural properties of AMP-activated protein kinase: dimerization, molecular shape, and changes upon ligand binding. J Biol Chem 283(26):18331-43. doi:10.1074/jbc.M708379200

Rogne M, Tasken K (2013) Cell signalling analyses in the functional genomics era. N Biotechnol 30(3):333-8. doi:10.1016/j.nbt.2013.01.003

Rose BA, Force T, Wang Y (2010) Mitogen-activated protein kinase signaling in the heart: angels versus demons in a heart-breaking tale. Physiol Rev 90(4):1507-46. doi:10.1152/ physrev.00054.2009

Ruderman NB, Xu XJ, Nelson L, Cacicedo JM, Saha AK, Lan F, Ido Y (2010) AMPK and SIRT1: a long-standing partnership? Am J Physiol Endocrinol Metab 298(4):E751-E760. doi:10.1152/ ajpendo.00745.2009

Russell RR 3rd, Li J, Coven DL, Pypaert M, Zechner C, Palmeri M et al. (2004) AMP-activated protein kinase mediates ischemic glucose uptake and prevents postischemic cardiac dysfunction, apoptosis, and injury. J Clin Invest 114(4):495-503. doi:10.1172/JCI19297

Sackett D (2010) Evolution and coevolution of tubulin's carboxy-terminal tails and mitochondria. In: Svensson OL (ed) Mitochondria: structure, function and dysfunction. Nova Biomedical Books, New York, pp 789-810

Saetersdal T, Greve G, Dalen H (1990) Associations between beta-tubulin and mitochondria in adult isolated heart myocytes as shown by immunofluorescence and immunoelectron microscopy. Histochemistry 95(1):1-10 
Saks V (ed) (2007) Molecular system bioenergetics—energy for life, basic principles, organization and dynamics of cellular energetics. Wiley- $\mathrm{VCH}$, Weinheim

Saks V (2008) The phosphocreatine-creatine kinase system helps to shape muscle cells and keep them healthy and alive. J Physiol 586(Pt 12):2817-8

Saks V (2009) Molecular system bioenergetics-new aspects of metabolic research. Int J Mol Sci 10 (8):3655-7

Saks V, Strumia E (1993) Phosphocreatine: molecular and cellular aspects of the mechanism of cardioprotective action. Curr Ther Res 53(5):565-98

Saks VA, Lipina NV, Sharov VG, Smirnov VN, Chazov E, Grosse R (1977) The localization of the MM isozyme of creatine phosphokinase on the surface membrane of myocardial cells and its functional coupling to ouabain-inhibited (Na+, $\mathrm{K}+$ )-ATPase. Biochim Biophys Acta 465 (3):550-8

Saks VA, Rosenshtraukh LV, Smirnov VN, Chazov EI (1978) Role of creatine phosphokinase in cellular function and metabolism. Can J Physiol Pharmacol 56(5):691-706

Saks VA, Belikova YO, Kuznetsov AV (1991) In vivo regulation of mitochondrial respiration in cardiomyocytes: specific restrictions for intracellular diffusion of ADP. Biochim Biophys Acta 1074(2):302-11

Saks V, Dos Santos P, Gellerich FN, Diolez P (1998) Quantitative studies of enzyme-substrate compartmentation, functional coupling and metabolic channelling in muscle cells. Mol Cell Biochem 184(1-2):291-307

Saks VA, Kaambre T, Sikk P, Eimre M, Orlova E, Paju K et al. (2001) Intracellular energetic units in red muscle cells. Biochem J 356(Pt 2):643-57

Saks V, Dzeja P, Schlattner U, Vendelin M, Terzic A, Wallimann T (2006a) Cardiac system bioenergetics: metabolic basis of the Frank-Starling law. J Physiol 571(Pt 2):253-73

Saks V, Favier R, Guzun R, Schlattner U, Wallimann T (2006b) Molecular system bioenergetics: regulation of substrate supply in response to heart energy demands. J Physiol 577(Pt 3):769-77

Saks V, Dzeja P, Schlattner U, Vendelin M, Terzic A, Wallimann T (2006c) Cardiac system bioenergetics: metabolic basis of the Frank-Starling law. J Physiol 571(Pt 2):253-73. doi:10.1113/jphysiol.2005.101444

Saks V, Kaambre T, Guzun R, Anmann T, Sikk P, Schlattner U et al. (2007a) The creatine kinase phosphotransfer network: thermodynamic and kinetic considerations, the impact of the mitochondrial outer membrane and modelling approaches. Subcell Biochem 46:27-65

Saks V, Anmann T, Guzun R, Kaambre T, Sikk P, Schlattner U et al. (2007b) The creatine kinase phosphotransfer network: thermodynamic and kinetic considerations, the impact of the mitochondrial outer membrane and modelling approaches. In: Wyss M, Salomons G (eds) Creatine and creatine kinase in health and disease. Springer, Dordrecht, pp 27-66

Saks VA, Dzeja P, Guzun R, Aliev MK, Vendelin M, Terzic A, Wallimann T (2007c) System analysis of cardiac energetics - excitation-contraction coupling: integration of mitochondrial respiration, phosphotransfer pathways, metabolic pacing and substrate supply in the heart. In: Saks V (ed) Molecular system bioenergetics. Energy for Life. Wiley, Weinheim, GmbH, pp 367-405

Saks V, Monge C, Anmann T, Dzeja P (2007d) Integrated and organized cellular energetic systems: theories of cell energetics, compartmentation and metabolic channeling. In: Saks V (ed) Molecular system bioenergetics. Energy for life. Wiley, Weinheim, GmbH, pp 59-110

Saks V, Guzun R, Timohhina N, Tepp K, Varikmaa M, Monge C et al. (2010) Structure-function relationships in feedback regulation of energy fluxes in vivo in health and disease: mitochondrial interactosome. Biochim Biophys Acta 1797(6-7):678-97

Saks V, Kuznetsov AV, Gonzalez-Granillo M, Tepp K, Timohhina N, Karu-Varikmaa M et al. (2012) Intracellular energetic units regulate metabolism in cardiac cells. J Mol Cell Cardiol 52:419-36

Salt I, Celler JW, Hawley SA, Prescott A, Woods A, Carling D et al. (1998) AMP-activated protein kinase: greater AMP dependence, and preferential nuclear localization, of complexes containing the alpha2 isoform. Biochem J 334(Pt 1):177-87 
Sartoretto JL, Kalwa H, Pluth MD, Lippard SJ, Michel T (2011) Hydrogen peroxide differentially modulates cardiac myocyte nitric oxide synthesis. Proc Natl Acad Sci USA 108(38):15792-7. doi:10.1073/pnas.1111331108

Sasaki H, Asanuma H, Fujita M, Takahama H, Wakeno M, Ito S et al. (2009) Metformin prevents progression of heart failure in dogs: role of AMP-activated protein kinase. Circulation 119 (19):2568-77. doi:10.1161/CIRCULATIONAHA.108.798561

Schlattner U, Wallimann T (2004) Metabolite channeling: creatine kinase microcompartments. In: Lennarz WJ, Lane MD (eds) In encyclopedia of biological chemistry. Academic, New York, USA, pp 646-51

Schlattner U, Forstner M, Eder M, Stachowiak O, Fritz-Wolf K, Wallimann T (1998) Functional aspects of the X-ray structure of mitochondrial creatine kinase: a molecular physiology approach. Mol Cell Biochem 184(1-2):125-40

Schlattner U, Tokarska-Schlattner M, Wallimann T (2006a) Molecular structure and function of mitochondrial creatine kinases. In: Vial C (ed) Creatine kinase. Nova, New York, pp 123-70

Schlattner U, Tokarska-Schlattner M, Wallimann T (2006b) Mitochondrial creatine kinase in human health and disease. Biochim Biophys Acta 1762(2):164-80

Schlattner U, Tokarska-Schlattner M, Ramirez S, Bruckner A, Kay L, Polge C et al. (2009) Mitochondrial kinases and their molecular interaction with cardiolipin. Biochim Biophys Acta 1788(10):2032-47. doi:10.1016/j.bbamem.2009.04.018

Schmidt A, Marescau B, Boehm EA, Renema WK, Peco R, Das A et al. (2004) Severely altered guanidino compound levels, disturbed body weight homeostasis and impaired fertility in a mouse model of guanidinoacetate N-methyltransferase (GAMT) deficiency. Hum Mol Genet 13(9):905-21. doi:10.1093/hmg/ddh112

Schroder R, Kunz WS, Rouan F, Pfendner E, Tolksdorf K, Kappes-Horn K et al. (2002) Disorganization of the desmin cytoskeleton and mitochondrial dysfunction in plectin-related epidermolysis bullosa simplex with muscular dystrophy. J Neuropathol Exp Neurol 61 (6):520-30

Schrödinger E (ed) (1944) What is life? The physical aspect of the living cell. Cambridge University Press, Cambridge, UK

Scott JW, Hawley SA, Green KA, Anis M, Stewart G, Scullion GA et al. (2004) CBS domains form energy-sensing modules whose binding of adenosine ligands is disrupted by disease mutations. J Clin Invest 113(2):274-84. doi:10.1172/JCI19874

Sebbagh M, Santoni MJ, Hall B, Borg JP, Schwartz MA (2009) Regulation of LKB1/STRAD localization and function by E-cadherin. Curr Biol 19(1):37-42. doi:10.1016/j. cub.2008.11.033

Selivanov VA, Alekseev AE, Hodgson DM, Dzeja PP, Terzic A (2004) Nucleotide-gated KATP channels integrated with creatine and adenylate kinases: amplification, tuning and sensing of energetic signals in the compartmentalized cellular environment. Mol Cell Biochem 256-257 (1-2):243-56

Shibata R, Ouchi N, Ito M, Kihara S, Shiojima I, Pimentel DR et al. (2004) Adiponectin-mediated modulation of hypertrophic signals in the heart. Nat Med 10(12):1384-9. doi:10.1038/nm1137

Shibata R, Sato K, Pimentel DR, Takemura Y, Kihara S, Ohashi K et al. (2005) Adiponectin protects against myocardial ischemia-reperfusion injury through AMPK- and COX-2-dependent mechanisms. Nat Med 11(10):1096-103. doi:10.1038/nm1295

Shinmura K, Tamaki K, Saito K, Nakano Y, Tobe T, Bolli R (2007) Cardioprotective effects of short-term caloric restriction are mediated by adiponectin via activation of AMP-activated protein kinase. Circulation 116(24):2809-17. doi:10.1161/CIRCULATIONAHA.107.725697

Soeller C, Cannell MB (1999) Examination of the transverse tubular system in living cardiac rat myocytes by 2-photon microscopy and digital image-processing techniques. Circ Res 84 (3):266-75

Solaz-Fuster MC, Gimeno-Alcaniz JV, Ros S, Fernandez-Sanchez ME, Garcia-Fojeda B, Criado Garcia $\mathrm{O}$ et al. (2008) Regulation of glycogen synthesis by the laforin-malin complex is 
modulated by the AMP-activated protein kinase pathway. Hum Mol Genet 17(5):667-78. doi:10.1093/hmg/ddm339

Sonntag AG, Dalle Pezze P, Shanley DP, Thedieck K (2012) A modelling-experimental approach reveals insulin receptor substrate (IRS)-dependent regulation of adenosine monosphosphatedependent kinase (AMPK) by insulin. FEBS J 279(18):3314-28. doi:10.1111/j.17424658.2012.08582.x

Srivastava RA, Pinkosky SL, Filippov S, Hanselman JC, Cramer CT, Newton RS (2012) AMP-activated protein kinase: an emerging drug target to regulate imbalances in lipid and carbohydrate metabolism to treat cardio-metabolic diseases. J Lipid Res 53(12):2490-514. doi:10.1194/jlr.R025882

Stapleton D, Mitchelhill KI, Gao G, Widmer J, Michell BJ, Teh T et al. (1996) Mammalian AMP-activated protein kinase subfamily. J Biol Chem 271(2):611-4

Starling EH, Visscher MB (1927) The regulation of the energy output of the heart. J Physiol 62 (3):243-61

Steeghs K, Benders A, Oerlemans F, de Haan A, Heerschap A, Ruitenbeek W et al. (1997) Altered $\mathrm{Ca}^{2+}$ responses in muscles with combined mitochondrial and cytosolic creatine kinase deficiencies. Cell 89(1):93-103

Steinberg SF (2012) Cardiac actions of protein kinase C isoforms. Physiology (Bethesda) 27 (3):130-9. doi:10.1152/physiol.00009.2012

Steinberg GR (2013) AMPK and the endocrine control of energy metabolism. Mol Cell Endocrinol 366(2):125-6. doi:10.1016/j.mce.2013.01.003

Steinberg GR, Kemp BE (2009) AMPK in health and disease. Physiol Rev 89(3):1025-78. doi:10.1152/physrev.00011.2008

Stockler S, Schutz PW, Salomons GS (2007) Cerebral creatine deficiency syndromes: clinical aspects, treatment and pathophysiology. Subcell Biochem 46:149-66

Stoppani J, Hildebrandt AL, Sakamoto K, Cameron-Smith D, Goodyear LJ, Neufer PD (2002) AMP-activated protein kinase activates transcription of the UCP3 and HKII genes in rat skeletal muscle. Am J Physiol Endocrinol Metab 283(6):E1239-48. doi:10.1152/ ajpendo.00278.2002

Streijger F, Oerlemans F, Ellenbroek BA, Jost CR, Wieringa B, Van der Zee CE (2005) Structural and behavioural consequences of double deficiency for creatine kinases BCK and UbCKmit. Behav Brain Res 157(2):219-34. doi:10.1016/j.bbr.2004.07.002

Strogolova V, Orlova M, Shevade A, Kuchin S (2012) Mitochondrial porin Por1 and its homolog Por2 contribute to the positive control of Snf1 protein kinase in Saccharomyces cerevisiae. Eukaryot Cell 11(12):1568-72. doi:10.1128/EC.00127-12

Suter M, Riek U, Tuerk R, Schlattner U, Wallimann T, Neumann D (2006) Dissecting the role of $5^{\prime}$-AMP for allosteric stimulation, activation, and deactivation of AMP-activated protein kinase. J Biol Chem 281(43):32207-16. doi:10.1074/jbc.M606357200

Suzuki A, Okamoto S, Lee S, Saito K, Shiuchi T, Minokoshi Y (2007) Leptin stimulates fatty acid oxidation and peroxisome proliferator-activated receptor alpha gene expression in mouse $\mathrm{C} 2 \mathrm{C} 12$ myoblasts by changing the subcellular localization of the alpha2 form of AMP-activated protein kinase. Mol Cell Biol 27(12):4317-27. doi:10.1128/MCB.02222-06

Tachikawa M, Ikeda S, Fujinawa J, Hirose S, Akanuma S, Hosoya K (2012) GammaAminobutyric acid transporter 2 mediates the hepatic uptake of guanidinoacetate, the creatine biosynthetic precursor, in rats. PLoS One 7(2):e32557. doi:10.1371/journal.pone.0032557

Taegtmeyer H (2010) Tracing cardiac metabolism in vivo: one substrate at a time. J Nucl Med 51 (Suppl 1):80S-7S

Taegtmeyer H, Ingwall JS (2013) Creatine-a dispensable metabolite? Circ Res 112(6):878-80. doi:10.1161/CIRCRESAHA.113.300974

Taegtmeyer H, Wilson CR, Razeghi P, Sharma S (2005) Metabolic energetics and genetics in the heart. Ann N Y Acad Sci 1047:208-18 
Tagawa H, Koide M, Sato H, Zile MR, Carabello BA, Cooper GT (1998) Cytoskeletal role in the transition from compensated to decompensated hypertrophy during adult canine left ventricular pressure overloading. Circ Res 82(7):751-61

Takimoto E (2012) Cyclic GMP-dependent signaling in cardiac myocytes. Circ J 76(8):1819-25

Tarasov AI, Griffiths EJ, Rutter GA (2012) Regulation of ATP production by mitochondrial $\mathrm{Ca}^{2+}$. Cell Calcium 52(1):28-35. doi:10.1016/j.ceca.2012.03.003

Taylor EB, Ellingson WJ, Lamb JD, Chesser DG, Compton CL, Winder WW (2006) Evidence against regulation of AMP-activated protein kinase and LKB1/STRAD/MO25 activity by creatine phosphate. Am J Physiol Endocrinol Metab 290(4):E661-9. doi:10.1152/ ajpendo.00313.2005

Taylor SS, Kim C, Cheng CY, Brown SH, Wu J, Kannan N (2008) Signaling through cAMP and cAMP-dependent protein kinase: diverse strategies for drug design. Biochim Biophys Acta 1784(1):16-26. doi:10.1016/j.bbapap.2007.10.002

Telesco SE, Radhakrishnan R (2012) Structural systems biology and multiscale signaling models. Ann Biomed Eng 40(11):2295-306. doi:10.1007/s10439-012-0576-6

ten Hove M, Lygate CA, Fischer A, Schneider JE, Sang AE, Hulbert K et al. (2005) Reduced inotropic reserve and increased susceptibility to cardiac ischemia/reperfusion injury in phosphocreatine-deficient guanidinoacetate-N-methyltransferase-knockout mice. Circulation 111(19):2477-85. doi:10.1161/01.CIR.0000165147.99592.01

Tepp K, Timohhina N, Chekulayev V, Shevchuk I, Kaambre T, Saks V (2011) Metabolic control analysis of integrated energy metabolism in permeabilized cardiomyocytes-experimental study. Acta Biochim Pol 57(4):421-30

Thornton C, Snowden MA, Carling D (1998) Identification of a novel AMP-activated protein kinase beta subunit isoform that is highly expressed in skeletal muscle. J Biol Chem 273 (20): $12443-50$

Tian R, Musi N, D’Agostino J, Hirshman MF, Goodyear LJ (2001) Increased adenosine monophosphate-activated protein kinase activity in rat hearts with pressure-overload hypertrophy. Circulation 104(14):1664-9

Timohhina N, Guzun R, Tepp K, Monge C, Varikmaa M, Vija H et al. (2009) Direct measurement of energy fluxes from mitochondria into cytoplasm in permeabilized cardiac cells in situ: some evidence for Mitochondrial Interactosome. J Bioenerg Biomembr 41(3):259-75. doi:10.1007/ s10863-009-9224-8

Tokarska-Schlattner M, Zaugg M, da Silva R, Lucchinetti E, Schaub MC, Wallimann T et al. (2005) Acute toxicity of doxorubicin on isolated perfused heart: response of kinases regulating energy supply. Am J Physiol Heart Circ Physiol 289(1):H37-47. doi:10.1152/ ajpheart.01057.2004

Tokarska-Schlattner M, Epand RF, Meiler F, Zandomeneghi G, Neumann D, Widmer HR et al. (2012) Phosphocreatine interacts with phospholipids, affects membrane properties and exerts membrane-protective effects. PLoS One 7(8):e43178. doi:10.1371/journal.pone.0043178

Torremans A, Marescau B, Possemiers I, Van Dam D, D'Hooge R, Isbrandt D et al. (2005) Biochemical and behavioural phenotyping of a mouse model for GAMT deficiency. J Neurol Sci 231(1-2):49-55. doi:10.1016/j.jns.2004.12.014

Townley R, Shapiro L (2007) Crystal structures of the adenylate sensor from fission yeast AMP-activated protein kinase. Science 315(5819):1726-9. doi:10.1126/science.1137503

Turner DC, Wallimann T, Eppenberger HM (1973) A protein that binds specifically to the M-line of skeletal muscle is identified as the muscle form of creatine kinase. Proc Natl Acad Sci USA 70(3):702-5

Uda K, Hoshijima M, Suzuki T (2013) A novel taurocyamine kinase found in the protist Phytophthora infestans. Comp Biochem Physiol B Biochem Mol Biol 165(1):42-8. doi:10.1016/j.cbpb.2013.03.003

van Oort MM, van Doorn JM, Hasnaoui ME, Glatz JF, Bonen A, van der Horst DJ et al. (2009) Effects of AMPK activators on the sub-cellular distribution of fatty acid transporters CD36 and FABPpm. Arch Physiol Biochem 115(3):137-46. doi:10.1080/13813450902975090 
Vendelin M, Kongas O, Saks V (2000) Regulation of mitochondrial respiration in heart cells analyzed by reaction-diffusion model of energy transfer. Am J Physiol Cell Physiol 278(4): C747-64

Vendelin M, Beraud N, Guerrero K, Andrienko T, Kuznetsov AV, Olivares J et al. (2005) Mitochondrial regular arrangement in muscle cells: a "crystal-like" pattern. Am J Physiol Cell Physiol 288(3):C757-67

Ventura-Clapier R, De Sousa E, Veksler V (2002) Metabolic myopathy in heart failure. News Physiol Sci 17:191-6

Ventura-Clapier R, Garnier A, Veksler V (2004) Energy metabolism in heart failure. J Physiol 555 (Pt 1):1-13

Viana R, Aguado C, Esteban I, Moreno D, Viollet B, Knecht E et al. (2008) Role of AMP-activated protein kinase in autophagy and proteasome function. Biochem Biophys Res Commun 369 (3):964-8. doi:10.1016/j.bbrc.2008.02.126

Vincent O, Carlson M (1999) Gal83 mediates the interaction of the Snf1 kinase complex with the transcription activator Sip4. EMBO J 18(23):6672-81. doi:10.1093/emboj/18.23.6672

Voss M, Paterson J, Kelsall IR, Martin-Granados C, Hastie CJ, Peggie MW et al. (2011) Ppm1E is an in cellulo AMP-activated protein kinase phosphatase. Cell Signal 23(1):114-24. doi:10.1016/j.cellsig.2010.08.010

Wallimann T (1975) Creatine kinase isoenzymes and myofibrillar structure [Nr. 5437]. ETH Zürich, Switzerland

Wallimann T (1996) 31P-NMR-measured creatine kinase reaction flux in muscle: a caveat! J Muscle Res Cell Motil 17(2):177-81

Wallimann T (2007) Introduction-creatine: cheap ergogenic supplement with great potential for health and disease. Sub-Cell Biochem 46:1-16

Wallimann T, Wyss M, Brdiczka D, Nicolay K, Eppenberger HM (1992) Intracellular compartmentation, structure and function of creatine kinase isoenzymes in tissues with high and fluctuating energy demands: the 'phosphocreatine circuit' for cellular energy homeostasis. Biochem J 281(Pt 1):21-40

Wallimann T, Tokarska-Schlattner M, Neumann D, Epand RF, Andres RH, Widmer HR, Hornemann T, Saks V, Agarkova I, Schlattner U (2007) The phosphocreatine circuit: molecular and cellular physiology of creatine kinases, sensitivity to free radicals, and enhancement by creatine supplementation. In: Saks V (ed) Molecular system bioenergetics. Energy for life. Wiley, Weinheim, GmbH, pp 195-264

Wallimann T, Tokarska-Schlattner M, Schlattner U (2011) The creatine kinase system and pleiotropic effects of creatine. Amino Acids 40(5):1271-96

Walsh K (2006) Akt signaling and growth of the heart. Circulation 113(17):2032-4. doi:10.1161/ CIRCULATIONAHA.106.615138

Wang MY, Unger RH (2005) Role of PP2C in cardiac lipid accumulation in obese rodents and its prevention by troglitazone. Am J Physiol Endocrinol Metab 288(1):E216-21. doi:10.1152/ ajpendo

Wang W, Fan J, Yang X, Furer-Galban S, Lopez de Silanes I, von Kobbe C et al. (2002) AMP-activated kinase regulates cytoplasmic HuR. Mol Cell Biol 22(10):3425-36

Wang Y, Gao E, Tao L, Lau WB, Yuan Y, Goldstein BJ et al. (2009) AMP-activated protein kinase deficiency enhances myocardial ischemia/reperfusion injury but has minimal effect on the antioxidant/antinitrative protection of adiponectin. Circulation 119(6):835-44. doi:10.1161/ CIRCULATIONAHA.108.815043

Watt MJ, Dzamko N, Thomas WG, Rose-John S, Ernst M, Carling D et al. (2006) CNTF reverses obesity-induced insulin resistance by activating skeletal muscle AMPK. Nat Med 12(5):541-8. doi:10.1038/nm1383

Winder WW, Hardie DG (1999) AMP-activated protein kinase, a metabolic master switch: possible roles in type 2 diabetes. Am J Physiol 277(1 Pt 1):E1-10 
Wiseman RW, Kushmerick MJ (1995) Creatine kinase equilibration follows solution thermodynamics in skeletal muscle. 31P NMR studies using creatine analogs. J Biol Chem 270 (21): $12428-38$

Woods A, Johnstone SR, Dickerson K, Leiper FC, Fryer LG, Neumann D et al. (2003) LKB1 is the upstream kinase in the AMP-activated protein kinase cascade. Curr Biol 13(22):2004-8

Woods A, Dickerson K, Heath R, Hong SP, Momcilovic M, Johnstone SR et al. (2005) $\mathrm{Ca}^{2+}$ / calmodulin-dependent protein kinase kinase-beta acts upstream of AMP-activated protein kinase in mammalian cells. Cell Metab 2(1):21-33. doi:10.1016/j.cmet.2005.06.005

Wu Y, Song P, Xu J, Zhang M, Zou MH (2007) Activation of protein phosphatase 2A by palmitate inhibits AMP-activated protein kinase. J Biol Chem 282(13):9777-88. doi:10.1074/jbc. M608310200

Wu QY, Li F, Guo HY, Cao J, Chen C, Chen W et al. (2013) Disrupting of E79 and K138 interaction is responsible for human muscle creatine kinase deficiency diseases. Int $\mathrm{J}$ Biol Macromol 54:216-24. doi:10.1016/j.ijbiomac.2012.12.034

Wyss M, Kaddurah-Daouk R (2000) Creatine and creatinine metabolism. Physiol Rev 80 (3): 1107-213

Xiao B, Heath R, Saiu P, Leiper FC, Leone P, Jing C et al. (2007) Structural basis for AMP binding to mammalian AMP-activated protein kinase. Nature 449(7161):496-500. doi:10.1038/ nature 06161

Xiao B, Sanders MJ, Underwood E, Heath R, Mayer FV, Carmena D et al. (2011) Structure of mammalian AMPK and its regulation by ADP. Nature 472(7342):230-3. doi:10.1038/ nature 09932

Xie M, Zhang D, Dyck JR, Li Y, Zhang H, Morishima M et al. (2006a) A pivotal role for endogenous TGF-beta-activated kinase-1 in the LKB1/AMP-activated protein kinase energysensor pathway. Proc Natl Acad Sci USA 103(46):17378-83. doi:10.1073/pnas.0604708103

Xie Z, Dong Y, Zhang M, Cui MZ, Cohen RA, Riek U et al. (2006b) Activation of protein kinase C zeta by peroxynitrite regulates LKB1-dependent AMP-activated protein kinase in cultured endothelial cells. J Biol Chem 281(10):6366-75. doi:10.1074/jbc.M511178200

Yamaguchi S, Katahira H, Ozawa S, Nakamichi Y, Tanaka T, Shimoyama T et al. (2005) Activators of AMP-activated protein kinase enhance GLUT4 translocation and its glucose transport activity in 3T3-L1 adipocytes. Am J Physiol Endocrinol Metab 289(4):E643-9. doi:10.1152/ajpendo.00456.2004

Yaniv Y, Juhaszova M, Wang S, Fishbein KW, Zorov DB, Sollott SJ (2011) Analysis of mitochondrial 3D-deformation in cardiomyocytes during active contraction reveals passive structural anisotropy of orthogonal short axes. PLoS One 6(7):e21985. doi:10.1371/journal. pone. 0021985

Young LH (2008) AMP-activated protein kinase conducts the ischemic stress response orchestra. Circulation 117(6):832-40. doi:10.1161/CIRCULATIONAHA.107.713115

Zaha VG, Young LH (2012) AMP-activated protein kinase regulation and biological actions in the heart. Circ Res 111(6):800-14. doi:10.1161/CIRCRESAHA.111.255505

Zhang P, Hu X, Xu X, Fassett J, Zhu G, Viollet B et al. (2008) AMP activated protein kinase-alpha2 deficiency exacerbates pressure-overload-induced left ventricular hypertrophy and dysfunction in mice. Hypertension 52(5):918-24. doi:10.1161/HYPERTENSIONAHA.108.114702

Zhang BB, Zhou G, Li C (2009) AMPK: an emerging drug target for diabetes and the metabolic syndrome. Cell Metab 9(5):407-16. doi:10.1016/j.cmet.2009.03.012

Zhu L, Chen L, Zhou XM, Zhang YY, Zhang YJ, Zhao J et al. (2011) Structural insights into the architecture and allostery of full-length AMP-activated protein kinase. Structure 19(4):515-22. doi:10.1016/j.str.2011.01.018

Zmijewski JW, Banerjee S, Bae H, Friggeri A, Lazarowski ER, Abraham E (2010) Exposure to hydrogen peroxide induces oxidation and activation of AMP-activated protein kinase. J Biol Chem 285(43):33154-64. doi:10.1074/jbc.M110.143685 
Zorov DB, Filburn CR, Klotz LO, Zweier JL, Sollott SJ (2000) Reactive oxygen species (ROS)induced ROS release: a new phenomenon accompanying induction of the mitochondrial permeability transition in cardiac myocytes. J Exp Med 192(7):1001-14

Zou MH, Hou XY, Shi CM, Nagata D, Walsh K, Cohen RA (2002) Modulation by peroxynitrite of Akt- and AMP-activated kinase-dependent Ser1179 phosphorylation of endothelial nitric oxide synthase. J Biol Chem 277(36):32552-7. doi:10.1074/jbc.M204512200

Zou MH, Kirkpatrick SS, Davis BJ, Nelson JS, Wiles WG, Schlattner U et al. (2004) Activation of the AMP-activated protein kinase by the anti-diabetic drug metformin in vivo. Role of mitochondrial reactive nitrogen species. J Biol Chem 279(42):43940-51. doi:10.1074/jbc. M404421200 